Portland State University

PDXScholar

Summer 8-15-2014

\title{
Designing the Plane While Flying It: A Case Study on Nursing Faculty Development during Academic Electronic Health Records Integration in a Small Liberal Arts College
}

Karen Elizabeth Maxwell

Portland State University

Follow this and additional works at: https://pdxscholar.library.pdx.edu/open_access_etds

Part of the Curriculum and Instruction Commons, and the Nursing Administration Commons Let us know how access to this document benefits you.

\section{Recommended Citation}

Maxwell, Karen Elizabeth, "Designing the Plane While Flying It: A Case Study on Nursing Faculty Development during Academic Electronic Health Records Integration in a Small Liberal Arts College" (2014). Dissertations and Theses. Paper 1930.

https://doi.org/10.15760/etd.1929

This Dissertation is brought to you for free and open access. It has been accepted for inclusion in Dissertations and Theses by an authorized administrator of PDXScholar. Please contact us if we can make this document more accessible: pdxscholar@pdx.edu. 
Designing the Plane While Flying It:

A Case Study on Nursing Faculty Development during

Academic Electronic Health Records Integration in a Small Liberal Arts College

by

Karen Elizabeth Maxwell

A dissertation submitted in partial fulfillment of the requirements for the degree of

\section{Doctor of Education}

in

Educational Leadership: Postsecondary Education

Dissertation Committee:

Candyce Reynolds, Chair

Dannelle Stevens

Andy Job

Ellen West

Portland State University

2014 
(C) 2014 Karen Elizabeth Maxwell 
ELECTRONIC HEALTH RECORDS IN NURSING EDUCATION

Abstract

The expectation of graduating nurses today is to be knowledgeable and responsive to rapidly changing technology in the health care environment. Although federal mandates, Institute of Medicine (IOM) recommendations, and nursing program accreditation initiatives are pushing an "informatics" healthcare agenda by promoting the implementation of electronic health record (EHR) systems by 2014 in all healthcare facilities, very few US nursing schools provide students with access and training in, EHR systems. In addition, nursing faculty may not have a clear understanding of healthcare informatics; the use of information and technology to communicate, manage knowledge, mitigate error, and support decision-making. Nursing education must address faculty issues related to this innovative paradigm in order to keep pace and participate as cocreators of relevant informatics technology curriculum that prepares graduates for real life workforce.

Understanding the challenges, concerns, and successes in implementing informatics may help nurse educators as they develop curriculum and teach in this environment. This case study explores and describes, with nursing faculty of a small liberal arts college, faculty knowledge, skills, and attitudes (KSAs) as they participate in an action research framed curriculum development program for informatics academic EHR (AEHR) integration. The research question: What is the experience of nursing educators and nursing faculty members involved in the integration of an AEHR project framed in the Learning by Developing model at a small liberal arts college school of nursing? 


\section{ELECTRONIC HEALTH RECORDS IN NURSING EDUCATION}

Significant insights as participants in the study influenced nurse educators' ideas regarding collaborative curricular design, meaningful assignments, and the importance of feedback. 
Dedication

To my dad, Martin George Maxwell aka "Max" who always believed in me. I recall back in my early twenties when I would visit my dad every Wednesday evening before chemistry class, a challenging subject of which neither of us had any prior knowledge. During these encounters, we would discuss my latest assignments and theoretical applications over tuna sandwiches and tomato soup. Little did I know at that time, my dad would end up as my first student and my best instructor. Although he knew nothing about chemistry, dad always asked me great questions, mostly because he was truly interested in how stuff worked. These weekly encounters afforded me a great opportunity to think aloud, test new theories, and collaboratively analyze my thoughts in a very positive learning environment, Learning by Developing an understanding of the subject together with my dad. Thank you dad, for the gifts of curiosity, perseverance, and bravery.

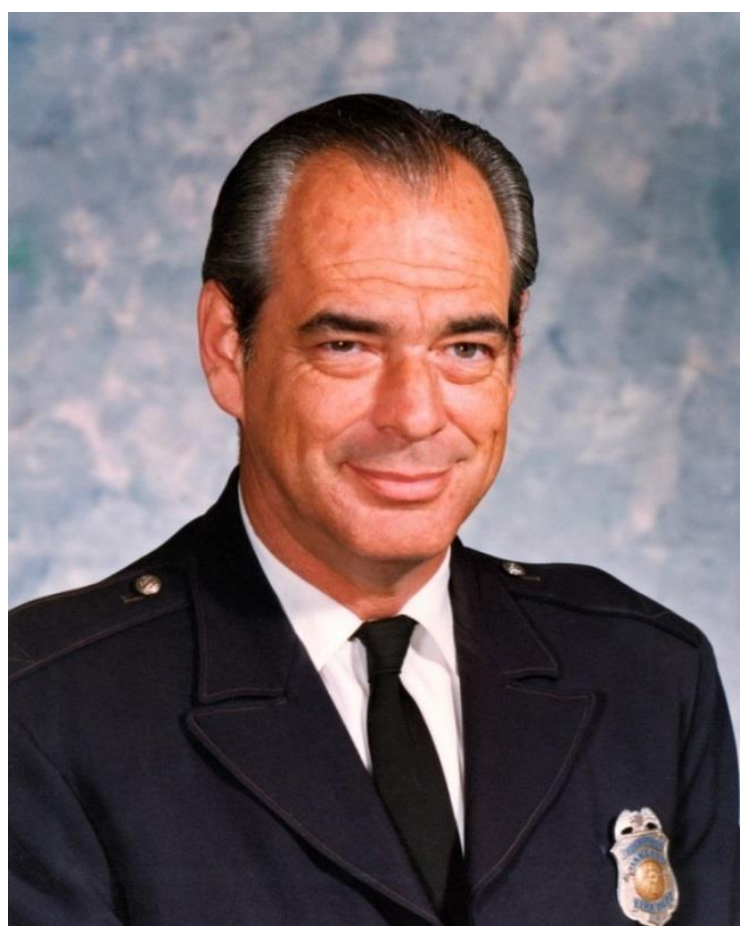

$2 / 13 / 1933$ to $8 / 15 / 2013$ 
ELECTRONIC HEALTH RECORDS IN NURSING EDUCATION

\section{Acknowledgments}

Although this journey has inspired me, taught me, challenged me, and exhausted me, I persevered to get it done but, not without the support, love, and encouragement of several key individuals. I first want to thank my best friend, husband, and love of my life, Arjen Sundman for his encouragement and dedication, always being by my side willingly attending to all my basic creature comfort needs during this process (coffee, food, cats, massages, laughter, technical support, etc.). I want to thank my wonderful kids Amanda and Doug, the special lights in my life that inspired me to completion against many odds.

Next, I would like to thank those on my committee. Special thanks to my advisor, Dr. Candyce Reynolds for always encouraging me to keep going with her favorite phase “...but you're almost done.” I would like to thank Dr. Dannelle Stevens for showing me a wonderful approach to writing, Dr. Andy Job for encouraging me to explore creative and meaningful transformative possibilities in teaching and learning, and Dr. Ellen West for her unique and practical perspectives in business design and process.

Special thanks to my wonderful friend and colleague Joyce E. Betita, the "first follower," who was the key in my transformation from "lone nut to leader." Together we shared the many challenges and rewards of innovative curricular design work. I also want to thank the participants in this study. I am honored to have you openly and honestly share your experiences. I am excited and inspired to continue growing and researching in this area of collaborative discovery.

I want to thank my special friends and colleagues in the EdD cohort 2007 for your companionship and understanding, forever cheering me on during this process. 
Table of Contents

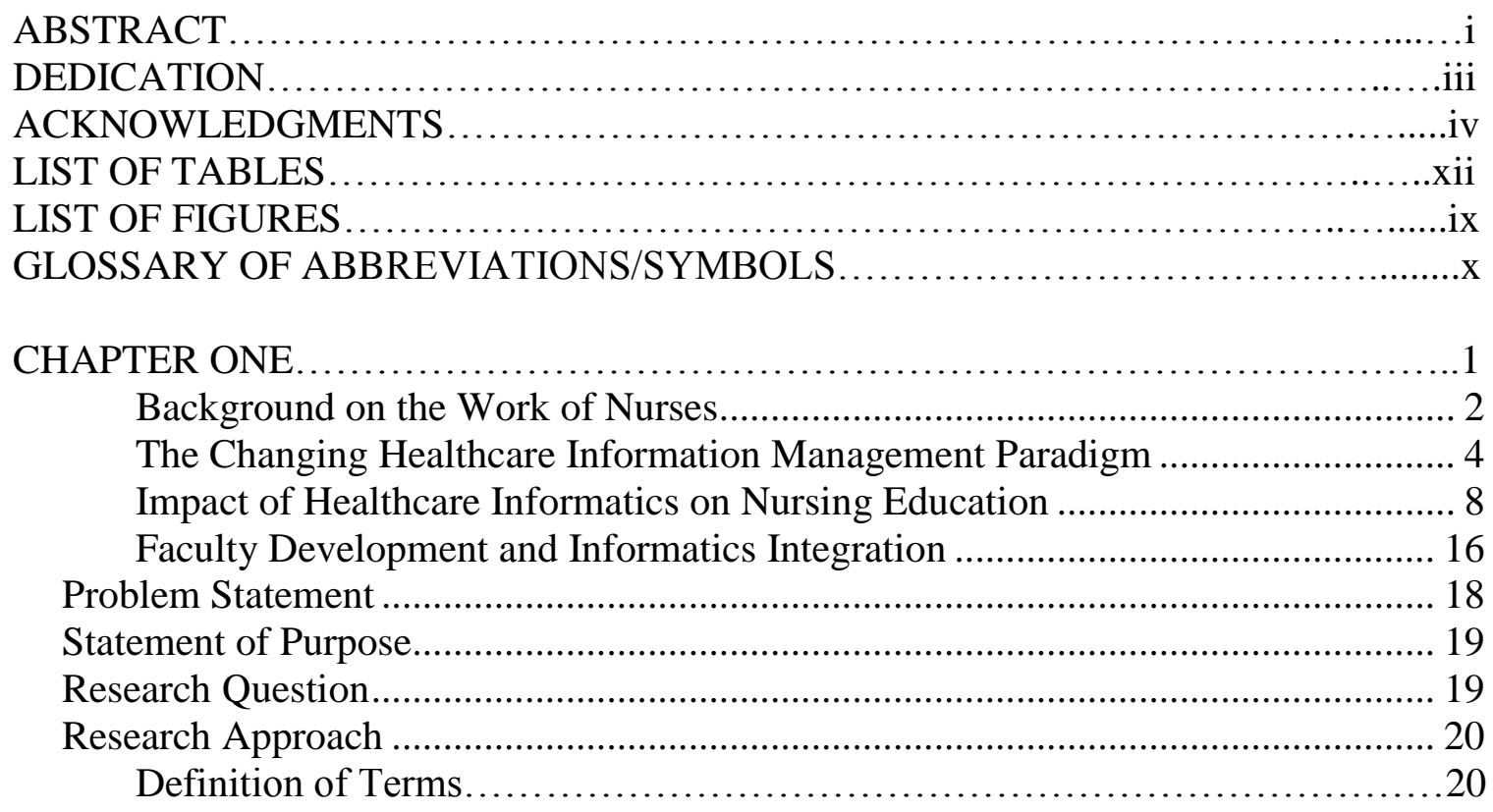

CHAPTER TWO .............................................................. 24

THE LITERATURE

EHR Implementation Processes in Schools of Nursing .................................... 25

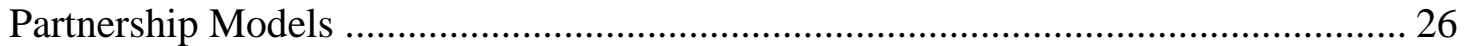

Academic EHR development and models ...................................................... 30

Nurse Educator/Faculty Informatics Knowledge and Skills............................. 36

Nursing Faculty Development Barriers and Strategies ..................................... 43

Conceptual Framework for Faculty Development and AEHR Integration .......... 46

Force-field Analysis and Summary ........................................................... 54

CHAPTER THREE.......................................................57

RESEARCH PARADIGMS AND METHODOLOGY

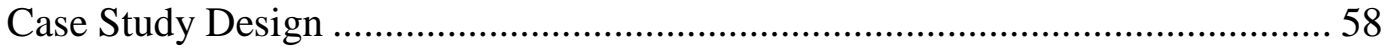

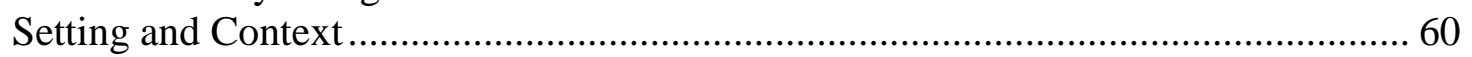

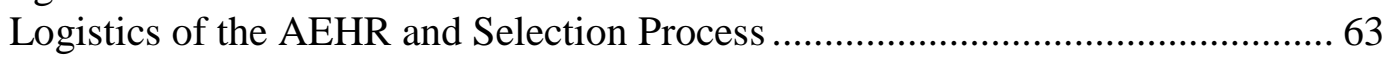

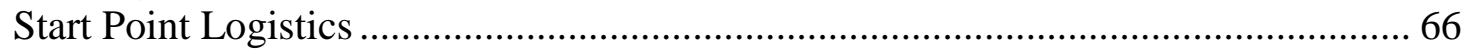

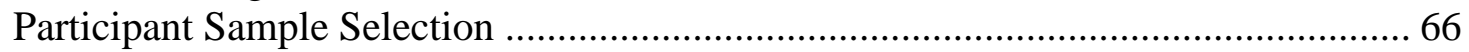

LbD Conceptual Framework for Action Research Integration Process ................ 67

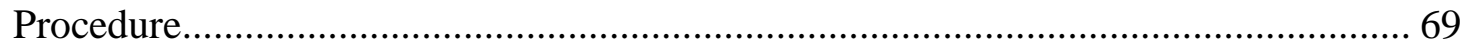

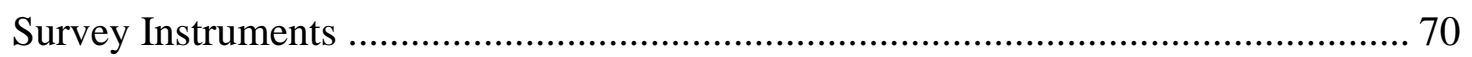

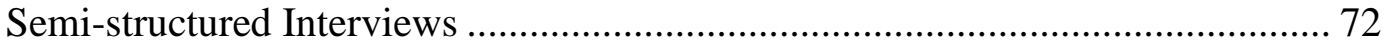

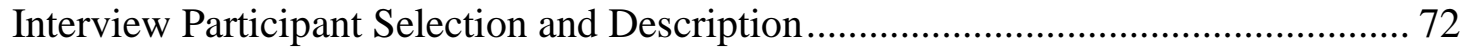

Interview Data Analysis...................................................... 75

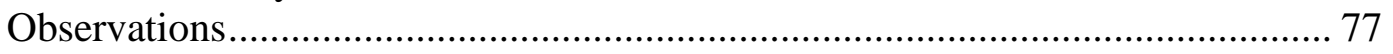


Artifacts 77

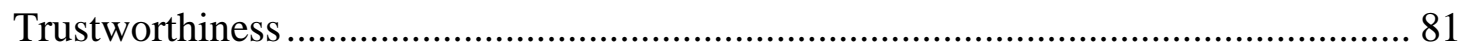

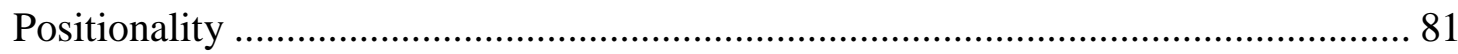

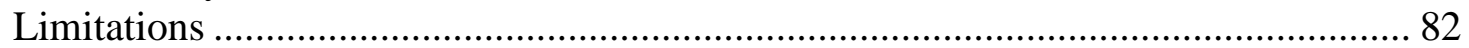

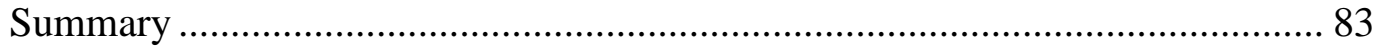

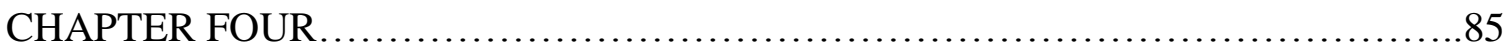

PART I REPORTING FINDINGS AND ANALYZING DATA

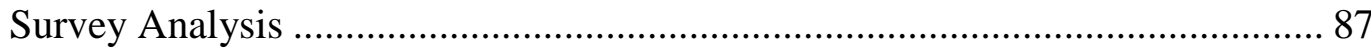

AEHR Integration Project Faculty Needs Assessment Survey ................................ 87

Informatics Competencies Assessment Survey .................................................. 89

Student Confidence Assessment with LOCAEHR Survey ..................................... 96

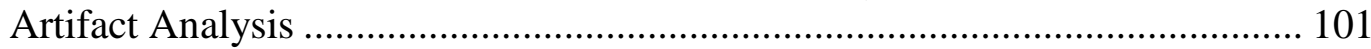

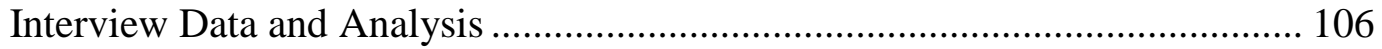

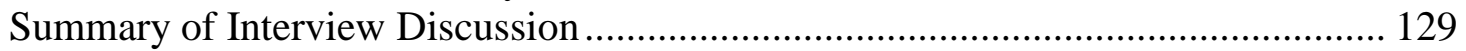

PART II FINDINGS AND ANALYSIS FRAMED BY THE LBD ..................131

The LbD Model as a Framework.......................................131

Story of Integration through the Lens of the LbD Model ..................................... 136

Summary of Key Evaluation Elements for LbD and Study Limitations .................. 162

Study limitations ............................................................................. 167

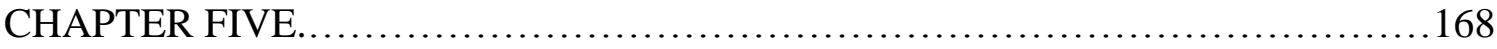

CONCLUSION AND LESSONS LEARNED

Faculty Development: a Collaborative Process .............................................. 170

Summary of Themes ................................................................................ 175

Recommendations for Continued Collaborative Integration ............................ 177

The Learning by Developing Model Situated in Larger Context, Moving Forward . 179

National Recommendations for Nursing Faculty Development....................182

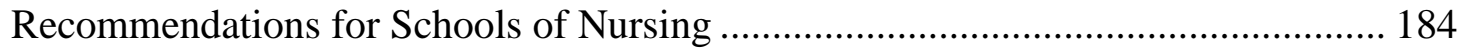

Recommendations for Policy Change in College and Universities ......................... 185

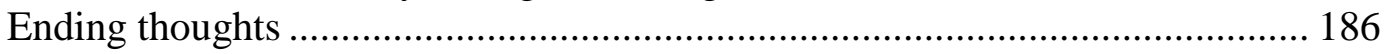

REFERENCES............................................................ 188

\section{APPENDICES}

A LIST OF TICC DIRECT CARE COMPONENTS FORMATTED AS CLINICAL INFORMATION MANAGEMENT COMPETENCIES FOR NURSES ........199

B AACN ESSENTIAL IV: INFORMATION MANAGEMENT AND APLICATION OF PATIENT CARE TECHNOLOGY. 
ELECTRONIC HEALTH RECORDS IN NURSING EDUCATION

C AEHR COMPARTAIVE PRODUCT ANALYSIS RESULTS BETWEEN CONTENDER SYTEMS \#1 AND \#2......................................205

D AEHR INTERGRATION PROJECT FACULTY NEEDS ASSESSMENT......207

E INFORMATICS INTERGATION WITH EHR COLLEGE CURRICULUM

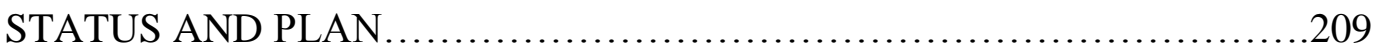

F INFORMATCS COMPETENCIES ASSESSMENT SURVEYS...............211

G DEMOGRAPHIC DATA FORM...........................................215

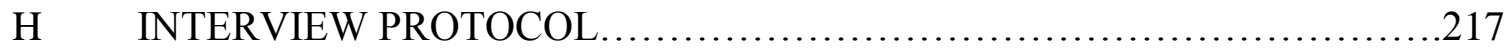

I INFORMED CONSENT FORM..........................................

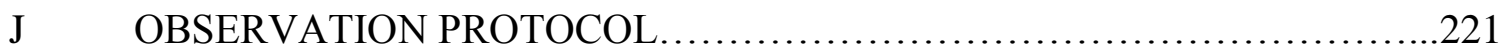

K STUDENT CONFIDENCE ASSESSMENT WITH LOCAEHR AEHR SURVEY 
List of Tables

Table

Page

1 Institute of Medicine's Eight Functionality Components and Key Elements of EHRs

2 QSEN Informatics Knowledge, Skills, and Attitudes Competencies

3 Partnership Model Descriptions \& Key Points

4 AEHR Integration Description, Challenges, and Strategies

34-35

5 Summary of Driving and Restraining Forces from Literature for Force-field Analysis

6 Elements of Study Framed in Creswell's Data Collection Specific for Case Study Analysis

7 Participants' Overview

8 Summary of Steps, Task, and Components for Coding Process 76

9 Data Points in Research Study for Triangulation of Information 80

10 AEHR Integration Project Faculty Needs Assessment Survey Results 89

11 Nurse Educator Informatics Competencies Assessment Survey

Results; Knowledge

12 Nurse Educator Informatics Competencies Assessment Survey Results; Skill

13 Nurse Educator Informatics Competencies Assessment Survey Results; Access

14 Comparison Percent of Nurse Educators and Faculty with Selfreported Competent or Higher Level Rating

15 Student Confidence Assessment with LOCAEHR Survey Results 100

16 Participants' Overview 106

17 Summary of Major Themes Based on Coded Fragments, Similar 108 Category Characteristics, and Descriptive Clusters.

18 Summary of Student Confidence Ratings with LOCAEHR 
ELECTRONIC HEALTH RECORDS IN NURSING EDUCATION

List of Figures

Figure Page

1 EHR Function in the Healthcare Environment 7

2 Diagram Outlining the Three Goals of Usability 41

3 Recognized Stages of the LbD Model as Examples that Steer 51 Implementation

4 Diagram of Critical Thinking Nursing Process Elements of Assess, 53 Diagnose, Plan, Intervene, and Evaluate

5 HESI Fundamental Exam Scores 103

6 HESI Custom III Exam Scores 104

7 HESI RN-EXIT Exam Scores 105

8 The LbD Model Chosen as a Conceptual Framework for Faculty 133 Development and Integration of the AEHR

9 A Newly Designed Eight-bed Patient-ward Simulation Room 148

10 Additional Lab Space Developed and Finished in August 2012

11 Force-field Analysis, Plan for Further Study 178 
Glossary of Abbreviations/Symbols

\begin{tabular}{|c|c|}
\hline $\mathrm{AACN}$ & American Association of Colleges of Nursing \\
\hline $\mathrm{ADN}$ & Associate Degree Nursing \\
\hline AEHR & Academic Electronic Health Record \\
\hline ANA & American Nurses Association \\
\hline ARRA & American Recovery and Reinvestment Act \\
\hline $\mathrm{Bb}$ & Blackboard \\
\hline BCMA & Bar Code Medication Administration \\
\hline BSN & Baccalaureate of Science Degree \\
\hline CIS & Computer Information System \\
\hline CMS & Centers for Medicare and Medicaid Services \\
\hline CPRS & Computerized Patient Record System \\
\hline DHHS & Department of Health and Human Services \\
\hline EBP & Evidenced Based Practice \\
\hline ED & Emergency Department \\
\hline EHR & Electronic Health Record \\
\hline ELC & Experiential Learning Center \\
\hline EMR & Electronic Medical Record \\
\hline $\mathrm{HCP}$ & Healthcare Provider \\
\hline HESI & Health Education Services Incorporated \\
\hline HIMSS & Information Management Systems Society \\
\hline HITECH & Health Information Technology for Economic and Clinical Health \\
\hline HPM & HESI Predictability Model \\
\hline HRSA & Health Resources and Services Administration \\
\hline ICU & Intensive Care Unit \\
\hline $\mathrm{IOM}$ & Institute of Medicine \\
\hline IT & Information Technology \\
\hline KBC & Knowledge Based Charting \\
\hline
\end{tabular}


Glossary of Abbreviations/Symbols (cont.)

KSA Knowledge, Skills and Attitudes

LbD Learning by Developing

LOC Liberal Oak College

LOCAEHR Liberal Oak College Academic Electronic Health Record

LRC Learning Resource Center

LTC Long Term Care

MSU Michigan State University

NANDA North American Nursing Diagnosis Association

NCLEX-RN National Council Licensure Examination-Registered Nurse

NIC Network Information Center

NLN National League of Nurses

NOADN National Organization for Associate Degree Nursing

NOC Network Operations Center

PAR Participatory Action Research

PCP Primary Care Provider

PDA Personal Digital Assistant

PHR Personal Health Record

QSEN Quality and Safety Education for Nurses

RN Registered Nurse

RWJF Robert Wood Johnson Foundation

SEEDS Simulated E hEalth Delivery System

SNOMED CT Systematized Nomenclature of Medicine Clinical Terms

SOAP Subjective, Objective, Assessment, Plan

SON School of Nursing

TICC Technology Informatics Competency Collaborative

TIGER Technology Informatics Guiding Educational Reform

WNL Within Normal Limits 
ELECTRONIC HEALTH RECORDS IN NURSING EDUCATION

\section{Chapter One}

"Tell me and I will forget; show me and I may remember; involve me and I will understand."

-Confucius

In the spring of 2004, President Bush called for national implementation of interoperable electronic health records (EHRs) by the year 2014 (Murphy, 2010). President Obama formalized this decree in the Health Information Technology Act signed in 2009 that requires all healthcare facilities to fully adopt EHRs by 2014. Since nurses comprise the largest part of the healthcare workforce (54\%) it is imperative that they know how to interact with these informatics tools to ensure safe and quality care (National League of Nursing Board of Governors, 2008). Furthermore, new nurse graduates, regardless of their practice setting, must develop technology literacy and healthcare information management skills, along with nursing theory and nursing practice (American Nurses Association [ANA], 2008). Given these compelling circumstances, it is remarkable that, as of 2010 , only one percent of more than 3,000 nursing schools in the United States provide student nurses access to electronic medical records in their undergraduate programs (Millard, 2010).

Nursing faculty are in a unique position as change agents and designers of the nursing school curriculum to provide future nursing graduates with conceptual knowledge and practical skills to keep pace with this new healthcare informatics paradigm. Unfortunately, Hebda and Calderone (2010) identified nursing faculty responsible for curriculum development as lagging behind in the informatics skills needed in today's healthcare delivery system. As faculty become familiar with 
informatics and examine their own attitudes, knowledge, and skill level, they may be more inclined to enrich the student learning experience by building technology enhanced experiences into their lesson plans (Hebda \& Calderone, 2010). This chapter provides relevant background information regarding the work of nurses and nurse educators, and sets the stage for describing the proposed study that may help uncover strategies to help nursing faculty engage their students in technology.

\section{Background on the Work of Nurses}

According to the American Nurses Association (2012) Nursing is defined as is the protection, promotion, and optimization of health and abilities, prevention of illness and injury, alleviation of suffering through the diagnosis and treatment of human response, and advocacy in the care of individuals, families, communities, and populations. Nurses are participants in a complex, ever evolving practice-based profession that has seen considerable changes and increasing sophistication over time. Today's nurse is a hybrid professional with many roles, skills, and obligations such as those seen in teachers, lawyers, engineers, ministers, physicians, psychotherapists, social workers, and institutional managers. At nursing's core remains the expectations for caring, advocacy, and ministering to the needs of those who are ill (Shulman, 2010). Pulling from this rich mixture of skill resources, nurses continuously make decisions that have significant impact in the care of their patients. Their expectations include quickly identifying, processing, and analyzing information in order to solve critical, and in some cases, lifethreatening problems in a health care environment that is rapidly changing by advancing technology, while maintaining a holistic focus on the patient and family (Rideout, 2001). 
ELECTRONIC HEALTH RECORDS IN NURSING EDUCATION

Nurse educators are registered nurses (RNs), with varying degrees of additional academic preparation, responsible for designing, implementing, evaluating, and revising academic and continuing education programs to prepare and mentor current and future generations of nurses. The National League of Nurses (NLN) task force developed and adopted eight core competencies to guide the work of nurse educators (Halstead et al., 2005). Specific language in this document addresses the nurse educator's qualifications to a) participate in curriculum design and evaluation of program outcomes, b) function as a change agent and leader, and c) pursue continuous quality improvement in the nurse educator role. Key educator skills based on these competencies that contribute to promoting the successful implementation of an academic EHR platform include a) participation through selecting and developing appropriate learning activities and evaluation strategies, b) use of appropriate change theories and strategies, c) a commitment to lifelong learning, and d) promotion of innovative practices in educational environments (Kalb,2008).

New nurse graduates, regardless of their practice setting, must develop technology literacy and healthcare information management skills, along with nursing theory and nursing practice (American Nurses Association, 2008). Therefore, it makes sense that nursing faculty actively participate in the development of informatics curricular revisions, essential to assuring quality educational experiences for future nurse graduate function in diverse, ever-changing health care environments. 


\section{The Changing Healthcare Information Management Paradigm}

Quality nursing documentation and healthcare information management is critical in the clinical practice environment. Health care assessments, treatments, diagnostics, and evaluations based on personal data collected are compiled and recorded by all providers of health care and kept in a document file, or what is referred to as, the patient's chart or health record. These records have existed for years in a variety of combined handwritten and typed-up paper formats at healthcare organizations such as hospitals, clinics, and long-term care facilities. As technology advances, so does the format in which these documents are accessed and stored. In hopes of improving patient safety and efficiency of care delivery, over the past decade, many acute care facilities have morphed their patient records into a hybrid existence of electronic and paper-based formatting. As health record data becomes more streamlined and accessible across healthcare facilities in future interoperable EHR formats, the timing, and quality of bedside data analysis and nursing assessment documentation becomes more critical to provider decision making.

For purposes of clarity, the terms electronic health record (EHR) and electronic medical record (EMR) are interchangeable throughout this paper. In a report from the Department of Health \& Human Services by Bell and Bradford (2008) defining key health information technology terms, a useable definition about "what is an EHR" provides the following:

The EHR is the focus of efforts throughout the health industry to employ the most comprehensive information available to best inform the care delivery process. The definition recognizes that health-related information about a patient is available in multiple locations and systems and that, if presented through a common and userfriendly interface, this information can improve the ability of clinical personnel to 
support the best possible diagnosis, treatment, and health management decisions for and with an individual. EMR systems in general provide four functions a) patient demographic and clinical data storing; b) results management; c) order entry management; and d) clinical decision support. An EHR is patient-focused in that it is not limited to what a single provider organization is able to accumulate on behalf of a patient under its care. Through the capabilities of interoperability, an EHR becomes an authorized means to access information from whatever sources have chronicled the health care experience of a patient over time. The boundaries of an EHR not limited to those of the organization documenting the information but around the patient and his or her health-related information. Though it is patient-focused, it is managed and used primarily by authorized care providers, as well as by members of their staff who have a need to access the EHR to support the process of care. (Bell \& Bradford, 2008, p. 17)

The aim of the Institute of Medicine (IOM) is to help those in government and the private sector make informed health decisions by providing evidence upon which they can rely. Established in 1970, the IOM functions as an independent, nonprofit organization that works outside of government to provide unbiased and authoritative advice to decision makers and the public (Institute of Medicine, 2013). In 2003, the Department of Health and Human Services (DHHS) asked the IOM to provide guidance on the key care delivery-related capabilities of an EHR system. As part of this research, the IOM National Research Council (2003), produced a report regarding specifications for eight core functionality components in the EHR; a) health information and data, b) results management, c) order entry management, d) decision support, e) electronic communication and connectivity, f) patient support, administrative processes, and g) reporting and population management. Table 1 provides a summary of these key core components used in the healthcare setting for information and care management along with descriptions of key elements. 
Table 1

Institute of Medicine's Eight Functionality Components and Key Elements of EHRs

\begin{tabular}{|c|c|}
\hline Core Components & Key Elements \\
\hline $\begin{array}{l}\text { Health information and } \\
\text { data }\end{array}$ & $\begin{array}{l}\text { Patient information needed to make sound clinical decisions organized in } \\
\text { well-designed interfaces (e.g., medication lists, allergies, clinical } \\
\text { narratives, demographics, defined datasets, reminders and alerts) }\end{array}$ \\
\hline Results management & $\begin{array}{l}\text { Ability to electronically manage all types of results (e.g., computerized } \\
\text { laboratory and radiology results) }\end{array}$ \\
\hline Order entry management & $\begin{array}{l}\text { Entry of medication and other care order, as well as ancillary services, } \\
\text { directly into a computer (e.g., computer provider order entry, e- } \\
\text { prescribing, "forcing functions" for medication dosing, frequency, } \\
\text { displaying relevant associated lab tests, and checking for drug-drug } \\
\text { interactions) }\end{array}$ \\
\hline Decision support & $\begin{array}{l}\text { Computer reminders and prompts to improve prevention, diagnosis, and } \\
\text { management of patient disease (e.g., dosing guidelines, screening } \\
\text { reminders, management of chronic diseases, evidenced-based protocols } \\
\text { and treatments ) }\end{array}$ \\
\hline $\begin{array}{l}\text { Electronic communication } \\
\text { and connectivity }\end{array}$ & $\begin{array}{l}\text { Online communication between the healthcare team, other partners, and } \\
\text { patients (e.g., secure messaging, home telemonitoring, workflow reports) }\end{array}$ \\
\hline Patient support & $\begin{array}{l}\text { Education and self-testing (e.g., computer-based patient education, } \\
\text { telehealth) }\end{array}$ \\
\hline Administrative processes & $\begin{array}{l}\text { Electronic scheduling systems and billing and claims management } \\
\text { (authorizations, drug recalls) }\end{array}$ \\
\hline $\begin{array}{l}\text { Reporting and population } \\
\text { health management }\end{array}$ & $\begin{array}{l}\text { Clinical data to meet public, private, and institutional requirements } \\
\text { (reporting of key quality indicators) }\end{array}$ \\
\hline
\end{tabular}

In summary, the purpose of the Electronic Health Record (EHR) is to provide a longitudinal electronic record of patient health information generated by one or more encounters in any care delivery setting as well as automate and streamline the clinician's workflow. In addition, the EHR functions as a complete record of a clinical patient encounters, supporting other care-related activities directly or indirectly via interface including evidence-based decision support, quality management, and outcomes reporting (Healthcare Information and Management Systems Society, 2014).

As generators and integrators of this data, nurses are in a distinct position to use technology to improve patient safety and provide quality care (Page, 2004). Findings 
from studies on EHR use in clinical settings reveal that computerized health records improve the safety, quality, and costs of health care by a) providing quality information for decision making, b) eliminating illegibility, c) offering better chart access, d) reducing documentation omissions and redundancy, and e) improving organizational efficiencies (Bakken et al., 2004; DesRoches, Donelan, Buerhaus, Potter, \& Zhonghe, 2008; Hillestad et al., 2005; Johnson, Carlson, Tucker, \& Willette, 2001; Kutney-Lee \& Kelly, 2011; McCullough, Casey, Moscovice, \& Prasad, 2010; Rantz et al., 2011). Figure 1 illustrates these connections available of the EHR for use in conjunction with the continuous cycle of assessment, treatment, reassessment, and monitoring for patient safety and quality in healthcare.

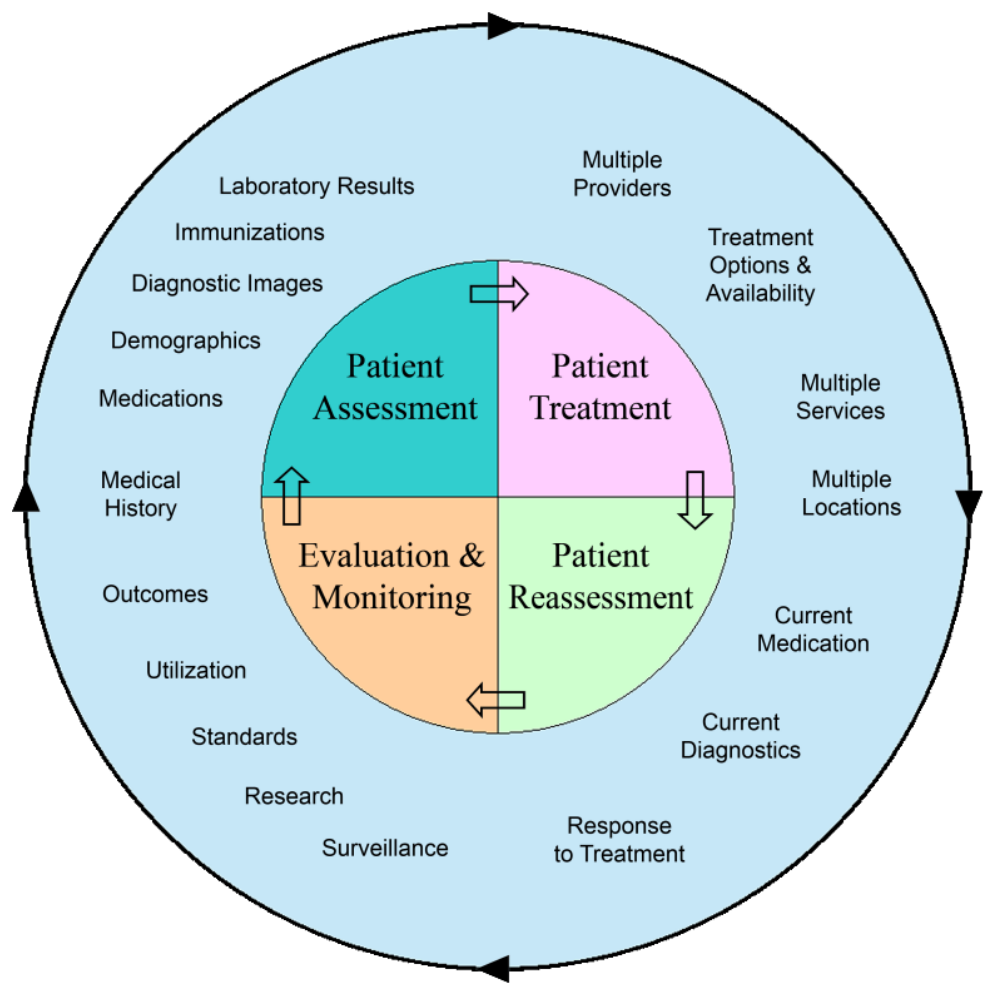

Figure 1. EHR function in the healthcare environment. Connections between the EHR components during the various care phases of patient assessment, treatments, reassessment, evaluation and monitoring are available at the fingertips of the healthcare providers. 
Since nurses are the primary managers of these documents in the clinical setting according to DesRoches e al. (2008), it therefore follows that nurse competence in information literacy, chart navigation, accuracy and thoroughness greatly influences patient care.

Government sanctioned monetary terms have been implemented to stress the urgency and importance of nationwide EHR adoption. For example, the Centers for Medicare and Medicaid Services (CMS) are offering eligible providers, including nurse practitioners and certified nurse-midwives, who choose to take the first steps toward adoption of EHR technology between 2011 and 2015, incentive payments through the Medicare and Medicaid EHR incentive programs. Meaningful use, as described by The American Recovery and Reinvestment Act of 2009, specifies three main criteria by which all EHR systems must meet in order to receive incentive payments. Simply put, meaningful use means that providers need to show that they are using EHR technology in ways that can be measured significantly in quality and in quantity (H.R. 1--111th Congress, 2009). This major change in documentation and information management to a fully interoperable computerized format means a paradigm shift not only for healthcare organizations but also for nursing educational institutions.

\section{Impact of Healthcare Informatics on Nursing Education}

The EHR is fast becoming the stethoscope for the 21 st century, yet a large majority of nursing schools in the United States fail to provide student nurses with access to electronic medical records in their undergraduate programs (Millard, 2010). Since nurses comprise the largest part of the healthcare workforce $(54 \%)$, it is imperative that 
they know how to interact with these informatics tools to ensure safe and quality care (National League for Nursing Board of Governors, 2008).

The importance of information management in healthcare has prompted creation of the following forces supporting this shift from paper-based to digital health care records including:

- A call by the federal government to use EHR for the majority of Americans by 2014.

- The creation of the Office of the National Coordinator of Health Information Technology.

- The Technology Informatics Guiding Educational Reform (TIGER) Initiative. Future EHR implementation is estimated at 70 percent in acute-care hospitals (Malloch, 2007). The adoption of at least a basic EHR system in hospitals increased from around 10 percent in 2008 to 44 percent in 2012 (DesRoches et al., 2013). Although this computer technology has been around for some time, spiraling healthcare costs and ongoing quality and safety issues have driven a national push from the federal government to implement interoperable EHRs (Manos, 2009; Office of the Press Secretary, 2009). In the spring of 2004, President Bush called for national implementation of interoperable electronic health records by the year 2014 (Murphy, 2010). On Feb. 17, 2009, President Obama signed into law the American Recovery and Reinvestment Act (ARRA). A portion of the law created the Health Information Technology for Economic and Clinical Health (HITECH) Act. Within this document, approximately $\$ 19$ billion in grants are available to increase the use of EHRs in the healthcare environment (ARRA, 2009). The American Recovery and Reinvestment Act 
of (2009), defines the EHR as “.... an electronic record of health-related information on an individual that is created, gathered, managed, and consulted by authorized health care clinicians and staff” (p. 115). In addition to initial federal funding grant initiatives in 2009, after 2014, rate adjustments for Medicare and Medicaid reimbursement favor those facilities with EHR adoption (ARRA, 2009).

Guidelines and support for informatics education integration in nursing curriculum are structured by national and regional professional and political nursing organizations. Additional market forces to previously mentioned federal mandates include a) informatics recommendations from the Institute of Medicine (IOM), b) suggested competencies from the federally funded Technology Informatics Guiding Education Reform (TIGER) organization, and c) Robert Wood Johnson Foundation (RWJF) funded initiatives from the Quality and Safety Education for Nurses (QSEN). Additional support for curriculum design recommendations include the American Association of Colleges of Nursing (AACN), and National League of Nursing (NLN) accreditation boards (AACN, 2008; Fetter, 2009a; Greiner, \& Knebel, 2003; Gugerty \& Delaney, 2009; NLN Board of Governors, 2008; Rizzolo, Skiba, \& Dulong, 2009; Sensmeier \& Anderson, 2009).

The IOM's report by Greiner, \& Knebel (2003), Health Professionals Education: A Bridge to Quality recommends the use of informatics as one of the five core competencies needed by all healthcare professionals to ensure patient quality and safety:

1. Provide patient-centered care

2. Work in interdisciplinary teams

3. Employ evidence-based practice 
4. Apply quality improvement

5. Utilize informatics

National attention on health information technology has accelerated since 2004 when President Bush announced plans to support adoption of electronic health records for all Americans. In January 2006, a small group of nursing leaders and advocates met and resolved to strengthen the voice of the nursing profession in the transformation of healthcare for the 21 st century. This group organized the Technology Informatics Guiding Education Reform (TIGER) Initiative. "The Technology Informatics Guiding Educational Reform (TIGER) Initiative aims to enable practicing nurses and nursing students to fully engage in the unfolding digital electronic era in healthcare" (Technology Informatics Guiding Educational Reform, 2014). According to a published TIGER report on education and faculty development by Rizzolo, Skiba, and DuLong (2009), "one of the greatest challenges to integrating informatics into the curriculum is the limited access to technology resources that many nursing schools experience” (p. 20).

The TIGER Summit identified numerous objectives related to the education of nurses and the respective development of faculty. Emphasis is on the need for more nursing informatics specialists. These issues were raised in a variety of venues, including Health Resources and Services Administration (HRSA) meetings and national conferences. Based on the TIGER Summit Summary Report, the following specific objectives were set for the TIGER Education and Faculty Development collaborative:

- Use the informatics competencies, theories, research, and practice examples throughout nursing curriculums. 
- Create programs and resources to develop faculty with informatics knowledge, skill and ability and measure the baseline and changes in informatics knowledge among nurse educators and nursing students.

- Develop a task force to examine the integration of informatics throughout the curriculum.

- Develop strategies to recruit, retain, and educate current and future nurses in the areas of informatics education, practice, and research.

- Improve and expand existing Nursing/Clinical/Health Informatics education programs.

- Encourage existing Health Services Resources Administration Division of Nursing to continue and expand their support for informatics specialty programs and faculty development.

- Encourage foundations to start programs that provide funding for curriculum development, research, and practice in nursing informatics and IT adoption.

- Collaborate with industry and service partners to support faculty creativity in the adoption of informatics technology and offer informatics tools within the curriculum. (Rizzolo, Skiba, \& DuLong, 2009).

The Technology Informatics Guiding Education Reform Competency

Collaborative (TICC) group formed from more than 40 nursing professional organizations across the country to develop recommendations for nationwide informatics competencies for practicing nurses and graduating nursing students. Their philosophy, according to the 2009 TICC report by Gugerty \& Delaney is “... while Nursing Informatics is a highly specialized field, there are foundational informatics competencies that all practicing nurses and graduating nursing students should possess to meet the standards of providing safe, quality, and competent care" (p. 1). Appendix A provides a comprehensive list of specific EHR recommendations for clinical information management competency outlined for schools of nursing. Specific areas of focus include a) demographic/patient information, b) consents and authorization, c) medication 
management, d) planning care, e) order/results management, f) care documentation, and decision support, g) notifications, and h) facilitating communication.

Quality and Safety Education for Nurses (QSEN) was developed in 2005 with funding from the Robert Wood Johnson Foundation with the overall goal of providing resources for nurses to meet the challenge of preparing future nurses with the knowledge, skills, and attitudes (KSAs) necessary to improve the quality and safety of the healthcare systems. The long-range goal of QSEN is to focus on nursing education in order to reshape professional identity formation in nursing to include commitment to quality and safety competencies recommended by the Institute of Medicine. The focus is on six quality and safety competency areas a) patient-centered care, b) teamwork and collaboration, c) evidence-based practice, d) quality improvement, e) safety, and f) informatics. They define informatics as the use of information technology to communicate, manage knowledge, mitigate error, and support decision-making. KSA is defined by Suskie (2010) as follows:

- Knowledge is a complex process of remembering, relating, or judging an idea or abstract phenomenon (cognitive abilities).

- Skills are the proficient manual, verbal or mental manipulation of data or things that allow for the execution of well-specified tasks (psychomotor abilities).

- Attitudes represent a state of mind, feelings, or beliefs about a particular matter (affective abilities). 
Organized in table 2 are the suggested specific competencies by Cronenwett et al. (2007)

for informatics knowledge, skills, and attitudes education competencies.

Table 2

QSEN Informatics Knowledge, Skills, and Attitudes Competencies

\begin{tabular}{|c|c|c|}
\hline Knowledge & Skills & Attitudes \\
\hline $\begin{array}{l}\text { Explain why information and } \\
\text { technology skills are essential for } \\
\text { safe patient care }\end{array}$ & $\begin{array}{l}\text { Seek education about how } \\
\text { information is managed in care } \\
\text { settings before providing care } \\
\text { Apply technology and } \\
\text { information management tools to } \\
\text { support safe processes of care }\end{array}$ & $\begin{array}{l}\text { Appreciate the necessity for } \\
\text { all health professionals to seek } \\
\text { lifelong, continuous learning } \\
\text { of information technology } \\
\text { skills }\end{array}$ \\
\hline $\begin{array}{l}\text { Identify essential information that } \\
\text { must be available in a common } \\
\text { database to support patient care } \\
\text { Contrast benefits and limitations } \\
\text { of different communication } \\
\text { technologies and their impact on } \\
\text { safety and quality }\end{array}$ & $\begin{array}{l}\text { Navigate the electronic health } \\
\text { record } \\
\text { Document and plan patient care } \\
\text { in an electronic health record } \\
\text { Employ communication } \\
\text { technologies to coordinate care } \\
\text { for patients }\end{array}$ & $\begin{array}{l}\text { Value technologies that } \\
\text { support clinical decision- } \\
\text { making, error prevention, and } \\
\text { care coordination } \\
\text { Protect confidentiality of } \\
\text { protected health information } \\
\text { in electronic health records }\end{array}$ \\
\hline $\begin{array}{l}\text { Describe examples of how } \\
\text { technology and information } \\
\text { management are related to the } \\
\text { quality and safety of patient care } \\
\text { Recognize the time, effort, and } \\
\text { skill required for computers, } \\
\text { databases and other technologies } \\
\text { to become reliable and effective } \\
\text { tools for patient care }\end{array}$ & $\begin{array}{l}\text { Respond appropriately to clinical } \\
\text { decision-making supports and } \\
\text { alerts } \\
\text { Use information management } \\
\text { tools to monitor outcomes of care } \\
\text { processes } \\
\text { Use high quality electronic } \\
\text { sources of healthcare information }\end{array}$ & $\begin{array}{l}\text { Value nurses' involvement in } \\
\text { design, selection, } \\
\text { implementation, and } \\
\text { evaluation of information } \\
\text { technologies to support patient } \\
\text { care }\end{array}$ \\
\hline
\end{tabular}

The purpose of national accreditation bodies is to protect the safety and welfare of the public through assurance of quality nursing education programs. Therefore, they provide guidance and structure for nursing curriculum development. In 2008, the American Association of Colleges of Nursing (AACN), a major accreditation body for baccalaureate nursing education, published a set of nine curricular essential elements intended to guide baccalaureate nursing program curricular development and revision. 
Essentials I through IX delineate the outcomes expected of graduates of baccalaureate nursing programs. Achievement of these outcomes will enable graduates to practice within complex healthcare systems and assume the roles of provider of care; designer/manager/coordinator of care; and member of a profession.

The AACN Essential (2008) that addresses informatics management and application of patient care technology specifically states “...baccalaureate graduates must have competence in the use of information technology systems, including decisionsupport systems, to gather evidence to guide practice. Specific introductory level nursing informatics competencies include the ability to use selected applications in a comfortable and knowledgeable way" (p. 18). In addition, suggested goals for nursing preparation are to include:

- Skills in using patient care technologies, information systems, and communication devices that support safe nursing care.

- Ability to apply safeguards and decision-making support to support a safe practice environment for both patients and healthcare workers.

- Understanding the use of computer information system (CIS) to document interventions related to achieving nurse sensitive outcomes.

- Recognize the role of information technology (IT) in improving the safety and quality of patient care (AACN, 2008).

These powerful forces have created the market drive to improve clinical information education for healthcare students at the academic level, yet change cannot occur without nursing faculty involvement to structure and implement informatics experiences for students (DeGagne, Bisanar, Makowski, \& Neumann, 2012). 
ELECTRONIC HEALTH RECORDS IN NURSING EDUCATION

\section{Faculty Development and Informatics Integration}

Although technology advancements have increased at a dramatic rate, attempts at incorporating a basic set of technology and information science competencies for nurses at various levels of education have been dragging (Millard, 2010). There are many reasons that the incorporation of EHR skills is very slow in curricular adoption by nursing faculty. Issues such as personal unfamiliarity with EHR systems or lack of nursing school/intuitional buy-in have been cited as reasons for educators to shy away from incorporating technology education within courses (Bakken et al. 2004; Connors, Weaver, Warren, \& Miller, 2002; Fetter, 2009b). Faculty who do not have access to the various clinical EHR information systems, that nurses will use as integral components of practice, will have difficulty understanding how the nursing curriculum needs to change (Skiba, 2006). In addition, many nursing faculty did not use EHR technology when they were full time practicing nurses; they began working as educators before the technology became so prevalent. In particular, Fetter (2009a) discovered barriers such as lack of faculty knowledge, skills, and motivation to integrate IT skills into the curriculum as a significant challenge. A study by Hebda and Calderone (2010) identified that nursing faculty responsible for curriculum development lag behind in the informatics skills that are needed in today's healthcare delivery system.

As nursing education evolves, nurse educators need to rethink some of their teaching strategies. According to Benner, Sutphen, Leonard, and Day (2010) nursing education must shift the teaching focus from covering the content to integration of concepts and clinical reasoning through new pedagogies such as unfolding cases and 
simulated experiences. Since faculty members may have no experience with EHRs, they will need to learn to function in the EHR environment as well as create academic EHR activities for the curriculum. Electronic Healthcare Records Systems are not only a change in the way nursing care documentation occurs, from a paper-based to computerized format but also, a change in the way nursing work is organized. This type of learning involves an integrative approach that fosters a revision in the way faculty may have experienced and/or view teaching and learning.

Collaboratively integrating an academic electronic health records platform into a concept based curriculum, although challenging, may prove beneficial not only to the education of student nurses, but also to the lifelong learning goals of nurse educators. The following assumptions by Curran (2008) were used as the basis for an integrated design faculty development program, for technology integration in undergraduate nursing education at Ohio State University:

- One does not learn technology unless there is a compelling reason to do it.

- Technology is a tool used to improve nursing practice rather than an end in itself.

- Technology needs to be introduced to nurses first as students, and not just when they enter the practice field.

- Technology can be a vehicle to transform how we teach nursing concepts to students; it requires an interactive engaged learner.

- Creating the most realistic environment for students eases their transition into actual practice setting.

- Faculty development activities must be sensitive to the faculty's historic expert role.

- Experiential learning of technology and informatics concepts by faculty will improve the ability to teach them.

- Informatics competencies are the foundation for learning to effectively use technology to deliver high quality patient care. (Curran, 2008, p.524) 
Designing a faculty development program using an integrated course design model may prove to be beneficial for faculty at a deeper level because they will learn a new way to integrate nursing knowledge and nursing concepts in an academic EHR (AEHR) platform, as well as experience an integrated framework for educating students. In addition, the nature of learning and teaching technology lends itself to an integrated format; one in which the learner can apply the information as they acquire new knowledge. A integrated faculty development strategy that includes creation of patient cases and situational simulated educational experiences as application projects, as part of the AEHR learning workshops, engages the faculty (Curran, Elfrink, \& Mays, 2009).

A model based on integrated learning experiences that would allow faculty to learn about the technology while designing the curriculum, the Learning by Developing (LbD) model, has been successfully used in Finland to transform nursing competencies for standardized, electronic nursing documentation and create an education model used to strengthen the knowledge and skills of nurses, nurse educators, and nurse students (OraHyytiäinen, Ikonen, Ahonen, Rajalahti, \& Saranto, 2010). Faculty development formatted on this LbD framework for integration of an EHR is based on pragmatic environment for curricular revision, therefore, it promotes ownership and engagement by faculty in designing learning strategies for nursing students (Raij, 2007). For this study, the LbD was chosen as a faculty development participatory action research protocol.

\section{Problem Statement}

It is clear that nurse educators and nursing faculty need to gain confidence so that they can use and teach concepts of information management and documentation within 
the EHR environment. Involvement in designing a program based on incorporating applied informatics into the school of nursing curriculum is essential for providing students with a competitive edge in the marketplace and a comprehensive understanding of how and why information technology (IT) is playing a role in the improvement of healthcare (Connors, Weaver, Warren, \& Miller, 2002). Although all nurses must be proficient in the use of EHR systems in the practice setting, and nursing faculty are responsible for the nursing curriculum, there is limited research on how to help faculty integrate EHR technology and concepts into the academic nursing curriculum. Understanding KSA of faculty in this process of integrating uncomfortable material into their courses would be helpful for future faculty development of expertise in this area.

\section{Statement of Purpose}

Promoting healthcare informatics proficiency for graduating nurses is the responsibility of nursing education. Understanding the challenges, concerns, and successes of faculty in implementing informatics curriculum may inform a successful process to direct this endeavor. The purpose of this case study is to explore and describe, with the nursing faculty of a small liberal arts college, the faculty knowledge, skills, and attitudes (KSAs) as they participate in an action research framed curriculum development program for implementation of applied informatics using an academic EHR platform.

\section{Research Question}

The question investigated is: What is the experience of nursing educators and nursing faculty members involved in the integration of an AEHR project framed in the Learning by Developing model at a small liberal arts college school of nursing? 


\section{Research Approach}

Nursing educators at a small liberal arts college participating in a faculty development program using the LbD model (Raij, 2007) during a 2-year pilot period of integration with a web-based AEHR platform were asked to participate in an exploratory, descriptive case study regarding their experiences. As part of the process, assessment surveys, workshop observation and evaluations, inquiry emails, curricular artifacts, and focused interviews were analyzed and adjustments incorporated into the AEHR development program for effectiveness. This study is significant because an exploratory, descriptive case study of nurse educators' and faculty members' experience during an integration process could provide information for faculty from other nursing schools that need help to integrate this technology.

\section{Definition of Terms}

academic electronic health record (AEHR): a computerized patient record with academic features added for the learning environment. The AEHR allows faculty to build cases and assess the student's ability to fully use and document patient records (Gloe, 2010).

attitudes: represent a state of mind, feelings, or beliefs about a particular matter (affective abilities) (Suskie, 2010).

competency: is the ability to perform a defined real-world task in a specific context.

computer literacy: the knowledge and skills needed to use basic computer applications and computer technology (American Nurses Association, 2008).

electronic health record (EHR): an electronic record of health-related information on an 
ELECTRONIC HEALTH RECORDS IN NURSING EDUCATION

individual that conforms to nationally recognized interoperability standards and that can be created, managed, and consulted by authorized clinicians and staff across more than one health care organization (Bell \& Bradford, 2008).

electronic medical record (EMR): an electronic record of health-related information on an individual that can be created, gathered, managed, and consulted by authorized clinicians and staff within one health care organization (Bell \& Bradford, 2008). information system: a system that is composed of human and computer elements that work interdependently to process data into information. The most relevant, important, and fundamental information management competencies for nurses are those that relate to the electronic health record system (EHRS) (Gugerty \& Delaney, 2009).

information literacy: the ability to recognize when information is needed and to locate, evaluate, and effectively use that information (American Library Association, 2000).

informatics: use of information and technology to communicate, manage knowledge, mitigate error, and support decision-making (Cronenwett et al., 2007) knowledge: is a complex process of remembering, relating, or judging an idea or abstract phenomenon (cognitive abilities) (Suskie, 2010).

nurse educator: includes all RN faculty and RNs working at the college to educate students that currently may not be working in a "faculty" position. This would include part time lab staff RNs or administrators.

nursing faculty: RNs working in positions labeled as “faculty". Employees considered 
ELECTRONIC HEALTH RECORDS IN NURSING EDUCATION

faculty include tenured, nontenured, assistant, associate, adjunct, visiting, and clinical associates.

nursing informatics: nursing informatics is a specialty that integrates nursing science, computer science, and information science to manage and communicate data, information, and knowledge in nursing practice. Nursing informatics facilitates the integration of data, information, and knowledge to support patients, nurses, and other providers in their decision making in all roles and settings. This support is accomplished through the use of information structures, information processes, and information technology (American Nurses Association, 2008). nursing practice: nursing is the protection, promotion, and optimization of health and abilities; prevention of illness and injury; alleviation of suffering through the diagnosis and treatment of human responses; and advocacy in health care for individuals, families, communities, and populations (American Nurses Association, 2012).

meaningful use: means providers need to show they're using certified EHR technology in ways that can be measured significantly for quality. The American Recovery and Reinvestment Act of 2009 specifies three main components of Meaningful Use a) the use of a certified EHR in a meaningful manner, such as e-prescribing, b) the use of certified EHR technology for electronic exchange of health information to improve quality of health care and c) the use of certified EHR technology to submit clinical quality and other measures ( H.R. 1--111th Congress, 2009). 
ELECTRONIC HEALTH RECORDS IN NURSING EDUCATION

personal health record (PHR): an electronic record of health-related information on an individual that conforms to nationally recognized interoperability standards and that can be drawn from multiple sources while being managed, shared, and controlled by the individual (Bell \& Bradford, 2008).

skills: are the proficient manual, verbal or mental manipulation of data or things that allow for the execution of well-specified tasks (psycho-motor abilities) (Suskie, 2010).

usability: the extent to which a product can be used by specified users to achieve specified goals with effectiveness, efficiency, and satisfaction in a specified context of use (Healthcare Information and Management Systems Society, 2011). 
Chapter Two

The Literature

"Never doubt that a small group of thoughtful, committed, citizens can change the world. Indeed, it is the only thing that ever has."

-Margaret Mead

The purpose of this case study is to explore and describe, with the nursing faculty and nurse educators of a small liberal arts college, their knowledge, skills, and attitudes (KSAs) as they participate in an action research framed curriculum development program for implementation of applied informatics using an academic EHR platform. Specifically, the question this researcher wants to answer is What is the experience of nursing educators and nursing faculty members involved in the integration of an AEHR project framed in the Learning by Developing model at a small liberal arts college school of nursing? To carry out the study, it was necessary to complete a critical review of current literature in order to provide framework for the study. This review was ongoing throughout the data collection, data analysis, and synthesis phases of the study.

This chapter explores the current knowledge about integration of EHR technology and concepts within academic settings in an attempt to discover successful strategies as well as barriers that affect this process, as well as identify gaps. In light of this, the discussion includes two major areas of literature: computerized health records integration in academic settings, and faculty development on informatics. Nursing faculty development regarding informatics was reviewed because nursing faculty members are a vital element in the success or failure of curriculum development. A clear understanding of nursing faculty and nurse educators' knowledge, development of skills, and attitudes regarding informatics, and during the integration of an EHR provides direction and 
structure for a successful integration process. Theoretical frameworks on integrative approaches to faculty development were explored to provide structure for the study.

To conduct this selected literature review, multiple resources were used including books, dissertations, Internet resources, professional journals, and periodicals published since 2000. These sources were accessed through ERIC ${ }^{\circledR}$, ProQuest $^{\circledR}, \mathrm{EBSCO}^{\circledR}$, PubMed $^{\circledR}$, CINAHL $^{\circledR}$, and Google Scholar ${ }^{\circledR}$. Search terms included the keywords “Computerized Patient Records", "Electronic Medical Record”, and "Electronic Health Record" with the same keywords plus "faculty nursing”, " nurse educator", "faculty learning", "education, nursing", “nursing education", and "education, nursing, baccalaureate." In addition, review of annotated bibliographies from the Quality \& Safety Education for Nurses (QSEN) and Technology Informatics Guiding Educational Reform (TIGER) websites.

\section{EHR Implementation Processes in Schools of Nursing}

EHR implementation processes in schools of nursing began as requirements for student EHR skills increased. This came about in order to ensure quality and safety of patients during clinical immersion experiences with students in clinical sites in the community. Students must be prepared to perform, as graduate and practicing nurses do, by first practicing clinical skills in a low stakes environment. With the recent immersion of EHR systems into healthcare facilities, this includes information management and documentation in the clinical site electronic health record system. EHR systems are specialized to particular healthcare facilities therefore to ensure student preparation, all nurse educators and nursing students are required to attend special training sessions on 
documentation processes in the EHR for that particular facility prior to scheduled clinical courses. These sessions are many times shorter in length and intensity than the training for nurse employees due to the short-term nature and limited access restrictions imposed by the clinical facility during student experiences at the clinical site(s). Because, content delivery for student training sessions is varied, student preparation for working in EHR systems is inconsistent and minimal. A few nursing schools across the country sought to improve this practice to better prepare students for clinical experiences.

In order to get a better understanding of the process of integrating EHR platforms into nursing school curriculum for the purposes of education, it is necessary to look at how the process occurs in nursing schools across the country. The literature revealed two different models of EHR integration; one is clinical facility/school of nursing (SON) partnerships, and the second is use of a specially designed academic electronic health record (AEHR) platform, not affiliated with any particular healthcare site. This review begins with further elaboration on partnership models.

\section{Partnership Models}

Partnership models are collaborations between a clinical facility, such as a clinic or a hospital, and a SON for special access to the training section of the clinical facility's EHR. These models evolved as a strategy to provide students extra EHR practice in clinical site systems thus, better preparation for clinical immersion experiences (Bostrom et al., 2006; Lucas, 2010; Melo \& Carlton, 2008; Nickitas et al., 2010). Most partnerships models for integration of EHR consists of the clinical agency allowing special access to a training section or "sandbox" EHR to the undergraduate SON either with or without 
special modifications of the training section (Melo, Carlton, 2008; Lucas, 2010; Nickitas et al., 2010). One partnership model uses a live system in a nurse-managed clinic with real patient data to train graduate nursing students as nurse practitioners (Bostrom et al., 2006).

Benefits of the partnership EHR education models, includes an avenue for more nursing student practice time in the EHR system with documentation and medication administration using barcode systems, and increased familiarity and thoroughness of student skills with EHR systems in the clinical practice areas.

Challenges encountered with these partnerships include IT department issues with userability of the system in regards to efficiency of the system, lack of faculty control over the process and content, limited ability to individualize documentation templates, and the need for an onsite informatics specialist. Critical components necessary for success include a) buy-in from administration, b) dedicated funding, c) college IT involvement, d) development and use of orientation materials, e) development of competency guides, and f) faculty engagement.

A win-win situation was mentioned in all partnership models reviewed: the nursing schools gain from having EHR technology available to students at a low cost, and access to an informatics specialist, while the clinical facility benefits from creating future nurses trained in their EHR system (Bostrom et al., 2006; Lucas, 2010; Melo \& Carlton, 2008; Nickitas et al., 2010). The monetary and human resource costs associated with installation and adaptation of EHR systems is considered a significant barrier to adaptation in practice and in academia (Lucas, 2010). The main issues or problems with 
partnerships are a) faculty perception of control over the content and process in the EHR system b) limiting its usability in multiple areas (Nickitas et al., 2010), and c) the ability to maintain the project over time (Melo \& Carlton, 2008). Project descriptions and key points that can be used to inform EHR integration programs include items such as a) a collaborative team consisting of an informatics specialist, information technology (IT) personnel, and faculty, b) special funding to pay for equipment purchasing and modifications, c) faculty training and release time, and d) supportive personnel. In summary, on the positive, partnership models afford students a needed exposure to the use of applied informatics technology in a low stakes environment at minimal cost. The drawback, however, is that in order to develop a conceptual understanding of informatics in clinical practice, a deeper understanding of EHR use in the clinical setting needs to occur beyond simple data entry. Partnership models are designed and controlled by institutions, thus, limiting the nurse educator or faculty abilities for involvement in the development of conceptual EHR assignments for the curriculum. A summary of the reviewed partnership models is provided in Table 3 . The next section will discuss the literature on development of academic EHRs and academic EHR model integration into schools of nursing. 


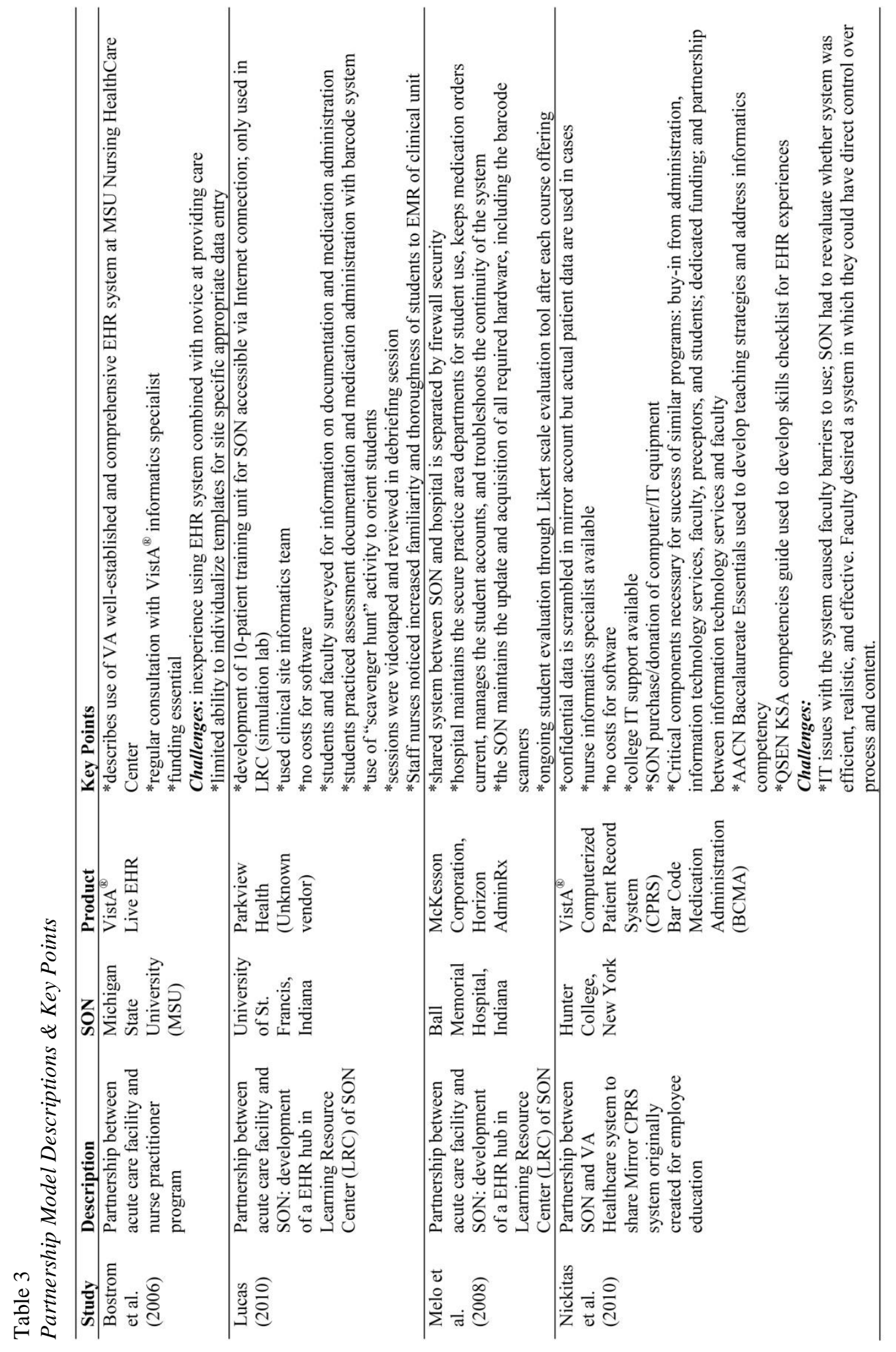


ELECTRONIC HEALTH RECORDS IN NURSING EDUCATION

\section{Academic EHR development and models}

Academic EHR (AEHR) integration first began in fall of 2001with a collaborative project between Cerner Corporation and the University of Kansas, School of Nursing (UK/SON) called Simulated E-hEalth Delivery System (SEEDS), an electronic health records system designed for purposes of teaching curriculum content to student nurses in an academic setting. This software product is an adapted academic version of the Cerner Power Chart system used in hospital and ambulatory care organizations for patient care (Conners et al., 2002). The benefits and purpose of developing an AEHR system is to provide a completely separate, safe, simulated environment for students. Students can then learn to apply theoretical nursing concepts and develop the necessary informatics skills required to function in a fully automated health care system without the high stakes risks involved in manipulation of live patient records. In addition, AEHR systems allow faculty input and manipulation of the case study data, providing structure and guidance for student learning activities.

The literature on implementing AEHR platforms into undergraduate nursing programs is limited to a few published projects from three vendors and their products a) Cerner PowerChart $^{\circledR}$, b) Eclipsys Sunrise Clinical Manager ${ }^{\circledR}$, and c) Elsevier NurseSquared $^{\circledR}$. As with the partnership models, investment in AEHR includes the following common infrastructure components a) funding, b) IT support/equipment needs,

c) involvement of informatics nurse specialist, d) faculty lead or project manager, e) leadership support, and f) faculty support strategies. 
Techniques used to integrate the AEHR include adding the AEHR to current skills training activities students do in a simulated lab setting. This is operationalized by faculty input of patient cases in the AEHR, then creating skills for the student nurse to perform which includes the documentation component (Meyer, Sternberger, \& Toscos, 2011). The use of case study or case method engages students in meaningful work, and helps learners discover and construct knowledge, which in turn facilitates the development of critical thinking and effective problem-solving skills essential in the work of nurses (Tomey, 2003). The nature of working in the AEHR by manipulation and documentation on cases allows the nursing faculty creative opportunities to present concepts in context where, as Benner, Sutphen, Leonard, \& Day (2010) describe, students learn a sense of salience, develop clinical imagination, and begin formation as professional nurses. This approach offers a way that integrates the classroom and clinical and prepares students to function in clinical situations that require answers to What is the patient experiencing? What are your nursing concerns? What information do you need? What actions need to be taken? (Benner, Sutphen, Leonard, \& Day, 2010).

The most significant benefit from working with an AEHR is the ability to provide a low-stakes learning environment for student nurse practice with EHR documentation/data entry skills. In addition, it provides a means by which the faculty can manipulate the environment for teaching nursing concepts and evaluate the individual learning of students. For example, in a project description by Taylor, Hudson, Vazzano, Naumann, and Neal (2010) the faculty were able to manipulate and create the EHR assessment templates to guide student learning in recognition of particular assessment 
terms and descriptions commonly found in practice. Students were not able to use the term within normal limits (WNL), a common wording when no abnormalities were discovered during an assessment. Instead, the fields in the template only had descriptions available. Students would need to develop an understanding of the terminology, identify the normal terms for a description, and then choose all components to describe or document the findings. For example, lungs clear in all fields, respirations even and unlabored, would be a description for normal breathing instead of writing WNL. Another feature was the ability to track student progress in a particular nursing course and across semesters. Since students had special login as required of any EHR system, faculty could review their work and provide learner-centered feedback via email.

Restraining forces, such as faculty challenges and resistance to change, can impede or block curriculum development projects such as the progress of AEHR implementation. Particular challenges identified from the literature include a) faculty frustration with the technology (Jeffries, Hudson, Taylor, \& Klapper, 2011), b) resistance from faculty in using the AEHR for assignments (Curry, 2011), c) lack of faculty understanding in AEHR use (Taylor et al., 2010), d) concerns about the quality of the cases, and e) lack of faculty time and energy (Johnson \& Bushey, 2011).

Strategies to address the faculty barriers include a) encourage faculty involvement and ownership of the program/technology incorporation (Jeffries et al., 2011; Johnson \& Bushey, 2011; Taylor et al., 2010), b) honor faculty expertise (Connors et al., 2002; Johnson \& Bushey, 2011; Meyer, Sternberger, \& Toscos, 2011; Taylor et al., 2010; Weaver, Warren, \& Delaney, 2005), and c) support faculty members when problems 
occur (Jeffries et al., 2011; Johnson \& Bushey, 2011; Taylor et al., 2010). Any program of faculty development for AEHR integration should consider these findings and plan accordingly. A summary of AEHR integration projects, their key descriptions, the schools involved, AEHR products studied, and key points including challenges and strategies identified in the literature are provided in Table 4. 


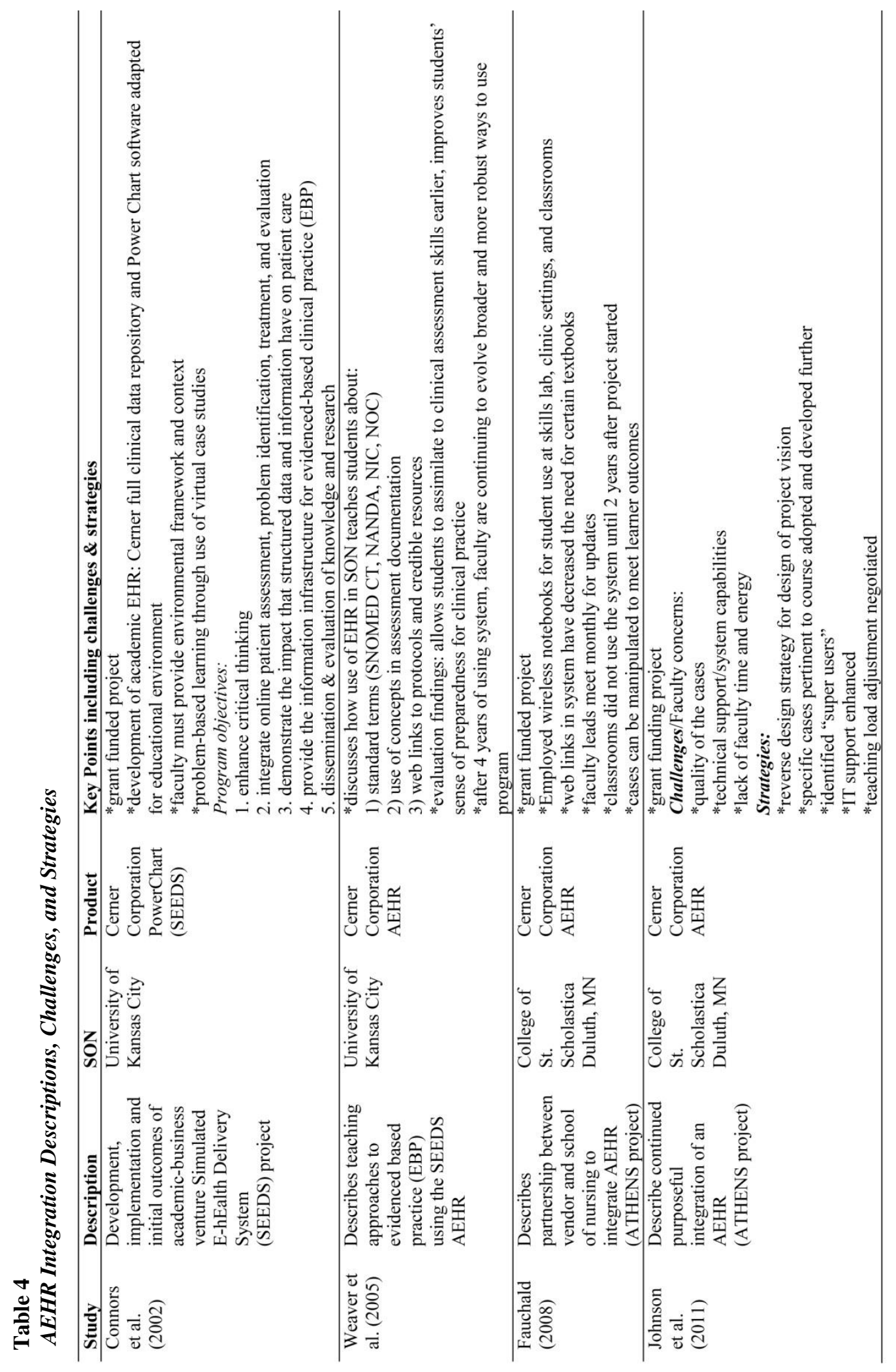




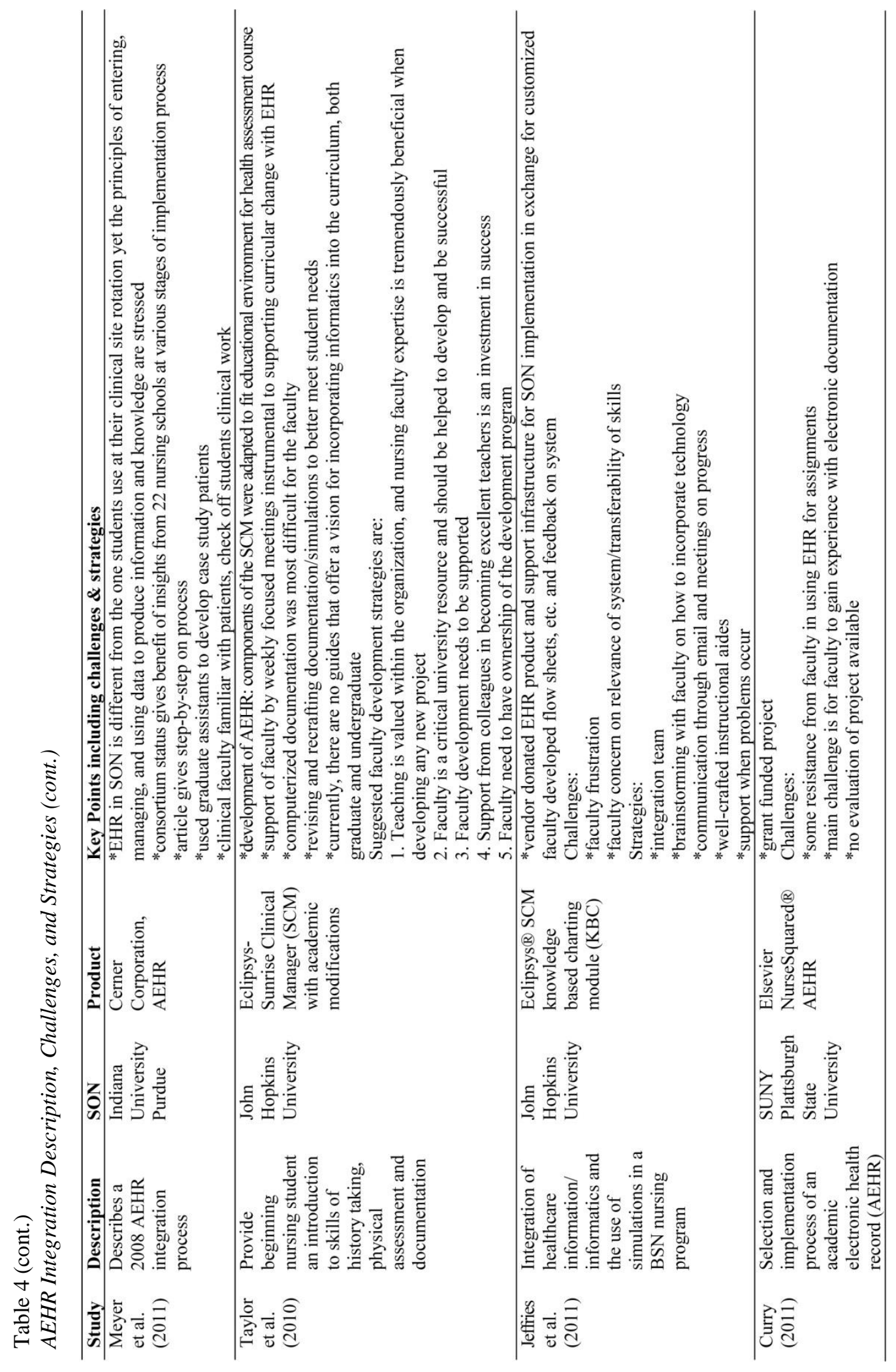




\section{Nurse Educator/Faculty Informatics Knowledge and Skills}

The most complex barrier for use of simulation and other technology in

undergraduate nursing education, according to Griffin-Sobel et al. (2010), is faculty buyin and adoption. In some cases, this barrier is related to fear of technology, and in most cases related to a lack of technical knowledge and/or skills (Griffin-Sobel et al., 2010). A search on literature for information about nurse educator/faculty knowledge of informatics uncovered three main studies that probed the following questions:

1) What specific informatics knowledge and skills are being taught in BSN and higher nursing programs and to what extent are nurse educators and faculty members prepared to teach informatics knowledge and skills? (McNeil et al., 2005).

2) Does your pre-licensure curriculum contain content/experiences aimed at the development of QSEN defined informatics competency? What is the perceived level of faculty preparedness to teach this competency? (Smith, Cronenwett, \& Sherwood, 2007).

3) How does the curriculum currently address informatics? How do faculty members personally integrate informatics into their courses? What informatics tools are used in the clinical setting? Faculty members self-rate their informatics knowledge. (Thompson \& Skiba, 2008).

The first report was a peer-reviewed study of 266 baccalaureate and higher nursing programs by McNeil et al. (2005) which revealed a gap in the knowledge needed by nursing educators to prepare graduate nurses to be skilled in information technology and how that technology was used to manage clinical information in daily practice. Additionally, the majority of nurse educators are at the novice or advanced beginner level with the use of informatics tools and informatics skills (McNeil et al., 2005). The literature review for this study concluded that although BSN programs were teaching 
some computer skills, less instruction was occurring related to informational literacy skills, and skills were not being linked to practice (McNeil et al., 2003). Qualitative data obtained during focus group discussion uncovered related factors such as a) faculty's lack of clear understanding of informatics, b) faculty's ambiguous thoughts about what constituted essential informatics content, and c) faculty's uncertainty about how to integrate this content into the nursing curriculum (McNeil, Elfrink, Beyea, Pierce, \& Bickford, 2006).

The second report was a peer-reviewed descriptive study on faculty preparedness to teach core competencies in quality and safety education in nursing (QSEN) by Smith, Cronenwett, and Sherwood (2007), conducted nationwide with 195 nursing programs. On the subject of teaching the use of information and technology to communicate, manage knowledge, mitigate error, and support decision-making, only $20 \%$ of BSN nursing programs and $26 \%$ of $\mathrm{BSN} /$ graduate programs reported ratings of faculty as expert/very comfortable in the area of informatics. Additionally, mean ratings of student satisfaction with beginning competencies in informatics was neutral (Smith et al., 2007).

Key findings from a nationwide survey on informatics requirements in nursing curricula by Thompson and Skiba (2008) with 1,557 faculty respondents and 540 administrators in 2006, confirms misunderstanding of the term informatics by faculty. For example, there were instances where faculty equated online learning and web-based instruction as being prepared in informatics, or more commonly, expressed that exposure to a computer constituted education in informatics (Thompson \& Skiba, 2008). 
The Technology Informatics Guiding Educational Reform (TIGER) Initiative report on faculty development in informatics by Rizzolo, Skiba, D, \& DuLong (2009) focused on overall informatics assessment in associate degree nursing (ADN) programs. Results from this investigation of clinical agencies and survey of National Organization for Associate Degree Nursing (NOADN) members provided the following seven insights:

1. Many ADN programs lack access to EHRs.

2. Not all faculty members are comfortable and/or familiar with technology in the clinical practice environment.

3. The learning curve is steep for EHRs and competes with limited clinical practicum on-site time.

4. Security and privacy issues may limit the students' access to EHRs at clinical practice sites.

5. Many school computer labs have limited or no access to EHR software for student practice.

6. Not all nursing school students have basic computer literacy skills.

7. More schools are reporting an increased use of PDAs and/or smart phones by students and faculty members in the clinical setting (Rizzolo, Skiba, \& DuLong, 2009).

A recent review of literature by DeGagne et al. (2012) found 19 studies over the past 10 years on integrating informatics into BSN curriculum. They posit three main conclusions from these studies. First, that no accepted centralized healthcare informatics standards exists that determines which competencies are appropriate or how to use them for undergraduate nursing education. Second, there is no clear consensus on the distinction between computer literacy and informatics concepts. Third, nursing faculty members were perceived as barriers to improving the curriculum (DeGagne et al., 2012). In addition, an exploratory study by Mahon, Nickitas, and Nokes (2010), on faculty members perceptions of teaching BSN students documentation skills, during the 
transition from paper-based to EHR systems (EHRS) in clinical settings, left many unanswered questions such as:

- How do faculty members view themselves assuming the role of both student and teacher while developing proficiency in EHRS?

- Do nursing faculty members embrace the new EHRS, or do they practice avoiding it?

- During this time of paper-to-EHRS transition, how do nursing faculty members succeed?

- Most importantly, how do nursing faculty members acquire the necessary knowledge, skills, and attitudes to successfully transition and impart these skills to students?

- What are the attitudes towards EHR technology? (Mahon, Nickitas, \& Nokes, 2010)

In a research article by McGinn et al. (2011), perspectives from managers, patients, and healthcare professionals, such as physicians nurses and pharmacists and medical archivists were analyzed from 60 publications regarding barriers and facilitators implementing electronic health records. Findings revealed that nurses had mixed opinions in regards to the EHR in terms of productivity. Specifically, “...increased time spent interacting with the EHR system decreased their job performance because they [the nurses] spent less time with their patients; however, the same study also found that nurses perceived EHRs as improving workplace productivity due to better access to and organization of patient care information" (p.5). In addition, managers complained that nurses experienced a loss of both physical and relational contact with patients due to their interaction with the technology. Factors common to all user groups included a) designer technical concerns, b) perceived ease-of-use, interoperability, c) privacy and security concerns, productivity, d) familiarity and ability with the EHR, e) motivation to use the 
EHR, and f) lack of time and workload. Time related and technical barriers were found to be the most cited barriers to the acceptance of EHR's and adoption of such systems.

Ease-of-use and productivity were seen as facilitators to encourage optimal EHR implementation (McGinn et al., 2011).

Additionally, perceived usefulness and motivation were the two chief factors to facilitating EHR implementation. Nurse educators were not mentioned specifically in any of these studies, although many nurse educators also work as registered nurses in clinical practice therefore, that group may not be singled out. The benefits of improving user experience is considered a significant implementation concept by the Healthcare Information Management and Systems Society (HIMSS) as a facilitator to EHR implementation (Staggers et al., 2011). Three focus areas in health information technology mentioned for increasing individual user effectiveness and efficiency are a) increase user productivity and efficiency, b) decrease user errors and increase safety, and c) improved cognitive support. An EHR platform that is open to user design upgrades and changes is imperative for end-user satisfaction and motivation to continue to use the technology. Nelson and Staggers (2013) provide an entire chapter in their health informatics book on the issue of technology usability.

User interface is considered a significant issue with health information technology maturity because products that are not designed for intended users can be inefficient and even dangerous. One example would be a medication administration system and process that involves so many complicated steps before a medication can get to the patient. The system becomes a barrier to safe and efficient care when the nurse choses to override the 
system in order to get the medication to the patient in a timely fashion. The safeguards intended to provide a layer of safety and double checks for medication administration processes simply becomes the barrier for the end user (the nurse) to work-a-round. The concept of usability consists of three goals: effectiveness, efficiency, and satisfaction. Although a top priority for health IT overall, health organization leaders and health informatics vendors may view incorporating usability into projects as adding time, effort and costs (HIMSS, 2011). Awareness and of usability and adjustments to EHR design must be included to ensure successful AEHR implementation. Figure 2 summaries the relationships regarding EHR usability in health organizations.

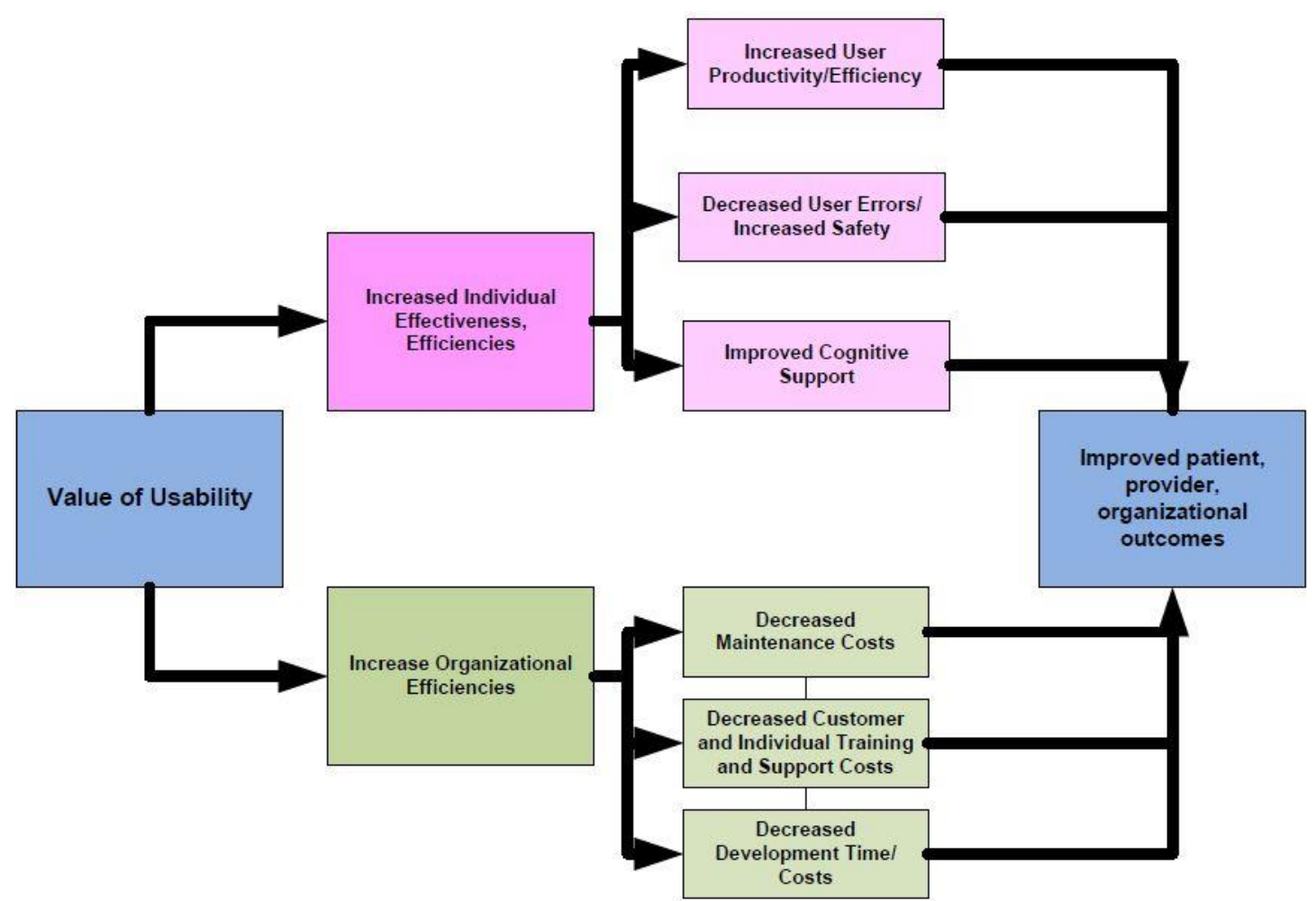

Figure 2. Diagram outlining the three goals of usability: effectiveness, efficiency, and satisfaction and their confections to improved patient and provider outcomes. The value of usability is based on factors related to individual as well as organizational effectiveness, which ultimately leads to improved patient, provider, and organizational outcomes. Adapted from "Promoting Usability in Health Organizations: initial steps and progress toward a healthcare usability maturity model" Health Information and Management Systems Society, 2011. 
Diffusion of innovation is a change theory developed by Rogers (2010) that explains how individuals respond to new ideas or practices such as information technology. The individuals within the social system subject to the innovation, in this case use of an AEHR platform, are organized into five groups a) innovators, b) early adopters, c) early majority, d) late majority, and e) laggards. The perception and acceptance of early adopters to the innovation affects the next group in line: the early majority. The early majority then join in as the perception gains acceptance, followed by the late majority until all have accepted the innovation over a period on time. The key element is the support of early adopters when the innovation is first introduced. The tipping point comes when the early majority has accepted the innovation (Rodgers, 2010).

In summary, it is clear from the literature that nursing faculty, in general, may lack knowledge, skills, and access to informatics in undergraduate nursing programs, and that this in turn contributes to barriers for EHR implementation in nursing schools. If these issues are not addressed, nursing schools will begin to experience what Skiba (2006) refers to as a digital divide, that is, "faculty who do not have access to the various clinical information systems that nurses will use as integral components of practice will have difficulty understanding how the nursing curriculum needs to change" (p.335).

Promoting an atmosphere of positive support and engagement during this change is essential to foster the acceptance and attitudes needed to implement this type of innovative technology into a curriculum. Therefore, opportunities for faculty development and support must be considered a necessary component for any nursing 
program considering integration of informatics concepts with an electronic health records platform. Additionally, usability plays a major role in the technology acceptance behaviors of healthcare personnel. The more positive the experience, the better the acceptance will be. The next section focuses on nursing faculty development literature for informatics curricular integration.

\section{Nursing Faculty Development Barriers and Strategies}

It is clear from the literature review that an educational program for faculty development regarding integration of educational EHR needs to contain several key principles such as a) incorporating strategies that address identified barriers, b) using a transdisciplinary approach to the project, and c) creating an integrated and supportive learning environment. Five specific key barriers and issues identified in the literature regarding AEHR integration knowledge, skills, attitudes, and user ability that bear consideration in the organization and implementation of an AEHR platform include:

a) faculty members as a whole have varied levels of knowledge and skills regarding informatics;

b) the learning curve for some faculty members is steep and often unrewarded;

c) faculty fear of technology;

d) unclear expectations of faculty informatics competencies; and

e) system user ability plays a very important role in faculty acceptance.

(McGinn et. al., 2011; Nelson, \& Staggers, 2013; Skiba, Rizzolo, DuLong, 2009)

A summary of strategies informed by the literature to reduce the barriers and improve faculty knowledge, skills, and attitudes (KSAs) include the following six recommendations:

a) provide informatics knowledge individualized to meet the level of the faculty learner(s) through workshops and seminars;

b) create evidenced based competency guidelines in collaboration with the 
nursing faculty;

c) have a nurse informatics specialist and IT services available for support;

d) Get "buy-in" support from administration;

e) procure funding/grants, and faculty course release time; and

f) include extra time and support during training periods (Curry, 2011; Jefferies, Hudson, Taylor, \& Klapper, 2011; Johnson et. al., 2011; Taylor et. al., 2010).

In addition, Griffin-Sobel et al. (2010) suggests the structure of a transdisciplinary approach to faculty development that is a) nonhierarchical, b) involves sharing of information from relevant publications and conferences, c) brainstorming sessions, and d) promotes encouraging one another.

A project description, Faculty Development Initiatives for the Integration of Informatics Competencies and Point-of-Care Technologies in Undergraduate Nursing Education by Curran (2008), discusses the need for education strategies to be "hands-on" or "...one in which you learn best by doing" (p. 524). The overall goal of this type of integrated learning framework creates an atmosphere focused on learning as opposed to explicit teaching. This type of atmosphere, focusing on the learning of informatics competencies, promotes an exploratory attitude for faculty. The faculty would in turn, develop curricula strategies to teach students using these concepts and tools (Curran, 2008). Curran based this faculty development initiative model on Fink's (2003) six principles of significant learning
a) foundational knowledge,
b) application of the new knowledge and skills,
c) integration with existing knowledge,
d) a human dimension,
e) caring, and
f) learning how to learn. 
The operational examples given for this model include a) faculty already possess the foundational knowledge of nursing, and b) faculty were asked to provide nursing student assignments with the AEHR demonstrating application of new knowledge, and integration with existing knowledge. The human dimension and caring aspects of the model were demonstrated through supportive measures such as a) hands-on class time with the AEHR, b) remote access to the system for exploration and experimentation, and c) individual meetings and coaching on assignment development (Curran, 2008). Key points of this project were a) the selection of a small group of star educators to develop and cultivate projects which led to educational improvements, b) creating ongoing relationships among the faculty, and c) a clear expectation that informatics will be embedded into the curricula. Although this was a descriptive article, which provided information on structuring a faculty development program for AEHR integration, there was no formal study on the experiences of the faculty, or their perceived effectiveness of the program development strategies.

When nurses are involved in the design, planning, and implementation of technology systems, fewer problems are noted during the implementation phase (Hunt, Sproat, \& Kitzmiller, 2004). Faculty engagement in the integration process of informatics promotes faculty development and use of more effective pedagogy. For example, Cornell (2009) studied the processes of change involved to implement the core competency of healthcare informatics as recommended by Greiner \& Knebel and the IOM (2003) in Health professionals education: A bridge to quality. The study involved three nursing schools that used patient case scenarios loaded into electronic health records in their 
computerized human simulation laboratories as the main form of informatics integration. Findings from the qualitative inquiry include that faculty participants' at all three nursing programs increased their use of the pedagogical approaches of active learning and problem-based learning in these simulated learning environments.

\section{Conceptual Framework for Faculty Development and AEHR Integration}

The Laurea University of Applied Sciences in Finland formalized an integrative pedagogy called Learning by Developing (LbD) as a strategy to integrate regional development, pedagogy, and research and development into one frame of operations. The $\mathrm{LbD}$ is an action research model of learning in a professional context which involves a) knowledge in theories and models, b) knowledge embedded in skills and abilities, c) moral knowledge, and d) experiential knowledge corresponding to the components of professional competence; i) knowing, ii) understanding, iii) doing, and iv) situational management (Taatila \& Raij, 2011).

This model fits well with the practice of nursing because in the practice environment for nurses, it is not enough to know and understand; you also have to be able to apply your knowledge and manage evolving situations. Since all nursing educators are required to be practicing registered nurses, thus have the experience of applying nursing theoretical concepts in practice, this model for organizing the AEHR integration should feel very familiar to them. In 2008, the LbD model was chosen as the method in Finland for creation and development of informatics skills and competencies in nursing education (Ora-Hyytiäinen et al., 2010). Theoretical assumptions of the model for this project 
concern the concepts of reality, knowledge, human, learning, change, and partnerships as explained below:

- Reality is assumed to have been interpreted within a sociocultural framework, meaning the people create their cultural norms and models together. These norms are negotiated consciously and unconsciously, in official or unofficial situations; for example, as discussions during break.

- Knowledge is seen as tacit and explicit. Tacit knowledge is the type used in nursing practice. This tacit knowledge is based on theoretical and research knowledge, but is especially formed through reflection on experiences. It is also procedural knowledge and depends on context. Explicit knowledge is that which you encounter when reading papers, books, reports, or statistics, and when using databases. Explicit knowledge used in the project is knowledge from research, experts, and legislation.

- Participants in the project are willing to learn and grow professionally. Nurses, nurse managers, nurse students, nurse educators are all actively working together. Adopting new ways to learn and develop is emotionally demanding for all; it is important to accept this demand and support each other through awareness and open discussion.

- Principles regarding single-loop and double-loop learning by Argyris and Schon (1978) allow for the possibility of change in one's habits at work, and justifications for change in joint habits. The practice community is changing the way nursing documentation is carried out; therefore, learning for all participants in this new paradigm has to be mutual. (Ora-Hyytiäinen et al., 2010)

There are mutual gains from participants in this project model. From the educator's point of view, the method integrates teaching, research (evidence based practice), and development. From the nurse's viewpoint, the method provides a mutual learning process for members of the practice community (electronic documentation and information management). From the student viewpoint, the method provides a new strategy in learning (learning informatics skills in a real practice environment, and creating knowledge together with those already in practice) (Ora-Hyytiäinen et al., 2010). 
Raij (2007) describes the LbD model as one that centers on a development project that is genuinely rooted in the world of work, requiring collaboration between lecturers (nurse educators), students, workplace experts and end users. Stemming from the review of the literature and practicality of this model for this research project, the LbD model was chosen as candidate for the conceptual framework model to guide the integration process of the AEHR project. Based on the summarized characteristics of the LbD action model described by Taatila and Raij (2011), the context of integrating an AEHR into a nursing program is compared and described for appropriate fit with this model:

1. The starting point is a genuine, working life-related research and development project: Integration of an AEHR into the nursing school curricula.

2. LbD is based on authentic partnerships between lectures, students, experts and clients as end users: faculty, nursing students, instructional technology department, integration specialist, adjunct faculty, precepting nurses, informatics nurse(s) at local hospital, and nursing students as client end users.

3. It includes the components and types of knowledge of professional competence as an integrated whole: nurse educators and faculty members develop informatics KSA in AEHR functioning, and create integrated learning experiences for students that include nursing concepts and AEHR KSA.

4. Sharing and interpreting observations lead to the abductive formation of a hypothesis, which will be verified through deductive and inductive reasoning: development of AEHR learning objectives and activities in the nursing school curricula lead to competence and comfort in student KSA with applied informatics which, in turn, leads to increased comfort and competence with informatics as a natural state of practice for graduate nurses.

5. The development project is seen as a learning environment that involves knowledge included in the work (knowledge in practice): development of how nursing practice can be designed into learning activities with an AEHR platform; knowledge acquired about it through research (knowledge of practice): nurse educator and faculty development of AEHR KSA competencies and how this integrates into nursing practice; and new competence produced for the work 
(knowledge for practice): faculty members develop applied KSA, and students develop applied nursing concepts and informatics KSA.

6. LbD facilitates collaboration between different experts acting as researchers, developers and transmitters of tools: Faculty have ownership in the project. Student feedback from nursing students and nursing faculty (as students) is sought after and honored. Adjustments made according to feedback and evaluation from all members of transdisciplinary team.

7. It forms a platform for demonstrating the students' competence: students learn and apply nursing concepts and informatics skills within the AEHR.

8. LbD results in learning for individuals and the community, the generation of new competence in forms of new habits and action models, and innovations:

AEHR KSA transfer to clinical settings. Students graduate with confidence and comfort with applied informatics.

9. Learning takes place when participants achieve new ways of action and new habits to meet an ever-changing world: faculty gain an understanding of informatics to incorporate into the curriculum. Students gain a deeper understanding of informatics and graduate ready for practice with EHR technology skills and become active participants in the design, selection, and evaluation of information used in the support of patient care. The community partners employ new nursing graduates with EHR skills and experience working collaboratively with professionals on evidenced based practice projects.

Raij et. al. (2011) defines five overarching themes to the LbD model as:

1. Authenticity refers to a genuine working life orientation and connection. The learning environment for project participants comprises a genuine, working lifeoriented research and development project. Outcomes generated by the project contribute to the renewal and development of the world of work.

2. Partnership refers to responsible collaboration among students, lecturers, working life experts and clients, featuring mutual commitment. Partnership is characterized by equality and is built on trust. The aim is to create long-term partnerships, which are built on systematic cooperation established on trust.

3. Experiencing refers to the communal use and sharing of experiential knowledge in research and development projects. Experiences support the learning process, steer the progress of the project, and enable evaluation of the project impact. Recognizing the consequences of ways of action and beliefs requires that students 
involved in development projects acquire genuine experience during the competence development process.

4. Research orientation refers to the utilization of research knowledge and knowledge of research methods in projects and personal competence development. Research and development projects involve drawing up a research plan and reporting in line with the principles of scientific research. The research orientation of development projects enables recognition and demonstration of their impact.

5. Creativity refers to the freedom to seek something new, create new ideas and search for new paths. It allows risk taking, sidetracking and even mistakes. Failing can be seen as a successful learning experience. Creativity is established on responsible freedom and gaining space. Creativity is part of the competence capital of graduates and is supported in development projects.

These five themes act as the underpinning for philosophical understanding and

collective ideals for institutions of higher learning that are important to the cohesiveness

of the curriculum. In addition, these themes fit well with the college mission and nursing school vision and mission for integration of an AEHR into the Liberal Oak College

curriculum, which focuses on life-long learning in a collaborative environment:

\section{Liberal Oak College Mission Statement}

Liberal Oak College advances a vision of learning, life, and community that:

* promotes intellectual challenge and creativity,

* values both theoretical and practical knowledge,

* engages thoughtful dialogue in a climate of mutual respect,

* honors the rich texture of diverse cultures and varied ways of understanding,

* piques curiosity for a lifetime of inquiry, and

* inspires the courage to live by moral and spiritual principle and to defend freedom of conscience.

\section{Liberal Oak College Nursing School Vision and Mission}

Vision: Liberal Oak College educates professional nurses for health stewardship of the complex global society.

Mission: The mission of Liberal Oak College is to create an inclusive community of learning grounded in the liberal arts values of social justice and life-long learning. The program prepares caring nurses who are committed to the profession and responsive to the needs of the global community in an ever- 
changing healthcare environment. Evidence based practice and research guide student learning within a culture that promotes professional excellence and scholarship.

A summary of the LbD model with its stages (a) through (j), key points for integrative learning workshops, student personal study plans, and overarching themes is illustrated in

Figure 3.

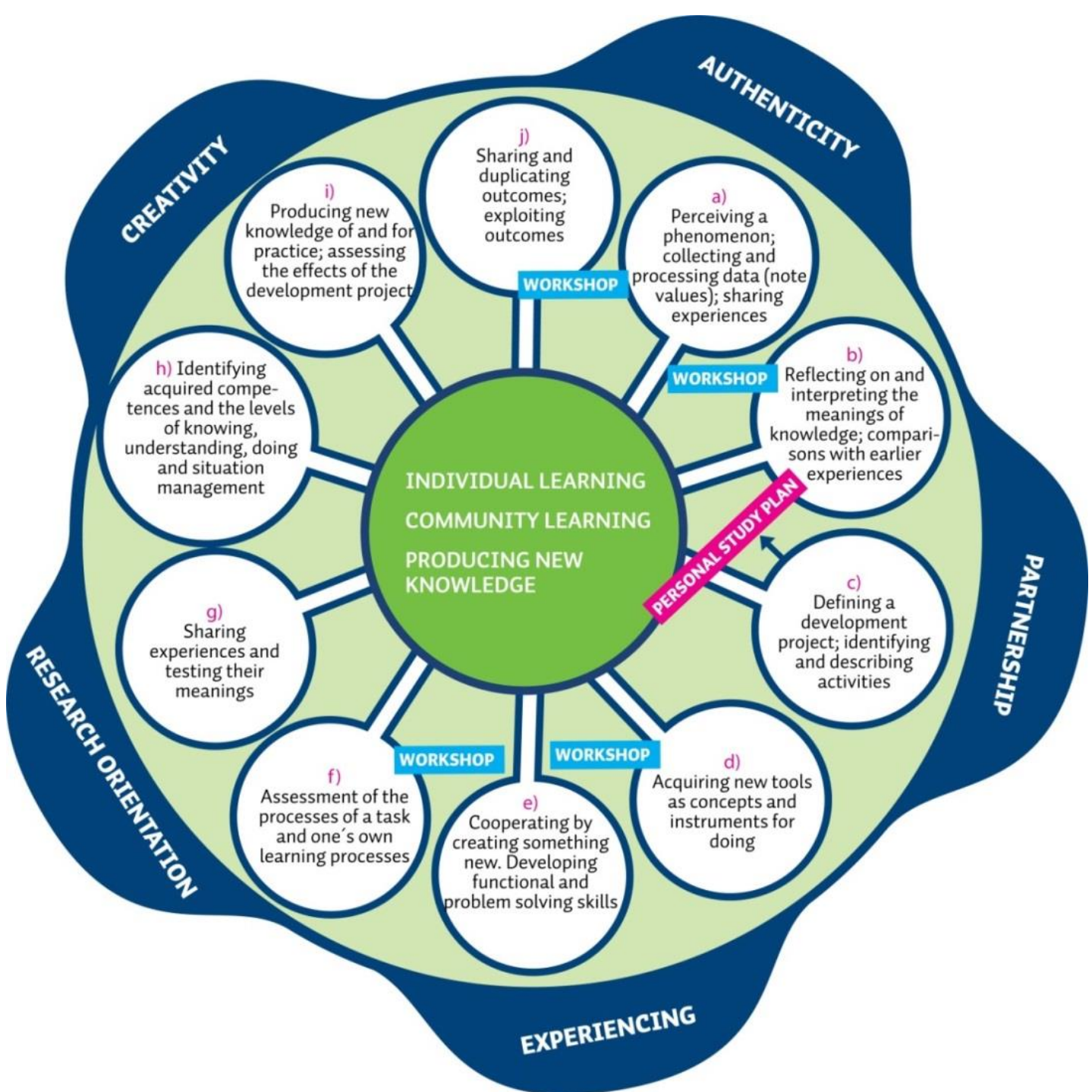

Figure 3. Recognized stages of the $\mathrm{LbD}$ action research model as examples that steer project implementation. Overarching themes of creativity, authenticity, partnership, experiencing, and research orientation are shown as collective ideals driving the process. Adapted with permission from "Learning by developing: LbD guide," by Raij et al., 2011. 
According to Herr and Anderson (2005), the nature of action research designed projects involves multiple cycles. The goal of this type of research project is to understand practice and the articulation of a rationale or philosophy of the practice in order to improve the practice. Within the action research project, intervention is included as part of the research cycle, as emphasized in the following four steps:

1. Develop plan of action to improve what is already happening;

2. Act to implement the plan;

3. Observe the effects of action in the context in which it occurs;

4. Reflect on these effects as a basis for further planning, subsequent action and on, through a succession of cycles. (Herr \& Anderson, 2005, p. 5)

In particular, participatory action research (PAR), primarily inspired from the work of Paulo Freire (1970), emphasizes participation and action geared towards development and change within communities and groups. PAR is a pluralistic approach to knowledge making and social change. The type of action research proposed for the small liberal arts college in this case study requires multiple participants and transformation of old ways of doing. As faculty members participate and develop their knowledge in the AEHR platform, the integration of informatics curricula evolves. This transformative process occurs as part of the participatory research whereby theory and practice are integrated, and the community and the researcher together produce critical knowledge aimed at the social transformation, in this case, computerized information management education for undergraduate nursing students and faculty. The results of the research are folded back into the project as new ways of doing (Herr \& Anderson, 2005). 
In comparison to action research, the nursing process is a very familiar framework known by all nurses in nursing education and practice. It serves as the common thread uniting all the various types of nurses who work in different care areas--the essential core of practice for the registered nurse to deliver holistic, patient-focused care (ANA, 2012). The nursing process operates with the basic steps of a) Assess: gather information about the situation, b) Diagnose: identify the problem, c) Plan: set goals of care, desired outcomes, and identify inappropriate nursing actions, d) Intervene: perform the nursing actions identified in planning and, e) Evaluate: determine if goals and expected outcomes were achieved (see Figure 4).

1. Assessment

2. Nursing Diagnosis

3. Plan

4. Intervene

5. Evaluate

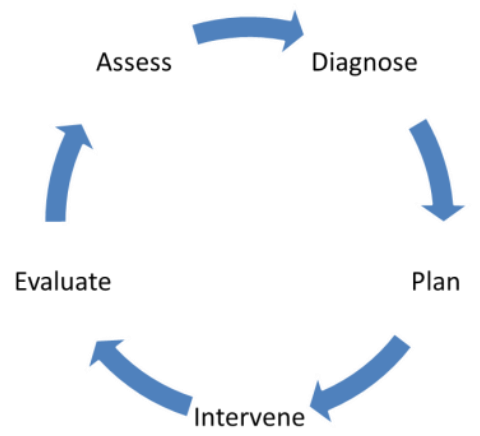

Figure 4: Diagram of the critical thinking nursing process elements of Assess, Diagnose, Plan, Intervene, and Evaluate that are very similar to the action research process of Plan, Act, Observe, and Evaluate.

Due to the familiar nature of the process of the action research format in the nursing process, the Learning by Developing theoretical model fits as a familiar type of process for nursing faculty for use as the conceptual framework for the AEHR integration process at Liberal Oak College. New knowledge development during one or more stages in the integration process in turn influences the other stages of the AEHR integration, which lends the researcher an evolving nature of methodology (Herr \& Anderson, 2005). 
The LbD model therefore was chosen as the conceptual framework for nursing faculty development and integration process of the AEHR platform and curricular development. The LbD model in particular provides a framework that facilitates creativity allowing all partners to participate as equals, sharing experiences and finding meanings, in order to produce new knowledge in their varying roles and responsibilities (Taatila \& Raij, 2011).

\section{Force-field Analysis and Summary}

In summary, the findings from the literature describe AEHR implementation projects, their barriers and strategies, as well as frameworks for engaging faculty to participate with innovation. Collectively, lessons learned from these study elements inform the design for the faculty development program for AEHR implementation at this small liberal arts college. The first step in action research process for this case study research project is assessment and data analysis.

In order to provide an informed plan for AEHR integration, assessment of previous research barriers, benefits, and strategies are compiled in a cohesive force-field analysis summary. Based on Kurt Lewin's Field Theory, the status quo is comprised of a semi-stable but dynamic equilibrium of forces acting for and against change (Card, 2013). By categorizing the driving and the restraining forces identified in the literature, an informed faculty development program can be designed to overcome expected obstacles and implement a development plan, based on researched success strategies. In addition, the analysis provides a launching point for action, which serves as a reference point, as the project progresses (Bozak, 2003). Table 5 details the driving and restraining forces from this literature review process. 
Table 5

Summary of Driving and Restraining Forces from Literature for Force-field Analysis

Driving Forces

- Buy-in from administration

- Funding/grants

- Nurse informatics specialist available

- QSEN KSA competencies guide used to develop skills checklist for EHR experiences

- AACN Baccalaureate Essentials used to develop teaching strategies and address informatics competencies

- College IT support available

- Small seminars and workshops on informatics

- Consultation for selected competencies

- Guest lectures or co-teaching by informatics expert faculty members

- Train-the-trainer model

- Decreased need for certain textbooks

- Allows students to assimilate to clinical assessment skills earlier

- Use clinical site informatics team

- Learning needs assessment of faculty

- Use of "scavenger hunt" activity

- Donated IT equipment Improves students' sense of preparedness for clinical practice

- Faculty provide environmental framework and context

- Faculty to manipulate cases to meet learner outcomes

- Teaching load adjustment negotiated

- Graduate assistants develop case studies

- Clinical faculty familiar with patients, check off students work
Restraining Forces

- Faculty mixed perception of informatics knowledge

- $\quad$ Limited faculty knowledge, skills, and motivation

- Learning curve is steep and often unrewarded

- Faculty fear of technology

- Unclear expectations of faculty competencies

- Lack of faculty time and energy

- Limited ability to individualize EHR templates for site specific appropriate data entry

- Quality of the cases questionable

- Faculty desired a system where they could have control over process and content

- IT system capabilities are limited

- Lack of technical support when needed

- Lack of administrator vision and support 
Research opportunities are possible through triangulation of multiple sources during the project such as surveys, artifacts, structured interviews from faculty, and field note observations during workshops and praxis group discussions. Considering the findings in the literature, the experiences of educators participating in a faculty development program for integration of an AEHR into a nursing school curriculum is very limited. Exploration of knowledge, skills, and attitudes (KSA) of faculty within the $\mathrm{LbD}$ framework during this process informs the AEHR project progression at the Liberal Oak College. Additionally, this information may provide insight for other schools of nursing considering integration of AEHR technology during curricular revision. The next section provides the methods for studying the faculty experiences as they participate in the AEHR integration project framed in the LbD model. 
ELECTRONIC HEALTH RECORDS IN NURSING EDUCATION

\author{
Chapter Three \\ Research Paradigms and Methodology \\ "To keep doing the same thing and expecting a different result is insane"
}

-Albert Einstein

Although the literature describes the barriers and challenges during informatics integration projects in nursing programs, and faculty member's knowledge, skills, and attitudes regarding informatics are identified as significant in the process, little documentation exists on the experiences of faculty participating in AEHR integration. The purpose of this case study is to explore and describe, with the nursing faculty of a small liberal arts college, the faculty knowledge, skills, and attitudes (KSAs) as they participate in an action research framed curriculum development program for implementation of applied informatics using an AEHR platform. The researcher believes that a better understanding of this phenomenon would allow educators to proceed with a more informed perspective in terms of design and facilitation of the integration process for informatics education in nursing programs.

In seeking to understand this phenomenon, this study addresses the question: What is the experience of nursing educators and nursing faculty members involved in the integration of an AEHR project framed in the Learning by Developing model at a small liberal arts college school of nursing? This chapter describes the study's research design and methodology including discussions around the following areas a) description of the research setting and context, b) background information and description of the AEHR integration project process, c) start point logistics, d) participant sample selection, 
e) method for data collection, f) process of analysis and synthesis of data, g) ethical considerations, h) issues of trustworthiness, positionality, and limitations of the study. The chapter ends with a brief concluding summary.

\section{Case Study Design}

A case study was the chosen inquiry methodology for this research. The case study approach, as a research method, focuses on context and a particular case such as an individual, a group, or a situation in detail within its natural context, and tries to probe into its characteristics, dynamics, and purposes. According to Yin (2009) case studies "... are the preferred method when how or why questions are being posed, the investigator has little control over the events, and the focus is on a contemporary phenomenon within real-life context" (p. 2). Therefore, the case study method fits to examine faculty development knowledge, skills, and attitudes during AEHR integration at a small liberal arts college.

Creswell (2008) posits that a case study is an in-depth exploration of a bounded system such as an activity, event, process, or individuals, based on extensive data collection. Bounded refers to the fact that the case is separated out in terms of time, place, or some physical boundaries. A case study provides an in-depth perspective based on a variety of collection materials. The researcher situates this case within its larger context or setting. In particular, Creswell adds that a case may represent a process consisting of a series of steps such as a college curriculum revision process that form a sequence of activities (Creswell, 2008). Therefore, a study of faculty development during the AEHR integration process fits well with this particular method. Data collection activities, as they 
relate to the case study approach and this study are described by Creswell (2008) to include the following activities: a) description of the site and individuals, b) access and rapport, gaining the confidence of the participants,

c) purposeful critical case sampling strategies that justify the case study method, d) recording descriptive information from observations, documents, interviews, and artifacts, e) interviewing and observing issues, and f) confidential use and storing of data. An instrumental type of case study as described by Stake (2005) is proposed for this exploratory descriptive investigation mainly to provide insight into the issue of faculty development during the use of the LbD model in AEHR integration. Stake (2005) uses the term instrumental case study "... if a particular case is examined mainly to provide insight into an issue or to redraw a generalization" (p.445). Therefore, case study methodology for exploring and describing nurse educator and faculty experiences during an action research method for AEHR curriculum development fits with the descriptions for the purposes of gaining in-depth understanding. A summary of these case study design elements in the action research model (LbD framework) used to gather data for this study is provided in Table 6. 
Table 6

Elements of Study Framed in Creswell's Data Collection Specific for Case Study Analysis

\begin{tabular}{|c|c|c|}
\hline $\begin{array}{l}\text { Data } \\
\text { collection } \\
\text { activity }\end{array}$ & Case study approach & Elements in the LbD framework for this study \\
\hline $\begin{array}{l}\text { Sites or } \\
\text { individuals }\end{array}$ & $\begin{array}{l}\text { A bounded system; such } \\
\text { as a process, an activity, } \\
\text { an event, a program, or } \\
\text { multiple individuals }\end{array}$ & $\begin{array}{l}\text { Small Liberal arts college school of nursing educators and } \\
\text { faculty members involved in a LbD based AEHR } \\
\text { integration faculty development program }\end{array}$ \\
\hline $\begin{array}{l}\text { Access and } \\
\text { rapport }\end{array}$ & $\begin{array}{l}\text { Gaining access through } \\
\text { the gatekeeper, gaining } \\
\text { the confidence of the } \\
\text { participants }\end{array}$ & $\begin{array}{l}\text { IRB review and approval of this proposal, written consent } \\
\text { explaining study purpose, time involvement, researcher's } \\
\text { position, how results will be used, and what gains the } \\
\text { participants may have }\end{array}$ \\
\hline $\begin{array}{l}\text { Purposeful } \\
\text { sampling } \\
\text { strategies }\end{array}$ & $\begin{array}{l}\text { Finding a "case" or } \\
\text { "cases," an "atypical" } \\
\text { case, or a "maximum } \\
\text { variation" or "extreme" } \\
\text { case }\end{array}$ & $\begin{array}{l}\text { A maximum variation (in order to capture and describe } \\
\text { multiple perspectives), critical case sampling of full and } \\
\text { part time nurse educators and faculty participating in LbD } \\
\text { framed activities for integration of the AEHR at the } \\
\text { Liberal Oak College }\end{array}$ \\
\hline Forms of data & $\begin{array}{l}\text { Extensive forms such as: } \\
\text { documents and records, } \\
\text { interviews, observation, } \\
\text { and artifacts }\end{array}$ & $\begin{array}{l}\text { Observations of nurse educators and faculty during } \\
\text { workshops and open lab sessions as participants, } \\
\text { semistructured interviews (audiotaped and transcribed), } \\
\text { documents from email task force meetings and faculty } \\
\text { assembly meetings, videotaped workshop sessions, } \\
\text { AEHR chart audits of faculty comments, student } \\
\text { assignments, email messages regarding the AEHR project } \\
\text { between Liberal Oak College nurse educators and staff, } \\
\text { and video recordings of workshops }\end{array}$ \\
\hline $\begin{array}{l}\text { Recording } \\
\text { information }\end{array}$ & $\begin{array}{l}\text { Field notes, interview and } \\
\text { observation protocols }\end{array}$ & $\begin{array}{l}\text { Protocol for observation sessions Appendix J; protocol } \\
\text { for interviews Appendix H; field notes recorded during } \\
\text { observations at workshops, task force meetings }\end{array}$ \\
\hline Field issues & $\begin{array}{l}\text { Interviewing and } \\
\text { observing issues }\end{array}$ & $\begin{array}{l}\text { Insider research position awareness, professional } \\
\text { approach to research; observation as participant, } \\
\text { nonparticipant, or middle ground position identified in } \\
\text { notes }\end{array}$ \\
\hline Storing data & $\begin{array}{l}\text { Field notes, transcriptions, } \\
\text { computer files }\end{array}$ & $\begin{array}{l}\text { Field notes notebook log kept by researcher in locked file, } \\
\text { transcriptions of interviews on password protected } \\
\text { computer file in researcher's computer }\end{array}$ \\
\hline
\end{tabular}

\section{Setting and Context}

As mentioned previously, the setting and context description is necessary according to Creswell (2008) to gain an understanding of the activity, event, process, or individuals in the case. The case study on nursing faculty experience during an action 
research framed AEHR integration therefore is described here in its context of time and place during this process.

Setting. The place for this study is a Small Liberal Arts College School of Nursing. For purposes of anonymity, the pseudonym Liberal Oak College will be used in place of the real name of the school in this study. This upper division school (established in 1858) is located offsite of the main campus in a large metropolitan area. The nursing program is offered to junior status transfer students, second-degree students, and statewide RN to BSN students via online format. Over the past 28 years, Liberal Oak College has awarded 2,951 baccalaureate science nursing (BSN) degrees. Campus on-site cohort groups currently graduate every summer, fall, and spring totaling approximately 200 annually as well as approximately $125 \mathrm{RN}$ to BSN online students.

Process. Thirty-one full time and 44 part time adjunct nursing faculty members at Liberal Oak College are currently in the process of implementing a redesigned conceptbased nursing curriculum, which began phase-in of courses in the fall semester 2011. The revised concept-based nursing curriculum is structured from recommendations of the American Association of Colleges of Nursing (AACN) nine essentials of baccalaureate education for professional nursing practice. As part of this revision, the faculty agreed to integrate an academic electronic health record (AEHR) platform into the curriculum as a way to meet or achieve the goals of Essential IV: Information Management and Application of Patient Care Technology. Although only partial funding was granted for the AEHR integration project, the faculty agreed to participate in the 2-year pilot AEHR integration with the AEHR platform researched by the EHR selection committee. For 
ELECTRONIC HEALTH RECORDS IN NURSING EDUCATION

purposes of anonymity, the pseudonym Liberal Oak College Academic Electronic Health Record (LOCAEHR) will be used to describe the academic electronic healthcare record (AEHR) platform used in the pilot project.

Context. The educational leaders of the Experiential Learning Center at Liberal Oak College managed the project and worked with faculty and staff to thread conceptual informatics learning experiences across all tracks of the curriculum. Prior to integration of the AEHR, students did not experience practice with documentation and data management in an EHR until they were in their last year of nursing school in the acutecare clinical courses. Student EHR preparation for acute-care clinical courses is varied. Some use online basic training in the clinical site's EHR, or a small 2-hour time block at the clinical site's EHR training facility. Not all students receive access to a live version of the EHR until the first day of clinical, therefore they are unable to practice any of the skills required for documentation and nursing management prior to this date. So then, not only do students need to adjust to the knowledge and skill demands in the acute-care setting in real life scenarios with people [patients] they also must learn how to be proficient in operating an electronic documentation and nursing management charting system.

Activity. The activities during the implementation period of LOCAEHR focused on development of informatics assignments that include nursing concepts, educating faculty, and evaluating the project. The plan is to thread informatics concepts with an academic electronic health record platform early in the nursing curriculum in the lab 
classes where students are learning and practicing their clinical skills, providing early opportunities to practice in an EHR platform.

\section{Logistics of the AEHR and Selection Process}

The idea for integrating an AEHR began in May of 2009 when the curriculum committee at Liberal Oak College chose to explore options for integration of an AEHR system. Collaborative community partnerships and several AEHR vendors were explored as options for selection based on an extensive list of criteria similar to those described by Gloe (2010) Selecting an Academic Electronic Health Record, for comparing and contrasting these options as a fit for the college. Collaboration was considered as a "great idea" from local community partners but once explored it was found not feasible at this time due to the lack of an appropriate AEHR platform for education purposes in the local community.

The transdisplinary task force for AEHR evaluation included; two full-time tenure track nursing faculty, one full-time health sciences faculty, the Experiential Learning Center (ELC) Director, the Director of High Fidelity Simulation, the Simulation Operations Manager, and the Director of Foundation and Corporate Relations. A communication thread was established on the school Blackboard (Bb) faculty access site and emails were sent for faculty feedback on AEHR vendors and project ideas. A list of criteria based on literature review was developed to guide exploration of vendor options. Although shared with all faculty members, specific information from the cost/features comparison list is confidential information and not included as part of this research study 
document. The key elements explored and compared among the three final contenders

were:

Start-up costs, yearly costs and student fees

Vendor support

Training support

IT support requirements

System limitations

Web based versus downloaded software

"real" EHR look and feel

Medication Administration with barcoded capability/function

Ability for faculty input into design changes of templates

Links to decision support tools/resources

Interdisciplinary access by role (primary care provider (PCP), nurse, instructor)

Complexity of the system

Nurse educators and faculty members were invited to all AEHR vendor

demonstrations. Communications between the task force through active emails strands. In the fall of 2010, the task force continued researching AEHR options through literature, demonstrations, and workshops. Grant funding was suggested and pursued as a resource for the project due to high AEHR vendor costs and lack of Experiential Learning Center (ELC) funds to support it. In December of 2010, a progress update was presented to the faculty assembly and approval was granted by consensus, provided grant funding was available to support the project. Further exploration continued. Sharing an AEHR with another nursing program was investigated as a possibility but did not meet the team ideals regarding userability. The system in question was complex and required 1-2 full time people to manage it. Two final "turn-key" vendor options were compared and analyzed for fit with the college. The task force used the detailed competitive product analysis 
criteria listed in Appendix $\mathrm{C}$ as well as questions regarding usability. Recommendations were formally reported back to the nursing faculty department.

Over the next year, the task force worked on project ideas, informational webinars, and continued grant identification and application submissions, a wiki site was set up for faculty collaboration and communication of ideas. Although faculty were enthusiastic at assembly meetings, only a few participated in open meetings regarding AEHR, and only taskforce members signed up on the wiki. This lack of voluntary engagement was considered something significant, and a possible issue in future development of the AEHR project. Committee members agreed on preference for an AEHR platform which required minimal faculty setup, and functioned in similar fashion to a clinical practice EHR over an AEHR system that required extensive faculty management. Engagement activities such as invitations to presentations and "water cooler" talks were the strategies employed to spark interest and enthusiasm.

As mentioned previously, the pseudonym for the chosen platform for integration in this study is Liberal Oaks College Academic Electronic Health Records (LOCAEHR). This platform is an AEHR database originally created from a clinical practice EHR currently used worldwide in healthcare organizations. LOCAEHR is a real EHR designed with training modules to aid student and faculty use and learning. It serves as a virtual "health care setting," addressing concepts related to inpatient and outpatient care, laboratory, diagnostic, and pharmacy functions, health promotion activities based on national standards of care, bar-coded labels for all medications, dosage calculator for safe medication administration education and training, and informatics documentation. In 
addition, LOCAEHR is $100 \%$ web based, includes a curriculum integration specialist to assist with development of meaningful assignments based on theory components of a course, and provides an online collaboration area for faculty with training videos and instructional documents.

\section{Start Point Logistics}

In October of 2011, one third of the necessary grant funding was awarded for a two-year pilot AEHR integration project. Consultation with administration and budget adjustments by the ELC director resulted in a recalculation of the AEHR project budget needs. The revised proposal budget was presented to the nursing faculty assembly and approval gained by consensus. Although there was much planning and investigation for two years prior, the official AEHR project integration did not began its implementation until the spring of 2012 after a contract was signed in December 2011 with the vendor.

The actually project implementation work began with a subscription confirmation to Liberal Oak Academic Electronic Health Record (LOCAEHR), the chosen AEHR educational tool. In addition, IRB approval occurred at this time therefore this is considered the official start time of the case study research.

\section{Participant Sample Selection}

A purposeful, criterion, non-probability sample was chosen for the semistructured interview portion of this case study. A random probability sample cannot achieve what a purposeful sample can accomplish in relation to the richness of the data (Munhall, 2001). Therefore, for interviews in case study research, intentional selection of individuals is preferred in order to gain the best understanding of the central 
phenomenon. This understanding emerges through a detailed comprehension of the faculty experiences thus leads to information that allows individuals to learn about the phenomenon, or to an understanding that provides voice to individuals who may not be heard otherwise (Creswell, 2008).

Although nursing faculty as a group serve the purpose of educating nursing students, they come with a variety of dimensions that represent the purposeful sample of nursing faculty. Factors such as educational background, age, full-time tenure or parttime adjunct status, and relevant $\mathrm{RN}$ work experiences contribute to the characteristics of the group as a whole. Intentional use of a mixed variation sampling of faculty members provided multiple perspectives of individuals, which represents the complex nature of nursing faculty. Sample size was dependent on response rate of faculty to the study invitation. The optimum sample for this study included the following criterion; RN faculty and nursing educators working full time or part time at the Liberal Oak College, with a variety of educational backgrounds, age ranges, gender differences, and educational degree statuses, who are participating in a LbD framed faculty development process strategy for AEHR integration at the Liberal Oak College.

\section{LbD Conceptual Framework for Action Research Integration Process}

As mentioned in chapter 2, Raij (2007) describes the LbD model as one that centers on a development project that is genuinely rooted in the world of work, requiring collaboration between lecturers (nurse educators), students, workplace experts and end users. Stemming from the review of the literature and practicality of this model for this research project, the LbD model was chosen as the conceptual framework model to guide 
the integration process of the AEHR project. After confirmation email exchange with the Laurea University of Applied Sciences in Finland for approval, the LbD model was adopted as the conceptual framework to guide the integration process of the AEHR project. Use of this LbD action research model within the context of the project of AEHR integration for nursing program curricula looks like this:

Development project: Integration of an AEHR platform in nursing program World of work: All clinical healthcare settings in the community Lecturers: Faculty and nurse educators teaching nursing courses at the college Students: Nursing students and nursing faculty Workplace experts: Adjunct clinical faculty, and currently practicing nurses End users: Student nurses (soon to be BSN nurses) working in the clinical settings

Based on the summarized characteristics of the LbD action research model described by Taatila and Raij (2011), the context and process of integrating the AEHR into the LOC nursing program is described as follows:

1. The starting point is a genuine, working life-related research and development project: Integration of an AEHR into the nursing school curricula.

2. LbD is based on authentic partnerships between lectures, students, experts and clients as end users: faculty, nursing students, instructional technology department, integration specialist, adjunct faculty, precepting nurses, informatics nurse(s) at local hospital, and nursing students as client end users.

3. It includes the components and types of knowledge of professional competence as an integrated whole: nurse educators and faculty members develop informatics KSA in AEHR functioning, and create integrated learning experiences for students that include nursing concepts and AEHR KSA.

4. Sharing and interpreting observations lead to the abductive formation of a hypothesis, which will be verified through deductive and inductive reasoning: development of AEHR learning objectives and activities in the nursing school curricula lead to competence and comfort in faculty and student KSA with applied informatics which, in turn, leads to increased comfort and competence with informatics as a natural state of practice for graduate nurses. 
5. The development project is seen as a learning environment that involves knowledge included in the work (knowledge in practice): development of how nursing practice can be designed into learning activities with an AEHR platform; knowledge acquired about it through research (knowledge of practice): nurse educator and faculty development of AEHR KSA competencies and how this integrates into nursing practice; and new competence produced for the work (knowledge for practice): faculty members develop applied KSA, and students develop applied nursing concepts and informatics KSA.

6. LbD facilitates collaboration between different experts acting as researchers, developers and transmitters of tools: Faculty have ownership in the project. Student feedback from nursing students and nursing faculty (as students) is sought and honored. Adjustments are made according to feedback and evaluation from all members of the transdisciplinary team.

7. It forms a platform for demonstrating the students' competence: students learn and apply nursing concepts and informatics skills within the AEHR.

8. LbD results in learning for individuals and the community, the generation of new competence in forms of new habits and action models, and innovations: AEHR KSA transfer to clinical settings. Students graduate with confidence and comfort with applied informatics.

9. Learning takes place when participants achieve new ways of action and new habits to meet an ever-changing world: faculty gain an understanding of informatics to incorporate into the curriculum. Students gain a deeper understanding of informatics and graduate ready for practice with EHR technology skills and become active participants in the design, selection, and evaluation of information used in the support of patient care. The community partners employ new nursing graduates with EHR skills and experience working collaboratively with professionals on evidenced based practice projects.

\section{Procedure}

Following agreement of the study proposal by the investigator's dissertation committee and institutional review board (IRB) for both the school under study as well as the researcher's doctoral program, the actual research process began. A number of different data-collection methods were examined during this study including a) surveys, b) interviews, and c) review of artifacts such as student assignments, workshop 
evaluations, email communications, and course evaluations. The use of triangulation by investigating multiple methods is critical in attempting to provide an in-depth understanding of the phenomenon under study. This strategy adds rigor, breadth, and depth to the study and provides corroborative evidence of the data obtained (Creswell, 2008; Denzin \& Lincoln, 2005).

\section{Survey Instruments}

Creswell (2008) describes surveys as a popular design in educational research, useful for describing trends or identifying quantitative data about attitudes, opinions, behaviors, or characteristics of the population under study. Data from the surveys in this case study helped to define the characteristics of the faculty experiencing AEHR integration at Liberal Oak College as well as provide information about knowledge, skill, and access levels from which to base workshop content and focus.

Faculty needs assessment survey. The first step in the process for developing a program of faculty development in AEHR is to assess the needs of faculty members. The AEHR integration project faculty needs assessment survey tool (detailed in Appendix D) was explained, disturbed, and collected during a faculty assembly meeting. The data collected gave an initial idea of the faculty needs and concerns. This information was used to inform the type of faculty development support structure such as workshops, oneon-one support, and communication during the pilot integration.

Informatics Competencies Assessment Survey. Faculty were invited to participate via email invitation in the Informatics Competencies Assessment Survey (detailed in Appendix F and G) in the first weeks of September 2012, the beginning of 
the fall semester. The purpose for these surveys is to collect demographic data, and to provide self-assessment details about faculty informatics competency knowledge, skills and access. These surveys, provided in detail as Appendix F and Appendix G, were designed for distribution in SurveyMonkey, an online survey tool with design, collection, and analyzing capabilities available to the Liberal Oak College through library services. The advantage of survey methodology is that it is relatively unobtrusive, familiar, and relatively easily administered and managed (Creswell, 2008). The demographics will provide information about characteristics and context of the faculty participants involved in the AEHR integration project.

The Informatics Competency Assessment survey is a modified version of the Jarzemsky (2010) survey found on the RWJF funded QSEN nursing resource website accessed from http://qsen.org/competencies/pre-licensure-ksas/. The survey items were developed from a research-based, master list of informatics competencies for the beginning-level nurse, as defined in the work of Staggers and Thompson (2002) and replicated items from a national survey study on nurse readiness to access evidencedbased information by Pravikoff, Tanner, and Pierce (2005). This list essentially outlines how nurses relate to technology in their workplace, i.e. for purposes of administration, communication, data access, documentation, client education, monitoring, quality improvement and research. The survey is a self-assessment rating of selected informatics knowledge, informatics skill, and informatics access on a Likert rating scale from $1=$ none to 5=proficient. The author added examples to each item to provide clarity, then used the 
survey in the classroom setting with nursing students. Permission to modify and use the instrument was obtained by email inquiry from the author in 2012.

\section{Semi-structured Interviews}

The interview was selected as one of the methods for data collection in this exploratory case study research. Nursing educators are a complex mix of people with diverse interests, educational backgrounds, practice experiences, healthcare interests, practice expertise, etc. Although the survey method is important in identifying the common and diverse characteristics of nursing educators, data related to faculty experiences requires a more in-depth view than could be obtained by survey method alone. According to Yin (2009) interviews are one of the most important sources of case study information. The focused interview in particular, a method by which a person is interviewed for short time frames such as an hour, helps to corroborate certain facts about a case in an open-ended conversational manner. The interview method, with open-ended focused questions derived from the QSEN literature, was chosen for this case study because it has potential to elicit rich, thick descriptions (Creswell, 2008). Further, it gives the researcher an opportunity to clarify statements and provide additional information regarding the attitudes of individuals in relation to informatics.

\section{Interview Participant Selection and Description}

According to Creswell (2008), it is better in qualitative research to select a few participants rather than many. Therefore, ten participants from a mix of full time and part time adjunct faculty that responded to email invitation were selected to participate in oneon-one interviews according to the interview protocol presented in Appendix $\mathrm{H}$. The 
interview process took place in the fall 2012 and spring 2013 terms at Liberal Oak

College. Before the interview began, the participant(s) reviewed and signed a consent form required for participation (Appendix I). All interviews were conducted face-to-face and recorded. The interview audiotape was transcribed verbatim within one week of the interview and this transcript clarified with the nurse educator participant for accuracy. All interviews took place in a private office. To insure confidentiality and provide a system for organizing interview data, the names of the nurse educator participants were changed to pseudonyms.

A purposeful sample of ten nurse educator /faculty member participants agreed to semi-structured interviews between February and June of 2013. In order to cover a spectrum of experiences, a diverse mix of full time and part time adjunct faculty qualified for the interview process. This diverse sample provided a more cohesive representation of the nursing program faculty. Of this sample group, all participants were female, two of the $10(20 \%)$ were of Asian descendent, the remainder are Caucasian. Five (50\%) were full-time tenure track faculty, 3 (33\%) were adjunct faculty, and $2(20 \%)$ were administrative nurse educators. Age range is from 41 to 63 years with the majority of the participants over age 54 (90\%). The number of years teaching nursing ranged from 2 to 27 with a median of 7 years of nurse educator experience. The number of years of experience as a RN ranged from 8 to 41 with the majority (60\%) having over 27 years of nursing experience. All nursing educator and faculty positions require an active $\mathrm{RN}$ license. The number of years of experience as an educator therefore also may include some of the years working clinically as a RN. Table 7 gives a general summary for 
participants based on experience as RN, experience as a nurse educator, academic degree and appointment position in the college.

Table 7

Participants' Overview

\begin{tabular}{|c|c|c|c|c|c|c|}
\hline Pseudonym & $\begin{array}{l}\text { Years } \\
\text { as RN }\end{array}$ & $\begin{array}{l}\text { Specialty } \\
\text { Area }\end{array}$ & $\begin{array}{l}\text { Years as } \\
\text { Educato } \\
\mathbf{r}\end{array}$ & $\begin{array}{l}\text { Teaching } \\
\text { area }\end{array}$ & $\begin{array}{l}\text { Highest } \\
\text { Degree }\end{array}$ & $\begin{array}{l}\text { Appointment/ } \\
\text { Position }\end{array}$ \\
\hline Alice & 20 & $\begin{array}{l}\text { Long term } \\
\text { care }\end{array}$ & 5 & Fundamentals & Masters & Other \\
\hline Brenda & 40 & $\begin{array}{l}\text { Acute care } \\
\text { pediatrics }\end{array}$ & 24 & Fundamentals & Doctorate & Full-time/classroom \\
\hline Claire & 12 & $\begin{array}{l}\text { Acute care } \\
\text { pediatrics }\end{array}$ & 5 & Acute Care & Baccalaureate & Adjunct/clinical \\
\hline Doris & 10 & $\begin{array}{l}\text { Long term } \\
\text { care }\end{array}$ & 3 & $\begin{array}{l}\text { Long-Term } \\
\text { Care }\end{array}$ & Doctorate & $\begin{array}{l}\text { Full-time/classroom } \\
\text { \& clinical }\end{array}$ \\
\hline Elaine & 33 & Acute care & 7 & Acute Care & Baccalaureate & Full-time/clinical \\
\hline Francine & 17 & ICU & 8 & Fundamentals & Doctorate & $\begin{array}{l}\text { Full-time/classroom } \\
\& \text { clinical }\end{array}$ \\
\hline Gloria & 41 & $\begin{array}{l}\text { Clinical } \\
\text { Specialist }\end{array}$ & 8 & Specialty & Masters & $\begin{array}{l}\text { Full-time } \\
\text { other/classroom }\end{array}$ \\
\hline Heidi & 29 & $\begin{array}{l}\text { Clinical } \\
\text { Specialist }\end{array}$ & 10 & Fundamentals & Masters & Adjunct/clinical \\
\hline Irene & 26 & $\begin{array}{l}\text { Nurse } \\
\text { Practitioner }\end{array}$ & 2 & $\begin{array}{l}\text { Long-Term } \\
\text { Care }\end{array}$ & Doctorate & Full-time/classroom \\
\hline $\begin{array}{l}\text { Jennifer } \\
\mathrm{N}=10\end{array}$ & 45 & $\begin{array}{l}\text { ICU, ED, } \\
\text { Long term } \\
\text { care }\end{array}$ & 26 & Specialty & Doctorate & Full-time/classroom \\
\hline
\end{tabular}

Interview questions. Four of the five open-ended questions used to guide the interview process for data collection are developed from the quality and safety for education of nurses (QSEN) attitude competencies in informatics. The fifth question is designed to pick up any additional information that may have been stimulated during the interview conversation.

Competency: Appreciate the necessity for all health professionals to seek lifelong, continuous learning of information technology skills.

Question: 1.What is your perception about the nurse's role in EHR?

Competency: Value technologies that support clinical decision-making, error 
prevention, and care coordination.

Question: 2.What are your thoughts about educating students about clinical decision-making tools in the EHR? Error prevention? Care coordination?

Competency: Protect confidentiality of protected health information in electronic health records.

Question: 3. What are your thoughts about teaching students confidentiality in the EHR?

Competency: Value nurses' involvement in design, selection, implementation, and evaluation of information technologies to support patient care.

Question: 4. Tell me about your experience in with educating students using the AEHR? Barriers? Strategies?

Question: 5. Do you have anything you would like to tell me regarding support, collaboration, or mentoring? (Smith et al., 2007)

\section{Interview Data Analysis}

I followed Creswell (2008) suggestions for organizing and analyzing interview

data. I chose to do a hand analysis of the data in order to be close to the data and have a hands-on feel for it. I transcribed all interview audio tapes verbatim including behavior observations such as laugher, pauses, or other audible noises identified on the tapes within 2 weeks of the interview. The transcribed data was further analyzed using an inductive process of narrowing the data into themes (Creswell, 2008).

The first step in the analysis was to do comparison within a single interview. During this process of open coding, every passage of the interview transcript was analyzed to determine "what had been said" then labeled with adequate code. The open codes discovered during this process were typed up and numbered for reference in a separate document then cut into separate sections. The result of this process yielded 144 coded fragments from the interview transcript. In the second step of this process, the 
coded fragments of similar qualities were compared further to find out what they have in common, how they differ, and in what context remarks were associated. The aim of this internal comparison process with open coding is to develop categories and label them with the most appropriate category codes, understand any difficulties, highlights, or inconsistencies, and attempt to interpret the parts of the interview in the context of the entire story as told by the interviewee. Periodic breaks during this process provided opportunities to record memos on ideas that arose during the coding process.

The next step in the process is the axial coding procedure. In the axial coding procedure, open coded fragments compared across the all interview transcripts and pieced to bring information together in new ways forming categories. This allows for clusters of connections between participants. Codes are compared and overlaps of similar concepts are reduced to axial codes. The axial codes are then grouped into patterns or major themes. The final process is the comparison to previous literature and interpretation analysis. The steps followed and adjusted for coding are summarized in Table 8 .

Table 8

Summary of Steps, Task, and Components for Coding Process

\begin{tabular}{|c|c|c|c|c|c|}
\hline & 1 & 2 & 3 & 4 & 5 \\
\hline Steps & $\begin{array}{l}\text { Initially read } \\
\text { through text } \\
\text { data }\end{array}$ & $\begin{array}{l}\text { Divide the text } \\
\text { into segments } \\
\text { of information }\end{array}$ & $\begin{array}{l}\text { Reduce } \\
\text { overlap and } \\
\text { redundancy }\end{array}$ & $\begin{array}{l}\text { Collapse codes } \\
\text { into process } \\
\text { descriptions }\end{array}$ & $\begin{array}{l}\text { Layering and } \\
\text { interrelating of } \\
\text { themes }\end{array}$ \\
\hline Task & $\begin{array}{l}\text { Highlight } \\
\text { significant } \\
\text { passages } \\
\text { Write notes } \\
\text { in margins } \\
\text { as ideas } \\
\text { come up }\end{array}$ & $\begin{array}{l}\text { Label } \\
\text { segments with } \\
\text { codes } \\
\text { Print all } \\
\text { segments and } \\
\text { cut into } \\
\text { sections }\end{array}$ & $\begin{array}{l}\text { Place into } \\
\text { piles of } \\
\text { similarity } \\
\text { Track } \\
\text { frequency of } \\
\text { occurrence }\end{array}$ & $\begin{array}{l}\text { Ask, "what are } \\
\text { they talking } \\
\text { about here?" } \\
\text { Describe in } \\
\text { narrative form }\end{array}$ & $\begin{array}{l}\text { Compare } \\
\text { themes to each } \\
\text { other } \\
\text { Compare to } \\
\text { previous } \\
\text { research }\end{array}$ \\
\hline Components & Raw data & $\begin{array}{l}\text { Open Codes } \\
\text { Clusters }\end{array}$ & $\begin{array}{l}\text { Axial Codes } \\
\text { Categories }\end{array}$ & $\begin{array}{l}\text { Major } \\
\text { Themes/ } \\
\text { patterns }\end{array}$ & Interpretations \\
\hline
\end{tabular}




\section{Observations}

Included during other forms of data collection are the nonverbal behaviors, cues, or environmental factors that may inform the data regarding tacit knowledge and attitudes of nursing faculty and nurse educators. According to Qualitative Research Design by Maxwell (1996), triangulation through the use of observation is useful for generating a more comprehensive interpretation of someone's perspective because “... while interviewing is often an efficient and valid way of understanding someone's perspective, observation can enable you to draw inferences about this perspective that you did not obtain by relying exclusively on interview data" (p. 94). Therefore intentional addition of observation notes during interviews, meetings, and workshops is very appropriate for this ethnographic case study design (Creswell, 2008).

Examples of observations that would be included are a) observations of faculty as they work with nursing students using the AEHR platform in lab classrooms, b) observations of faculty and nurse educator interview participants during the interview process, c) observations of faculty and nurse educators workshop participants during AEHR workshop sessions, and d) observations of faculty and nurse educators during meetings regarding AEHR. An observation protocol is included in Appendix $\mathbf{J}$.

\section{Artifacts}

According to Creswell, (2008) a valuable source of information in qualitative research can be documents. Examples of public documents at Liberal Oak College that contribute to this study are minutes from faculty assembly meetings, official memos, and records in the public domain, email comments and web site data illustrate both private 
and public documents. All names were removed from the document data, and information in the documents was synthesized into general statements and themes.

Student assignments housed in the AEHR. The students have profile accounts housed in the AEHR. These profiles contain student work and are a necessary component of the overall evaluation process for nursing students. Prior to implementation of the AEHR in clinical course, students would receive feedback regarding their assignments from clinical instructors, either through track changes in a word document or handwritten notes on the assignment itself, along with a letter grade. The feedback mechanism in place for AEHR clinical assignments is by accessing the student's portfolio housed in the AEHR. Student assignments in the LOCAEHR system were analyzed for faculty comments/feedback. This data point provides information regarding students' skills in documentation of nursing concepts as well as the instructors' skills in using the AEHR as a tool for providing feedback to students on their academic progress. Both student work and instructor feedback was examined and compared with the QSEN descriptions for skills competencies. Discussion regarding these artifacts occurs in chapter 4, part 2 the Story of Integration through the Lens of the LbD Model.

Course evaluation tools. Periodic evaluation tools are used to evaluate the quality of instruction at the school nursing. Artifacts such as semester course evaluations, and student pre-National Council Licensure Examination-Registered Nurse (NCLEXRN) scores may include components that reflect the AEHR integration process. These artifacts were collected and examined for relevancy to the project. 
For convenience a summary description of the data points for triangulation, the corresponding data collection tools, what is measured/possible discovery, who the data is collected from, and when this data collection took place is provided in Table 9. 


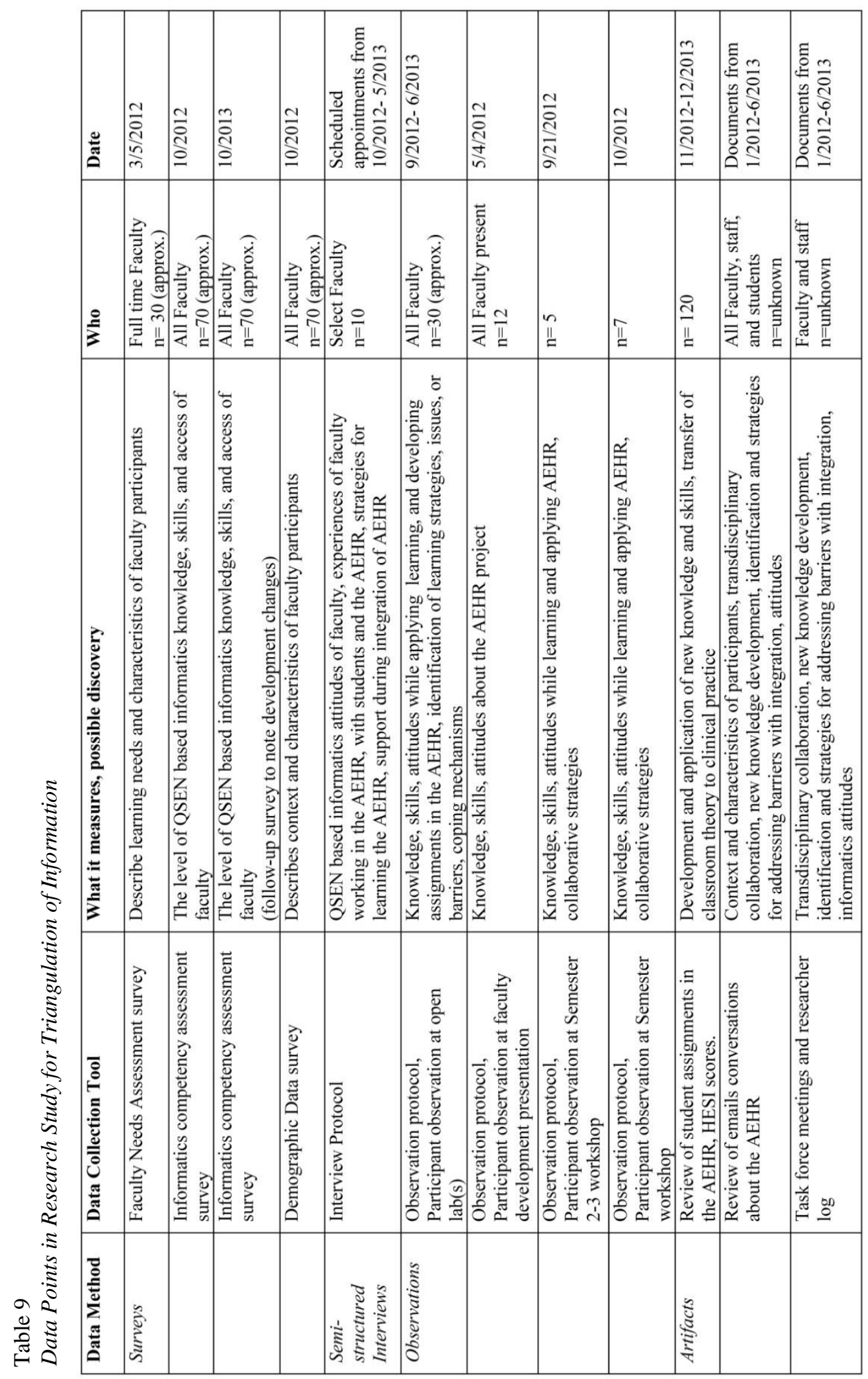




\section{Trustworthiness}

Reliability and validity of the data analysis was promoted by using the method of triangulation. Creswell (2008) defines triangulation as a process of simultaneously collecting both quantitative and qualitative data, then going through a process in merging the data, and using the results to increase the understanding of a research problem. For example, data collected from faculty surveys were factor analyzed and these factors then became themes that were compared with the codes and themes from the qualitative interview data.

\section{Positionality}

As manager of the integration of an AEHR into the nursing program at a small liberal arts college, I, the researcher have the opportunity to present a unique view of the processes involved from the insider perspective. I have over 34 years of nursing practice experience, including 10 years of faculty experience. Although I have a very diverse nursing background, the majority of my expertise is in the acute care setting. I consider myself competent in the clinical setting working in an EHR system, and understand that hands-on practice and experience improves this performance. I am a strong advocate for educating students in an environment that is safe, nurturing, and integrative in nature. As a nurse that was first educated on paper-based documentation and practiced that way for many years prior to this new technology integration, I have an appreciation for the faculty that may have limited or no EHR experience. It is my passion to bridge theory and practice and I see this project as an opportunity to provide cohesiveness and integrative 
learning strategies for the Liberal Oak College and the nursing education community at large.

I safeguarded bias by providing multiple data points. I strived to maintain a neutral position as a researcher and approached information objectivity. My role as researcher is to discover, my role as a facilitator is to engage faculty and promote development of AEHR use.

\section{Limitations}

Limitations are simply defined by Doordan (1998) as the weaknesses or uncontrolled variables affecting a study. Considering the nature of the researcher's relationship to the study site, a related limitation identified is participant reactivity, a phenomenon described by Maxwell (1996) in which interviewees may have difficulty adjusting to the researcher taking on the role of interviewer. Because several participants know the researcher, their responses could be influenced, or affected. They may try overly hard to cooperate with the researcher by offering responses they perceive she is seeking or perceive may be helpful. On the other hand, they may have guarded answers and be less candid in their responses.

Plans to deal with limitations include a) acknowledging the research agenda and stating the positionality of the researcher up front, b) address bias by removing all participants names and coding all interviews transcripts blindly so as not to associate any material or data with any particular individual, and c) making a conscious effort to create an environment that is conductive to honest and open dialogue. The researcher has served 
in roles at the college requiring confidentially and has experience with the interview process.

\section{Summary}

This chapter outlines the methods and procedures planned to address the primary research question: What is the experience of nursing educators and nursing faculty members involved in the integration of an AEHR project framed in the Learning by Developing model at a small liberal arts college school of nursing? Stemming from recommendations in the literature, information sought to address the research question in a comprehensive fashion, and information back into the project, a case study research paradigm gave depth and richness to the data. The AEHR integration framed in a Learning by Developing framework participatory action model, promotes an evolving, integrative, environment whereby faculty have an opportunity to be fully engaged in the design and implementation of this technology through collaborative transdisciplinary networking. The evolving nature of the case study approach to the project included triangulation of methods such as surveys, documents, and interview data during the fall 2011 and spring 2014 integration period. Additional evaluation methodology developed along the way supplemented the project evolution. Continuous literature review and project evaluation points reviewed throughout the data collection period informed the research study as well as the project direction and activities.

The next chapter will focus on the analysis of data and report of significant findings (part I) followed by their application to the evolution of the integration project as 
framed by the LbD conceptual action model steps defined and described in chapter two (part II). The chapter will conclude with a summary including limitations of the study. 
ELECTRONIC HEALTH RECORDS IN NURSING EDUCATION

Chapter Four

Part I Reporting Findings and Analyzing Data

"It isn't all over; everything has not been invented; the human adventure is just beginning."

-Gene Roddenberry

The purpose of this study was to explore and describe, with the nursing faculty of a small liberal arts college, the faculty knowledge, skills and attitudes (KSAs) as they participate in action research framed curriculum development program for implementation of applied informatics using an academic electronic health records platform. Although the literature describes the barriers and challenges during informatics integration projects in nursing programs, and faculty member's knowledge, skills, and attitudes regarding informatics are significant in the process, little documentation exists on the experiences of faculty participating in an academic electronic health records (AEHR) integration. As mentioned earlier in chapter one, for this study, KSA is defined by Suskie (2010) as follows:

- Knowledge is a complex process of remembering, relating, or judging an idea or abstract phenomenon (cognitive abilities).

- Skills are the proficient manual, verbal or mental manipulation of data or things that allow for the execution of well-specified tasks (psycho-motor abilities).

- Attitudes represent a state of mind, feelings, or beliefs about a particular matter (affective abilities).

This research is framed as a case study. It emerged from my personal experience as a practicing nurse for over 35 years and nurse educator for the last 10, and from my exploration of ways to bridge nursing theory with clinical practice, and create meaningful 
applicable learning experiences for students. Nursing is an ever-evolving practice therefore the need for nurse educators to work with the most current evidence and technology is vital for the preparation of current and future nurses. Having an understanding of the process of nursing educators' experience while learning and teaching in a new paradigm may inform faculty development processes for nurse educators.

This researcher believes that a better understanding of this phenomenon would allow educators to proceed with a more informed perspective in terms of design and facilitation of the integration process for informatics education in nursing programs. In seeking to understand this phenomenon, the data presented in this section provides evidence to address the question: What is the experience of nursing educators and nursing faculty members involved in the integration of an AEHR project framed in the Learning by Developing model at a small liberal arts college school of nursing?

What follows is the findings presented in two main formats, the first format is a summary analysis of surveys and interviews that informed the AEHR integration, and the second format tells a story of the integration process framed in the Learning by Developing model. The first section will begin with the survey analysis followed by, standard course evaluation data, then finally detailed analysis of interview data. The second part folds the research data back into the project, presented as the story of integration through the lens of the LbD framework. 
ELECTRONIC HEALTH RECORDS IN NURSING EDUCATION

\section{Survey Analysis}

Surveys used throughout the AEHR integration helped to inform the process. The specific surveys used during the AEHR integration process included a) the AEHR Integration Project Faculty Needs Assessment Survey, b) the Informatics Competencies Assessment Survey and, c) the Student Confidence Assessment with LOCAEHR Survey. The overall purpose of these surveys was to elicit information from faculty and students regarding their knowledge, skills, and confidence regarding electronic health records. Information from the surveys informs the faculty and student AEHR educational preparation needs by providing relevant information for design of educational workshops, orientation sessions, and student assignment development. Details of this process is found under the section titled Story of integration through the lens of the LbD. What follows next is a description and factual data analysis from each of the three surveys.

\section{AEHR Integration Project Faculty Needs Assessment Survey}

The first survey is a one-page document distributed at a nursing faculty assembly meeting. The purpose of this survey was to collect very basic information from the faculty about their exposure to electronic healthcare records, see if they had a chance to explore the LOCAEHR system on their own, and gather data to inform future workshop structure and content. As with any learner-centered development process, it is best to assess the learners' knowledge or start point about a subject prior to beginning a program of development in order to tailor the information appropriately (Bransford, 2000). Of the 30 distributed surveys to full-time faculty members, 13 were returned $(n=13)$ for overall return rate of $43 \%$. Of those responding to the survey, $84 \%(\mathrm{n}=11)$ reported having 
experience using electronic health records in practice with a variety of clinical healthcare system EHR brands including Mysis/Allscripts ${ }^{\circledR}$, Epic $^{\circledR}$, College Health $^{\circledR}$, VistA ${ }^{\circledR}$ CPRS, Horizon Clinicals ${ }^{\circledR}$, and Next Gen ${ }^{\circledR}$.

The information provided by the needs assessment survey was significant to the process structure for planning faculty and staff development activities. A summary of this survey uncovered several significant findings a) of the 13 faculty respondents to the survey, only 6 have logged into the LOCAEHR system, b) four reported doing the scavenger hunt self- directed orientation activity, and c) two have viewed the short 4-5 minute tutorial videos made available from the LOCAEHR website. More than half of the faculty respondents, 7 out of 13 , reported uncertainty of how to use an AEHR in the curriculum. In addition, faculty voiced concerns regarding management of the LOCAEHR integration. These concerns included a) having time to learn how to use the system, b) the steep learning curve in learning about it, c) assistance with assignment development, d) experiencing a smooth integration across the curriculum and, e) how applicable to clinical practice this platform will be. A summary of the AEHR Integration Project Faculty Needs Assessment Survey results is provided in Table 10. 
Table 10

AEHR Integration Project Faculty Needs Assessment Survey Results

\begin{tabular}{|c|c|}
\hline Question(s) & Answer(s) \\
\hline $\begin{array}{l}\text { 1. Do you have experience using electronic health } \\
\text { records in practice? } \\
* \text { If yes, which system? }\end{array}$ & $\begin{array}{l}\text { Yes }(\mathrm{n}=11) \\
\text { Mo }(\mathrm{n}=2) \\
\text { Mysis/Allscripts, Epic }^{\circledR} \text {, College Health, } \\
\text { VistA }^{\circledR} \text { CPRS, Horizon Clinicals }{ }^{\circledR} \text {, Next Gen }{ }^{\circledR}\end{array}$ \\
\hline $\begin{array}{l}\text { 2. Have you logged into the Liberal Oaks (LO) } \\
\text { academic electronic health record (AEHR)? }\end{array}$ & Yes $(n=6)$ \\
\hline 3. Have you done the scavenger hunt? & Yes $(n=4)$ \\
\hline $\begin{array}{l}\text { 4. Have you viewed any of the tutorial videos in "the } \\
\text { community" in NP? }\end{array}$ & Yes $(n=2)$ \\
\hline $\begin{array}{l}\text { 5. What would you like to know about LOCAEHR? } \\
\text { AVAILABLE ASSIGNMENTS } \\
\text { ASSIGNMENT DEVELOPMENT } \\
\text { HOW TO MAKE A CHART WITH MY CASE } \\
\text { STUDIES } \\
\text { HOW TO USE THE PORTFOLIO TO GRADE } \\
\text { ASSIGNMENTS }\end{array}$ & $\begin{array}{l}(n=11) \\
(n=10) \\
(n=9) \\
(n=8)\end{array}$ \\
\hline $\begin{array}{l}\text { 6. Would you attend an overview workshop on } \\
\text { LOCAEHR? } \\
\text { Other comments: }\end{array}$ & $\begin{array}{l}\text { "if time allows," "prefer 1:1," } \\
\text { "maybe," "to be determined" }\end{array}$ \\
\hline $\begin{array}{l}\text { 7. How do you see LOCAEHR working in your } \\
\text { course? }\end{array}$ & $\begin{array}{l}\text { "Unsure" }(\mathrm{n}=7) \\
\text { Documentation of skills } \\
\text { Documentation of assessments } \\
\text { Care planning } \\
\text { Case studies }\end{array}$ \\
\hline 8. What are your concerns regarding LOCAEHR? & $\begin{array}{l}\text { Having the time to learn to use it }(n=6) \\
\text { Steep learning curve for faculty } \\
\text { Assistance with assignment development } \\
\text { Smooth integration across curriculum } \\
\text { Application to clinical practice EHRs }\end{array}$ \\
\hline
\end{tabular}

\section{Informatics Competencies Assessment Survey}

The second survey is an online 26-item electronic format of the Informatics

Competency Assessment Survey (detailed in Appendix F). The purpose of this survey

was to collect information about faculty knowledge skills and access with informatics, thus providing a baseline regarding the faculty familiarity with basic informatics 
competencies currently required from practicing nurses. As mentioned in chapter 3 , the Informatics Competency Assessment survey is a modified version of the Jarzemsky (2010) survey found on the RWJF funded QSEN nursing resource website. This 26-item list outlines how nurses relate to technology in their workplace, i.e. for purposes of administration, communication, data access, documentation, client education, monitoring, quality improvement, and research.

The survey is designed as a self-assessment rating of selected informatics knowledge, informatics skill, and informatics access on a Likert scale from $1=$ none to $5=$ proficient. Clinical examples under each statement item provide additional information for clarity of item meaning. Permission to modify and use this assessment instrument was granted, after email inquiry, from the author. The modified 26-item survey and demographic data information was formatted into SurveyMonkey® online survey tool and distributed to approximately 94 full-time and adjunct nurse educators via email between December 2012 and early February 2013. Of the 94 email survey inquiries, $44 \%$ responded $(n=47)$ via the online system.

Demographic background for this sample group of nurse educators is as follows: age range of participants is from 28 to 70 years with an average age of 54, and a median age of 59. Sixty-eight percent of the faculty respondents are over age 50. Four percent are male. The number of years teaching nursing at college level ranged from less than one year to over 40 . Less than half $(47 \%)$ are full-time faculty, the remaining $53 \%$ reported as adjunct faculty. The number of years as a practicing registered nurse ranged from 3 to 47 . A little less than half (48\%) of the sample reported currently holding a clinical nursing 
position of which two thirds $(66 \%)$ of these working nurses are required to use an electronic health record. Brand types of electronic health records systems reported by this sample nurses includes $\operatorname{Epic}^{\circledR}(n=14), \operatorname{Vist}^{\circledR}{ }^{\circledR}(n=1), \operatorname{Allscripts}^{\circledR}(n=2), \operatorname{NextGen}^{\circledR}(n=1)$, and PracticeFusion ${ }^{\circledR}(\mathrm{n}=1)$.

The information obtained from this survey provided insight regarding informatics knowledge and skill set of faculty, as well as how often and in what manner they used informatics competencies. For example, knowledge, skill, and access competencies rated very high $(100 \%)$ for respondents reporting themselves as competent, independent, or master users of computer communication applications such as email, and also high (95\%) for competence with basic desktop software such as word processing, printing, and power point presentation skills. Forty percent of nurse educators and faculty reported a lack of knowledge and skills related to computer documentation of patient data, assessments, interventions, and plan of care. In addition, slightly more than half (52\%) never or rarely have access to an EHR system for the purposes of documentation of patient data, assessments, interventions, and plan of care. Faculty reported competency of informatics knowledge regarding ways nursing data can improve practice, limitations of computer use in health care, and patients' rights related to computerized information with an average of $86 \%$ competency in these areas. Fourteen percent reported that would need help at times. Four percent $(n=2)$ reported a lack of informatics knowledge for recognizing the value of clinician involvement in design, selection, implementation, and evaluation of computer applications while over $87 \%$ felt confident in this knowledge. 
The following tables contain the detailed data results from the Nurse Educator Competency Assessment Survey for Knowledge, Table 11; Nurse Educator Competency Assessment Survey for Skills, Table 12, and Nurse Educator Competency Assessment Survey for Access, Table 13. Sections with the highest percentage scores are bolded. For convenience, an additional table was created. The informatics technology, daily function components mentioned on all three surveys, a) administrative functions, b) communication, c) data access, d) documentation, e) education, and f) patient monitoring were compiled to compare the knowledge, skills, and access in one overall summary of the percent of self-reported competency for knowledge, skills, and access. This information is provided in table 14 as the Comparison Percent of Nurse Educators with self-reported Competent or Higher Level Rating. Further application for this additional comparison is provided in the LbD integration section of this chapter. 
Table 11

Nurse Educator Informatics Competencies Assessment Survey Result; Knowledge

\begin{tabular}{|c|c|c|c|c|c|c|}
\hline $\begin{array}{l}\text { Questions } 1-12 \text { rate } \\
\text { KNOWLEDGE about of the } \\
\text { following informatics } \\
\text { competencies: }\end{array}$ & $\begin{array}{l}\text { Know } \\
\text { nothing } \\
\text { about } \\
\text { this }\end{array}$ & $\begin{array}{l}\text { Know } \\
\text { some, } \\
\text { need } \\
\text { help at } \\
\text { times }\end{array}$ & $\begin{array}{l}\text { (3) } \\
\text { Know } \\
\text { enough to } \\
\text { use } \\
\text { competently }\end{array}$ & $\begin{array}{l}\text { (4) } \\
\text { Independent } \\
\text { user, } \\
\text { comfortable } \\
\text { with } \\
\text { technology }\end{array}$ & $\begin{array}{l}\text { Kn) } \\
\text { Know } \\
\text { enough } \\
\text { to teach } \\
\text { others }\end{array}$ & $\begin{array}{r}\text { Total } \\
\text { Response }\end{array}$ \\
\hline $\begin{array}{l}\text { 1) Knowledge of computer applications } \\
\text { for administration Example: patient acuity } \\
\text { classification }\end{array}$ & $\begin{array}{r}21.28 \% \\
(n=10)\end{array}$ & $\begin{array}{r}34.04 \% \\
(n=16)\end{array}$ & $\begin{array}{r}17.02 \% \\
(\mathrm{n}=8)\end{array}$ & $\begin{array}{r}21.28 \% \\
(n=10)\end{array}$ & $\begin{array}{r}6.38 \% \\
(n=3)\end{array}$ & $(n=47)$ \\
\hline $\begin{array}{l}\text { 2) Knowledge of computer applications } \\
\text { for communication Example: email, } \\
\text { internet }\end{array}$ & $\begin{array}{r}0 \% \\
(n=0)\end{array}$ & $\begin{array}{r}0 \% \\
(\mathrm{n}=0)\end{array}$ & $\begin{array}{l}8.51 \% \\
(n=4)\end{array}$ & $\begin{array}{r}23.40 \% \\
(n=11)\end{array}$ & $\begin{array}{r}68.09 \% \\
(n=32)\end{array}$ & $(\mathrm{n}=47)$ \\
\hline $\begin{array}{l}\text { 3) Knowledge of computer applications } \\
\text { for data access Example: local clinical } \\
\text { information systems (hospital intranet } \\
\text { systems) }\end{array}$ & $\begin{array}{r}10.64 \% \\
(\mathrm{n}=5)\end{array}$ & $\begin{array}{r}17.02 \% \\
(\mathrm{n}=8)\end{array}$ & $\begin{array}{r}27.66 \% \\
(n=13)\end{array}$ & $\begin{array}{r}27.66 \% \\
(n=13)\end{array}$ & $\begin{array}{r}21.28 \% \\
(\mathrm{n}=10)\end{array}$ & $(\mathrm{n}=47)$ \\
\hline $\begin{array}{l}\text { 4) Knowledge of computer applications } \\
\text { for documentation Example: hospital } \\
\text { system for documenting patient data, } \\
\text { assessments, interventions, plan of care } \\
\text { and discharge planning (Epic }{ }^{\circledR}, \text { VistA) }\end{array}$ & $\begin{array}{r}10.64 \% \\
(\mathrm{n}=5)\end{array}$ & $\begin{array}{r}29.79 \% \\
(\mathrm{n}=14)\end{array}$ & $\begin{array}{r}12.77 \% \\
(n=6)\end{array}$ & $\begin{array}{r}14.88 \% \\
(n=7)\end{array}$ & $\begin{array}{r}31.91 \% \\
(\mathrm{n}=15)\end{array}$ & $(\mathrm{n}=47)$ \\
\hline $\begin{array}{l}\text { 5) Knowledge of computer applications } \\
\text { for education Example: on-line literature } \\
\text { searches; PDA resources; patient } \\
\text { education (Health Facts for You) }\end{array}$ & $\begin{array}{r}4.26 \% \\
(n=2)\end{array}$ & $\begin{array}{r}10.64 \% \\
(n=5)\end{array}$ & $\begin{array}{r}34.04 \% \\
(\mathrm{n}=16)\end{array}$ & $\begin{array}{r}21.28 \% \\
(n=10)\end{array}$ & $\begin{array}{r}31.91 \% \\
(\mathrm{n}=15)\end{array}$ & $(\mathrm{n}=47)$ \\
\hline $\begin{array}{l}\text { 6) Knowledge of computer applications } \\
\text { for patient monitoring Example: } \\
\text { automated BP, pulse oximetry, telemetry }\end{array}$ & $\begin{array}{r}10.64 \% \\
(\mathrm{n}=5)\end{array}$ & $\begin{array}{r}12.77 \% \\
(n=6)\end{array}$ & $\begin{array}{r}21.28 \% \\
(n=10)\end{array}$ & $\begin{array}{r}8.51 \% \\
(n=4)\end{array}$ & $\begin{array}{r}48.94 \% \\
(n=22)\end{array}$ & $(\mathrm{n}=47)$ \\
\hline $\begin{array}{l}\text { 7) Knowledge of computer applications } \\
\text { for basic desktop software Example: } \\
\text { keyboarding, word processing, printing, } \\
\text { Power point presentation skills }\end{array}$ & $\begin{array}{r}0 \% \\
(\mathrm{n}=0)\end{array}$ & $\begin{array}{l}4.26 \% \\
(n=2)\end{array}$ & $\begin{array}{r}17.02 \% \\
(\mathrm{n}=8)\end{array}$ & $\begin{array}{r}12.77 \% \\
(\mathrm{n}=6)\end{array}$ & $\begin{array}{r}65.96 \% \\
(\mathrm{n}=31)\end{array}$ & $(\mathrm{n}=47)$ \\
\hline $\begin{array}{l}\text { 8) Knowledge of current peripheral } \\
\text { devices used in patient care Example: } \\
\text { hand-helds (med administration; blood } \\
\text { glucose meters); bedside computer } \\
\text { terminals }\end{array}$ & $\begin{array}{r}8.51 \% \\
(n=4)\end{array}$ & $\begin{array}{r}21.28 \% \\
(\mathrm{n}=10)\end{array}$ & $\begin{array}{r}17.02 \% \\
(\mathrm{n}=8)\end{array}$ & $\begin{array}{r}19.15 \% \\
(n=9)\end{array}$ & $\begin{array}{r}34.04 \% \\
(n=16)\end{array}$ & $(n=47)$ \\
\hline $\begin{array}{l}\text { 9) Informatics knowledge: data Example: } \\
\text { recognizes ways that nursing data can be } \\
\text { used to improve practice }\end{array}$ & $\begin{array}{r}0 \% \\
(\mathrm{n}=0)\end{array}$ & $\begin{array}{r}17.39 \% \\
(n=8)\end{array}$ & $\begin{array}{r}17.39 \% \\
(n=8)\end{array}$ & $\begin{array}{r}28.26 \% \\
(n=13)\end{array}$ & $\begin{array}{r}36.96 \% \\
(n=17)\end{array}$ & $(n=46)$ \\
\hline $\begin{array}{l}\text { 10) Informatics knowledge: impact } \\
\text { Example: recognizes benefits and } \\
\text { limitations of computer use in health care }\end{array}$ & $\begin{array}{r}0 \% \\
(\mathrm{n}=0) \\
\end{array}$ & $\begin{array}{r}14.89 \% \\
(n=7)\end{array}$ & $\begin{array}{r}27.66 \% \\
(n=13)\end{array}$ & $\begin{array}{r}29.79 \% \\
(n=14)\end{array}$ & $\begin{array}{r}27.66 \% \\
(n=13) \\
\end{array}$ & $(\mathrm{n}=47)$ \\
\hline $\begin{array}{l}\text { 11) Informatics knowledge: } \\
\text { privacy/security Example: recognizes } \\
\text { patients' rights related to computerized } \\
\text { health information }\end{array}$ & $\begin{array}{r}0 \% \\
(\mathrm{n}=0)\end{array}$ & $\begin{array}{r}10.64 \% \\
(\mathrm{n}=5)\end{array}$ & $\begin{array}{r}8.51 \% \\
(n=4)\end{array}$ & $\begin{array}{r}36.17 \% \\
(n=17)\end{array}$ & $\begin{array}{r}44.68 \% \\
(n=21)\end{array}$ & $(n=47)$ \\
\hline $\begin{array}{l}\text { 12) Informatics knowledge: systems } \\
\text { Example: recognizes value of clinician } \\
\text { involvement in design, selection, } \\
\text { implementation and evaluation of } \\
\text { computer applications }\end{array}$ & $\begin{array}{l}4.26 \% \\
(n=2)\end{array}$ & $\begin{array}{r}8.51 \% \\
(n=4)\end{array}$ & $\begin{array}{r}21.28 \% \\
(n=10)\end{array}$ & $\begin{array}{r}40.43 \% \\
(n=19)\end{array}$ & $\begin{array}{r}25.53 \% \\
(\mathrm{n}=12)\end{array}$ & $(n=47)$ \\
\hline
\end{tabular}


ELECTRONIC HEALTH RECORDS IN NURSING EDUCATION

Table 12

Nurse Educator Informatics Competencies Assessment Survey results; Skill.

\begin{tabular}{|c|c|c|c|c|c|c|}
\hline $\begin{array}{l}\text { Questions } 13-20 \text { rate } \\
\text { SKILL (ability to } \\
\text { perform) with the } \\
\text { following informatics } \\
\text { competencies: }\end{array}$ & $\begin{array}{l}\text { (1) } \\
\text { no } \\
\text { skill }\end{array}$ & $\begin{array}{l}\text { (2) } \\
\text { can } \\
\text { perform } \\
\text { some, } \\
\text { need } \\
\text { help at } \\
\text { times } \\
\end{array}$ & $\begin{array}{l}\text { (3) } \\
\text { can do } \\
\text { skill } \\
\text { competently }\end{array}$ & $\begin{array}{l}\text { (4) } \\
\text { independent } \\
\text { user, } \\
\text { comfortable } \\
\text { with } \\
\text { technology }\end{array}$ & $\begin{array}{l}\text { (5) } \\
\text { proficient } \\
\text { in skill, } \\
\text { can teach } \\
\text { to others }\end{array}$ & $\begin{array}{r}\text { Total } \\
\text { response }\end{array}$ \\
\hline $\begin{array}{l}\text { 13) Computer skills for } \\
\text { administrative functions } \\
\text { Example: patient acuity } \\
\text { classification }\end{array}$ & $\begin{array}{r}30.43 \% \\
(\mathrm{n}=14)\end{array}$ & $\begin{array}{r}23.91 \% \\
(\mathrm{n}=11)\end{array}$ & $\begin{array}{r}15.22 \% \\
(\mathrm{n}=7)\end{array}$ & $\begin{array}{r}15.22 \% \\
(\mathrm{n}=7)\end{array}$ & $\begin{array}{r}15.22 \% \\
(\mathrm{n}=7)\end{array}$ & $(\mathrm{n}=46)$ \\
\hline $\begin{array}{l}\text { 14) Computer skills for } \\
\text { communication Example: } \\
\text { email, internet }\end{array}$ & $\begin{array}{r}0 \% \\
(\mathrm{n}=0)\end{array}$ & $\begin{array}{r}0 \% \\
(\mathrm{n}=0)\end{array}$ & $\begin{array}{r}10.87 \% \\
(\mathrm{n}=5)\end{array}$ & $\begin{array}{r}19.57 \% \\
(\mathrm{n}=9)\end{array}$ & $\begin{array}{l}69.57 \% \\
(\mathrm{n}=32)\end{array}$ & $(\mathrm{n}=46)$ \\
\hline $\begin{array}{l}\text { 15) Computer skills for data } \\
\text { access Example: local clinical } \\
\text { information systems (hospital } \\
\text { intranet systems) }\end{array}$ & $\begin{array}{r}13.04 \% \\
(\mathrm{n}=6)\end{array}$ & $\begin{array}{l}28.26 \% \\
(n=13)\end{array}$ & $\begin{array}{l}4.35 \% \\
(\mathrm{n}=2)\end{array}$ & $\begin{array}{l}28.26 \% \\
(\mathrm{n}=13)\end{array}$ & $\begin{array}{l}26.09 \% \\
(\mathrm{n}=12)\end{array}$ & $(\mathrm{n}=46)$ \\
\hline $\begin{array}{l}\text { 16) Computer skills for } \\
\text { documentation Example: } \\
\text { hospital system for } \\
\text { documenting patient data, } \\
\text { assessments, interventions, } \\
\text { plan of care and discharge } \\
\text { planning (Epic }{ }^{\circledR}, \text { Health Link) }\end{array}$ & $\begin{array}{r}11.11 \% \\
(\mathrm{n}=5)\end{array}$ & $\begin{array}{l}35.56 \% \\
(\mathrm{n}=16)\end{array}$ & $\begin{array}{r}15.56 \% \\
(\mathrm{n}=7)\end{array}$ & $\begin{array}{r}11.11 \% \\
(\mathrm{n}=5)\end{array}$ & $\begin{array}{l}28.89 \% \\
(\mathrm{n}=13)\end{array}$ & $(\mathrm{n}=45)$ \\
\hline $\begin{array}{l}\text { 17) Computer skills for } \\
\text { education Example: on-line } \\
\text { literature searches; PDA } \\
\text { resources; patient education } \\
\text { (Health Facts for You) }\end{array}$ & $\begin{array}{r}0 \% \\
(\mathrm{n}=0)\end{array}$ & $\begin{array}{r}15.56 \% \\
(\mathrm{n}=7)\end{array}$ & $\begin{array}{r}24.44 \% \\
(\mathrm{n}=11)\end{array}$ & $\begin{array}{l}26.67 \% \\
(\mathrm{n}=12)\end{array}$ & $\begin{array}{l}33.33 \% \\
(\mathrm{n}=15)\end{array}$ & $(\mathrm{n}=45)$ \\
\hline $\begin{array}{l}\text { 18) Computer skills for patient } \\
\text { monitoring Example: } \\
\text { automated BP, pulse oximetry, } \\
\text { telemetry }\end{array}$ & $\begin{array}{r}10.87 \% \\
(\mathrm{n}=5)\end{array}$ & $\begin{array}{r}17.39 \% \\
(\mathrm{n}=8)\end{array}$ & $\begin{array}{r}17.39 \% \\
(\mathrm{n}=8)\end{array}$ & $\begin{array}{l}26.09 \% \\
(\mathrm{n}=12)\end{array}$ & $\begin{array}{l}28.26 \% \\
(\mathrm{n}=13)\end{array}$ & $(\mathrm{n}=46)$ \\
\hline $\begin{array}{l}\text { 19) Computer skills in basic } \\
\text { desktop software Example: } \\
\text { keyboarding, word processing, } \\
\text { printing, Power point } \\
\text { presentation skills }\end{array}$ & $\begin{array}{r}0 \% \\
(\mathrm{n}=0)\end{array}$ & $\begin{array}{l}4.44 \% \\
(n=2)\end{array}$ & $\begin{array}{r}13.33 \% \\
(\mathrm{n}=6)\end{array}$ & $\begin{array}{l}22.22 \% \\
(\mathrm{n}=10)\end{array}$ & $\begin{array}{r}60 \% \\
(\mathrm{n}=27)\end{array}$ & $(\mathrm{n}=45)$ \\
\hline $\begin{array}{l}\text { 20) Computer skills with } \\
\text { peripheral devices used for } \\
\text { patient care Example: hand- } \\
\text { helds (med administration; } \\
\text { blood glucose meters); bedside } \\
\text { computer terminals }\end{array}$ & $\begin{array}{l}8.89 \% \\
(n=4)\end{array}$ & $\begin{array}{r}17.78 \% \\
(\mathrm{n}=8)\end{array}$ & $\begin{array}{r}20 \% \\
(\mathrm{n}=9)\end{array}$ & $\begin{array}{r}17.78 \% \\
(\mathrm{n}=8)\end{array}$ & $\begin{array}{l}35.56 \% \\
(\mathrm{n}=16)\end{array}$ & $(\mathrm{n}=45)$ \\
\hline
\end{tabular}


ELECTRONIC HEALTH RECORDS IN NURSING EDUCATION

Table 13

Nurse Educator Informatics Competencies Assessment Survey results; Access

\begin{tabular}{|c|c|c|c|c|c|}
\hline $\begin{array}{l}\text { Questions } 21-26 \text { rate } \\
\text { ACCESS (how often you } \\
\text { use) the following } \\
\text { informatics competencies: }\end{array}$ & $\begin{array}{l}\text { (1) } \\
\text { never have } \\
\text { access }\end{array}$ & $\begin{array}{l}(2) \\
\text { rarely } \\
\text { access }\end{array}$ & $\begin{array}{l}\text { (3) } \\
\text { access } \\
\text { enough to } \\
\text { do } \\
\text { competently }\end{array}$ & $\begin{array}{l}\text { (4) } \\
\text { weekly } \\
\text { access, } \\
\text { comfortable } \\
\text { with } \\
\text { technology }\end{array}$ & $\begin{array}{r}\text { Total } \\
\text { Response }\end{array}$ \\
\hline $\begin{array}{l}\text { 21) Use of computer skills for } \\
\text { administrative functions Example: } \\
\text { patient acuity classification }\end{array}$ & $\begin{array}{r}39.13 \% \\
(\mathrm{n}=18)\end{array}$ & $\begin{array}{r}34.78 \% \\
(\mathrm{n}=16)\end{array}$ & $\begin{array}{r}17.39 \% \\
(\mathrm{n}=8)\end{array}$ & $\begin{array}{r}8.70 \% \\
(\mathrm{n}=4)\end{array}$ & $(\mathrm{n}=46)$ \\
\hline $\begin{array}{l}\text { 22) Use of computer skills for } \\
\text { communication Example: email, } \\
\text { internet }\end{array}$ & $\begin{array}{r}0 \% \\
(\mathrm{n}=0)\end{array}$ & $\begin{array}{r}0 \% \\
(\mathrm{n}=0)\end{array}$ & $\begin{array}{r}13.04 \% \\
(\mathrm{n}=6)\end{array}$ & $\begin{array}{l}86.96 \% \\
(n=40)\end{array}$ & $(\mathrm{n}=46)$ \\
\hline $\begin{array}{l}\text { 23) Use of computer skills for data } \\
\text { access Example: local clinical } \\
\text { information systems (hospital } \\
\text { intranet systems) }\end{array}$ & $\begin{array}{r}30.43 \% \\
(\mathrm{n}=14)\end{array}$ & $\begin{array}{r}19.57 \% \\
(\mathrm{n}=9)\end{array}$ & $\begin{array}{r}17.39 \% \\
(\mathrm{n}=8)\end{array}$ & $\begin{array}{l}32.61 \% \\
(\mathrm{n}=15)\end{array}$ & $(\mathrm{n}=46)$ \\
\hline $\begin{array}{l}\text { 24) Use of computer skills for } \\
\text { documentation Example: hospital } \\
\text { system for documenting patient } \\
\text { data, assessments, interventions, } \\
\text { plan of care and the intensive care } \\
\text { unit discharge planning (Epic }{ }^{\circledR} \text {, } \\
\text { VistA, Health Link }^{\circledR}, \text { etc.) }\end{array}$ & $\begin{array}{r}30.43 \% \\
(\mathrm{n}=14)\end{array}$ & $\begin{array}{l}21.74 \% \\
(\mathrm{n}=10)\end{array}$ & $\begin{array}{r}17.39 \% \\
(\mathrm{n}=8)\end{array}$ & $\begin{array}{r}30.43 \% \\
(\mathrm{n}=14)\end{array}$ & $(\mathrm{n}=46)$ \\
\hline $\begin{array}{l}\text { 25) Use of computer skills for } \\
\text { education Example: on-line } \\
\text { literature searches; PDA resources; } \\
\text { patient education (Health Facts for } \\
\text { You) }\end{array}$ & $\begin{array}{r}2.17 \% \\
(\mathrm{n}=1)\end{array}$ & $\begin{array}{r}17.39 \% \\
(\mathrm{n}=8)\end{array}$ & $\begin{array}{r}36.96 \% \\
(\mathrm{n}=17)\end{array}$ & $\begin{array}{l}43.48 \% \\
(n=20)\end{array}$ & $(\mathrm{n}=46)$ \\
\hline $\begin{array}{l}\text { 26) Use of computer skills for } \\
\text { patient monitoring Example: } \\
\text { automated BP, } \\
\text { pulse oximetry, telemetry }\end{array}$ & $\begin{array}{l}21.74 \% \\
(\mathrm{n}=10)\end{array}$ & $\begin{array}{l}26.09 \% \\
(\mathrm{n}=12)\end{array}$ & $\begin{array}{r}19.57 \% \\
(\mathrm{n}=9)\end{array}$ & $\begin{array}{l}31.61 \% \\
(\mathrm{n}=15)\end{array}$ & $(\mathrm{n}=46)$ \\
\hline
\end{tabular}


Table 14

Summary Comparison of Nurse Educators with Self-reported Competent or Higher Level Rating $(n=47)$

\begin{tabular}{lrrr}
\hline Informatics Technology Component & Knowledge & Skill & Access \\
\hline $\begin{array}{l}\text { Computer applications for administration. } \\
\text { Example: patient acuity classification }\end{array}$ & $55 \%$ & $46 \%$ & $26 \%$ \\
\hline $\begin{array}{l}\text { Computer applications for communication. } \\
\text { Example: email, internet }\end{array}$ & $100 \%$ & $100 \%$ & $100 \%$ \\
\hline $\begin{array}{l}\text { Computer applications for data access. } \\
\begin{array}{l}\text { Example: local clinical information systems (hospital } \\
\text { intranet systems) }\end{array}\end{array}$ & $76 \%$ & $59 \%$ & $76 \%$ \\
\hline $\begin{array}{l}\text { Computer applications for documentation. } \\
\text { Example: hospital system for documenting patient data, } \\
\text { assessments, interventions, plan of care and discharge } \\
\text { planning (Epic }{ }^{\circledR}, \text { VistA) }\end{array}$ & $60 \%$ & $56 \%$ & $48 \%$ \\
\hline $\begin{array}{l}\text { Computer applications for education. } \\
\text { Example: on-line literature searches; PDA resources; } \\
\text { patient education (Health Facts for You) }\end{array}$ & $87 \%$ & $84 \%$ & $80 \%$ \\
\hline $\begin{array}{l}\text { Computer applications for patient monitoring.. } \\
\text { Example: automated BP, pulse oximetry, telemetry }\end{array}$ & $79 \%$ & $72 \%$ & $51 \%$ \\
\hline
\end{tabular}

\section{Student Confidence Assessment with LOCAEHR Survey}

The third survey, detailed in Appendix K, is an artifact of the integration process.

For purposes of consistency and organization, it is discussed in this section of the chapter.

The survey was developed for the purposes of routine curricular assessment of a new innovative curricular strategy to evaluate students' experiences with the LOCAEHR assignments. Seventeen questions regarding confidence level from 0 to 5 were rated ( $0=$ not applicable to $5=$ know enough to teach others). The cut-off level for a rating of confidence with the LOCAEHR system is 3, know enough to use competently. Each question refers to a particular assignment that students completed in the LOAHER. The student survey distributed via SurveyMonkey ${ }^{\circledR}$ online survey tool and email invitation was sent to student cohorts of the first, second, and third semesters of the nursing curriculum in the fall of 2013. This participant group consisted of 265 students. Of those 
invited to the survey, 55 (20\%) responded. The response rate is lower than desired, yet information collected provided insights as to student confidence in using the AEHR in the fundamental skills lab on campus.

The percent following percent values reflect the comparison of students that selfidentify as confident using the AEHR versus those that would like more help with the technology. The percentage of student that rated confident with knowledge skills for understanding confidentiality is $90.7 \%$, and identify patient chart components is $63.0 \%$. In general, students rated themselves as more confident than not with the following data entry skills:

Data entry: intake and output; $47.3 \%$ need help compared to $53.7 \%$ confident Data entry: vital signs; $14.5 \%$ need help compared to $85.7 \%$ confident Data entry: risk assessment grids; $49.1 \%$ need help compared to $50.9 \%$ confident Data entry: pain assessment grid; $31.5 \%$ need help compared to $68.5 \%$ confident In addition, students generally rated themselves confident with documenting focused physical assessment findings that fell within normal limits (WNL) 57.1\% confident versus $42.9 \%$ need more help. Students were not as confident with physical assessments that consisted of abnormal findings, $47.3 \%$ confident versus $52.7 \%$ need more help. Physical assessment assignments that contain abnormal findings are designed to elicit student learning functions at the analyzing level in Bloom's higher order thinking skills. Assignments that contain procedures, medication administration, and handoff reports are higher up as well, requiring students to develop evaluating or creating types of thinking skills in nursing (Forehand, 2010). 
Students self-reported less confidence with analyzing, evaluating, or creating types of documentation functions such as:

Documenting: wound assessment information;

$78.6 \%$ need help compared to $21.4 \%$ confident $(n=53)$

Documenting: mental health assessment information;

$85.5 \%$ need help compared to $14.5 \%$ confident $(n=52)$

Documenting: clinical functional health pattern information;

$57.4 \%$ need help compared to $42.6 \%$ confident $(n=53)$

Documenting: nursing procedures \& interventions;

$66.7 \%$ need help compared to $33.3 \%$ confident $(n=52)$

Medication administration using LOCAEHR;

$61.8 \%$ need help compared to $38.2 \%$ confident $(n=52)$

Documentation: of a handoff report in LOCAEHR;

$78.9 \%$ need help compared to $21.1 \%$ confident $(n=54)$

The summary in Table 15 contains the details of this survey artifact. Additional

comments on the survey from students provided further insights for faculty about how the

AEHR assignments are perceived. The experience of many students was captured by the following student comments:

"I do not feel confident in my abilities to navigate the LOCAEHR system. I have had more experience working with the Epic ${ }^{\circledR}$ system during clinical rotations and as a result, feel more confident with using that system. I find Epic ${ }^{\circledR}$ more user friendly and a better tool to prepare students for what they will experience in the workforce."

"LOCAEHR is so different from any of the EHR systems in use now it really comes across as busy work. It would be just as useful to type up entries in Word just to make sure we are getting details and lingo down correctly. Also, feedback is so limited through LOCAEHR, it makes the whole exercise seem fruitless.

What I really want to know is how well I am capturing the pertinent information, how accurate I am, and how well I am using appropriate terminology and abbreviations."

"I did appreciate that it reminded me that I will need to document as a nurse when I was in the first semester. It would be more helpful to learn how to write progress notes in LOCAEHR, since we will actually be doing progress notes as RNs." 
"I use VistA ${ }^{\circledR}$ so I get lots of practice. I knew where everything was and felt so comfortable at my clinical site using the EHR."

Additional comments that reflect students' usability experiences in the LOCAEHR

system include the following:

- "LOCAEHR does not translate well into practice"

- "Feedback is needed on assignments, without feedback, LOCAEHR is not a helpful learning experience"

- "Titles of documentation notes are confusing"

- "LOCAEHR is nothing like the Epic ${ }^{\circledR}$ EHR used by most acute facilities in clinical practice"

- "LOCAEHR is not user friendly or intuitive"

- "Medication administration in LOCAEHR is confusing"

- "Prefer to use a system similar to the Epic ${ }^{\circledR}$ EHR"

- "It would be helpful to have a recorded/interactive training like the one for Epic ${ }^{\circledR}$ to walk students through the use of the system"

- "LOCAEHR is great if you plan to work at the VA hospitals" 


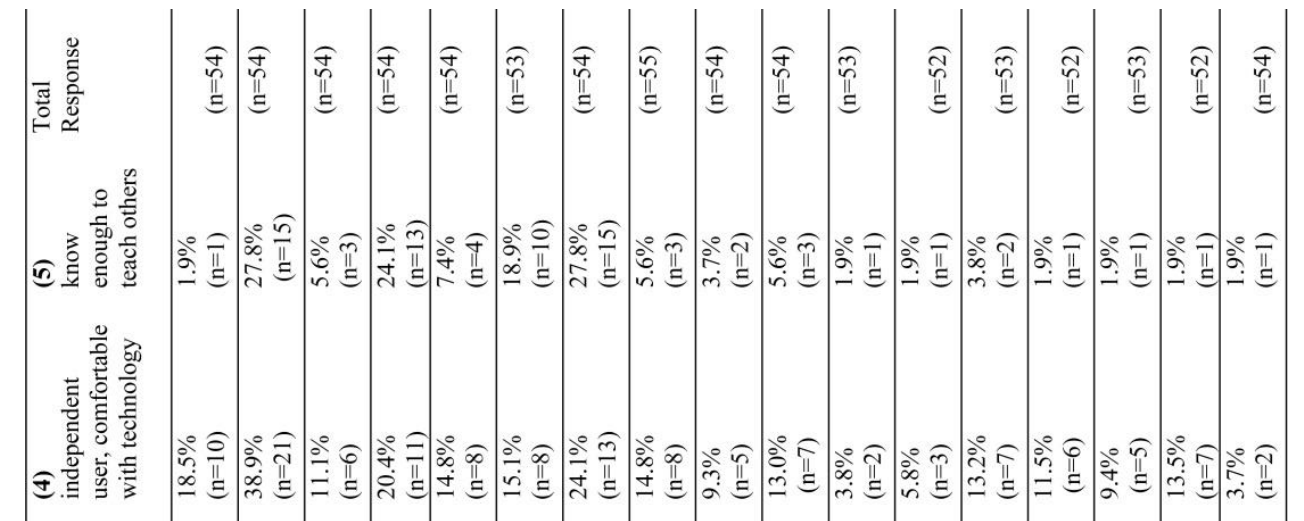

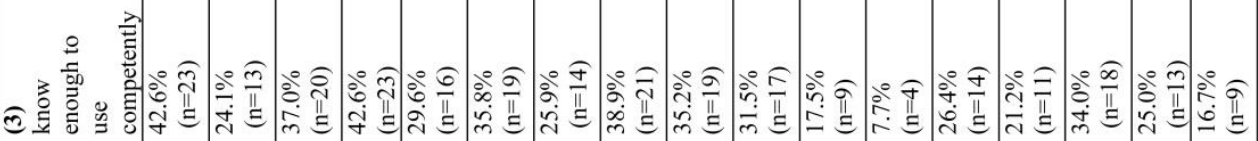

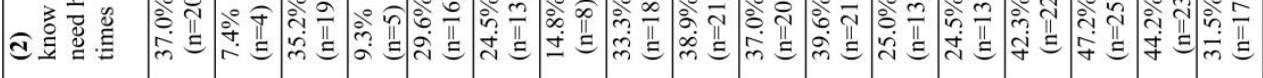

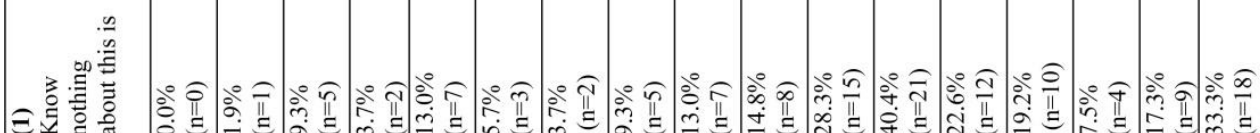

응

总蓄

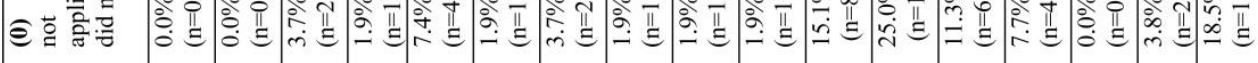

कृ

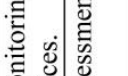

竞. 


\section{Artifact Analysis}

Course evaluation tools: Periodic evaluation tools are used to evaluate the quality of instruction at the school nursing. Artifacts such as semester course evaluations and student pre-NCLEX scores may include components that reflect the AEHR integration process. The course specific evaluations are a voluntary yet encouraged and do not contains specifics regarding AEHR curriculum. The Student confidence survey mentioned earlier in this chapter is an artifact that was designed specifically for this study and will be mentioned again in the next section. This part of the study report will focus on high stakes testing evaluations that are a normal part of the college quality assurance and new grad preparation process. The college in this study has contracted out with a company for national high stakes testing purposes. The Health Education Services Incorporated (HESI) RN exams are periodically administered throughout the nursing students' enrollment at the end of semester courses. These exams are based on NCLEX$\mathrm{RN}$ national exams required for $\mathrm{RN}$ licensing ad have demonstrated a high degree of accuracy in predicting outcomes for NCLEX-RN exam success (Langford, R., \& Young, A., 2013; Zweighaft, E., 2013; Adamson, C., \& Britt, R., 2009).

HESI Summary Reports provide content area scores that can be used to evaluate curricular strengths and weaknesses. National trend scores are based comparative NCLEX RN pass rates and used as a benchmark for predicting success. These scores are calculated using a HESI proprietary mathematical model (Nibert, Young, \& Britt, 2008) . According to Elsevier ${ }^{\odot}$ (2014), the HESI score reflects application of the HESI Predictability Model (HPM) to the composite score. HESI scores range from zero to over 
1000, and some as high as 1500 depending on exam difficulty. Those who score 900 and above are predicted to pass the NCLEX-RN. Students scoring below 750 are considered at risk and consulted for remediation. The benchmark set for the school in this study is 850. The national score rankings are useful for determining how many students in the nation scored below and above a given aggregate's mean (average) HESI composite score(s) (Young \& Willson, 2012).

HESI reporting tools can be further aggregated out to display data regarding questions that are relevant in terms of content areas based on QSEN informatics (detailed in Table 2) and AACN Essential IV (detailed in Appendix B) Information Management and Application of Patient Care Technology. The composition of the data grafts on the following pages in this paper reflects scores for only those questions that reflect QSEN and AACN informatics components and comparison to national scores of the same.

The AEHR integration began in semester 1 and 2 courses in the spring of 2012, and later in the fall semester 3 clinical course in spring of 2013. The semester 1 fundamentals course, and semester 3 custom exam scores, and semester $4 \mathrm{RN}$ exit exams (E2) scores analyzed for this study include data aggregated from cohort testing groups before, during, and after AEHR course integration from 2010 to 2014. 
The first diagram is an illustration of the informatics components aggregated out from the semester 1, HESI fundamentals exam. The semester 1 students have no exposure to healthcare informatics in the form of EHR except the LOCAEHR activities integrated into the semester 1, Integrated Experiential Learning (IEL) lab courses, which began in the spring of 2012. The trends in these scores are moving in an upward fashion since the spring of 2011 above the national levels for AACN essential IV informatics based questions (see Figure 5).

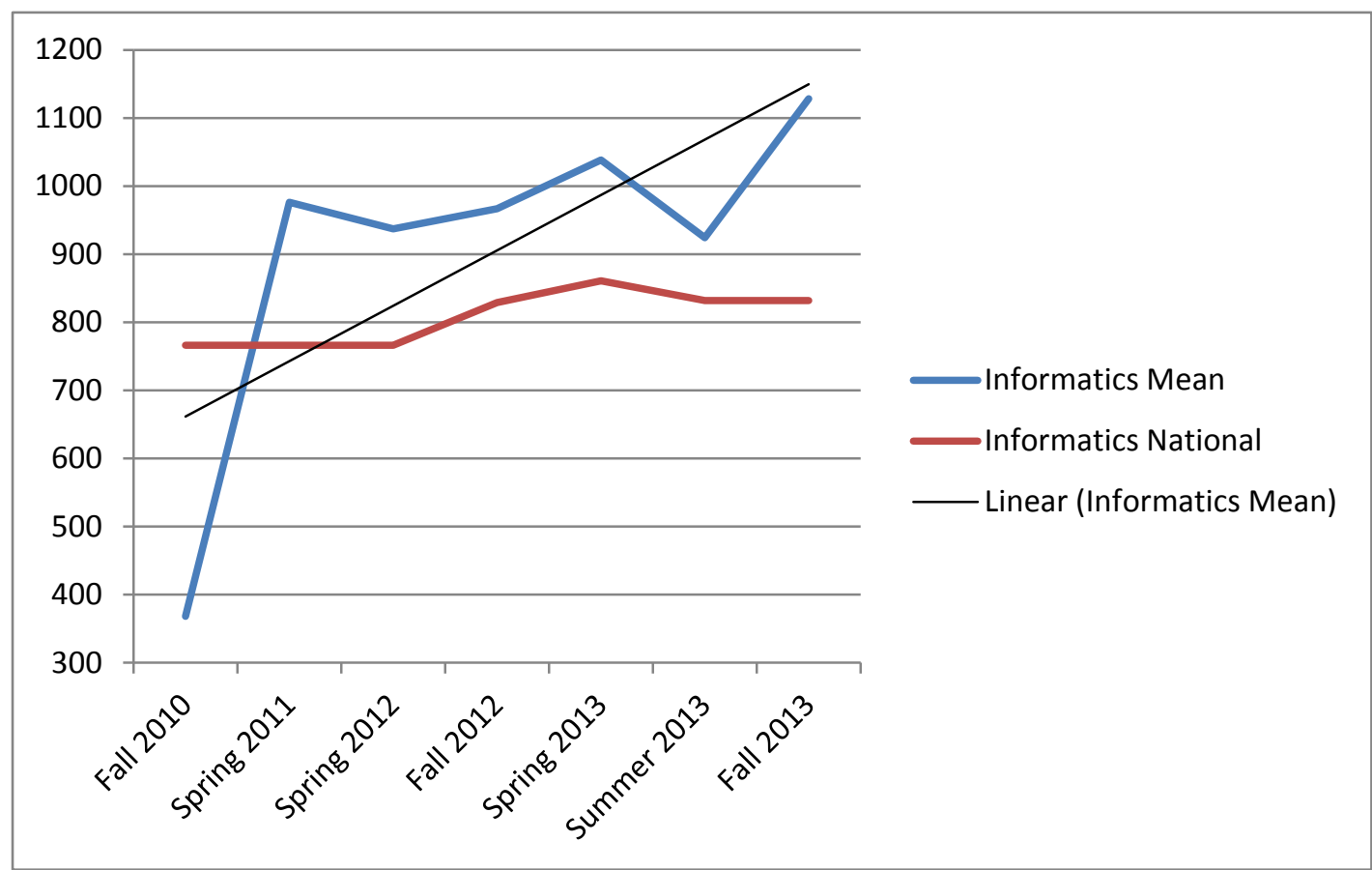

Figure 5. HESI fundamental exam scores aggregated for semester student cohorts and specific AACN essential IV informatics based questions compared to national HESI scores. The students in these cohorts have completed semester one out of four in the LOC nursing program. 
The second diagram in Figure 6 is an illustration of the informatics components aggregated out form the semester 3 HESI custom III exam. In addition to completion of semester 1 and semester 2 courses, the students in this group have completed a course in the acute care clinical area which involves using either the Vist ${ }^{\circledR}$ or Epic $^{\circledR}$ brands of healthcare EHR systems. In addition, students in the cohort Spring 2013 had exposure to the AEHR in their previous semester1, Integrated Experiential Learning (IEL) lab courses. This graph shows an upward trajectory of scores the semester following the AEHR platform integration (spring 2013), well above national trends.

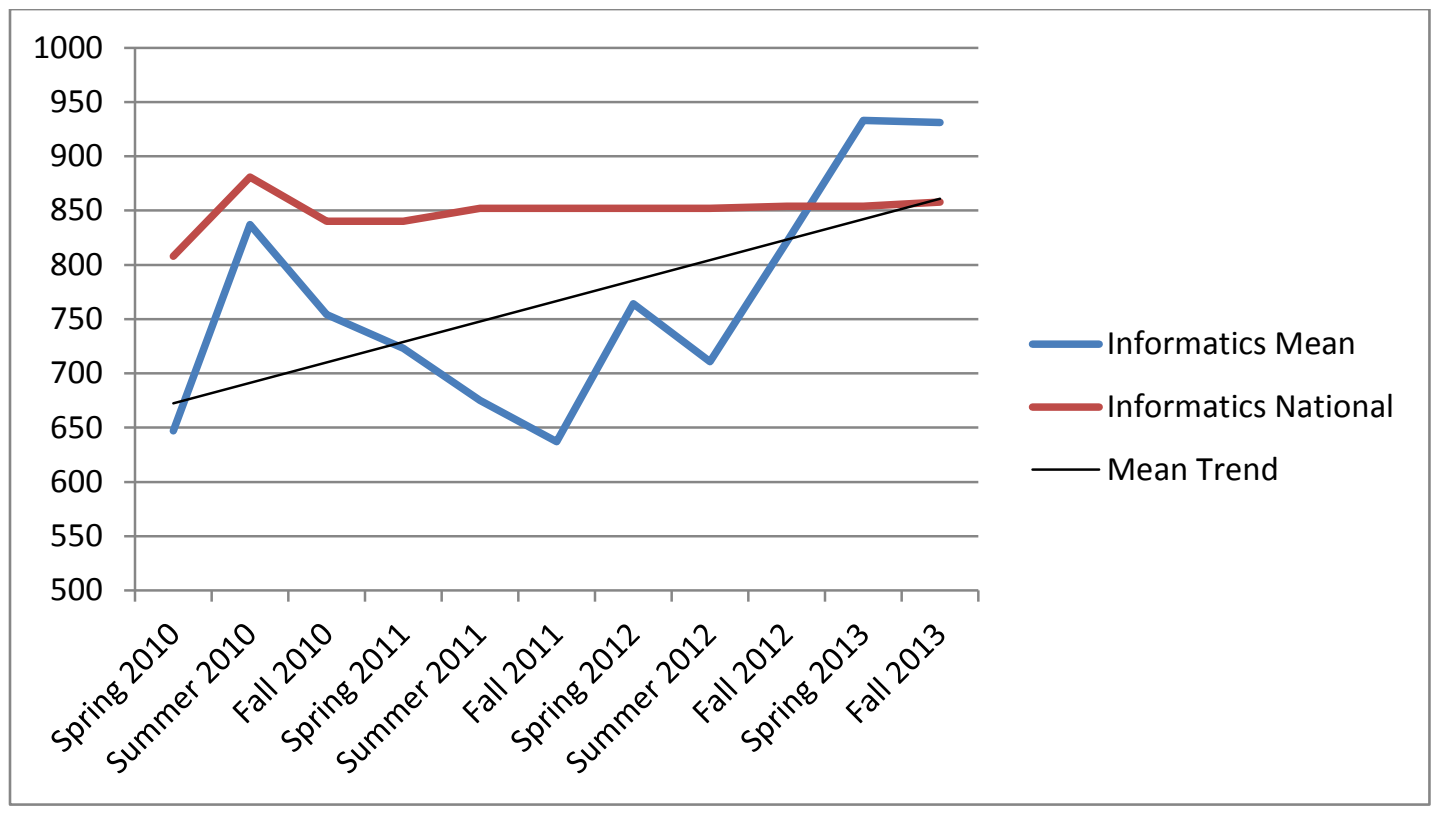

Figure 6. HESI Custom III exam scores aggregated for semester student cohorts and specific AACN essential IV informatics based questions compared to national HESI scores. The students in these cohorts have completed semester three out of four in the LOC nursing program. 
The third diagram in Figure 7 is an illustration of the informatics components aggregated out from the semester 4 HESI RN-EXIT exam $\left(E^{2}\right)$ scores. These students have had two full semesters with possible exposure to either the Vist ${ }^{\circledR}$ or Epic ${ }^{\circledR}$ brands of healthcare EHR systems (or both). The students in the group in the year and semester of Spring 2013 and onward had been exposed to the AEHR system in their LOC fundamentals courses. Except for one group in the spring of 2011 and fall of 2013, the AACN essential IV based informatics question scores are above the national HESI scores for the same data sets.

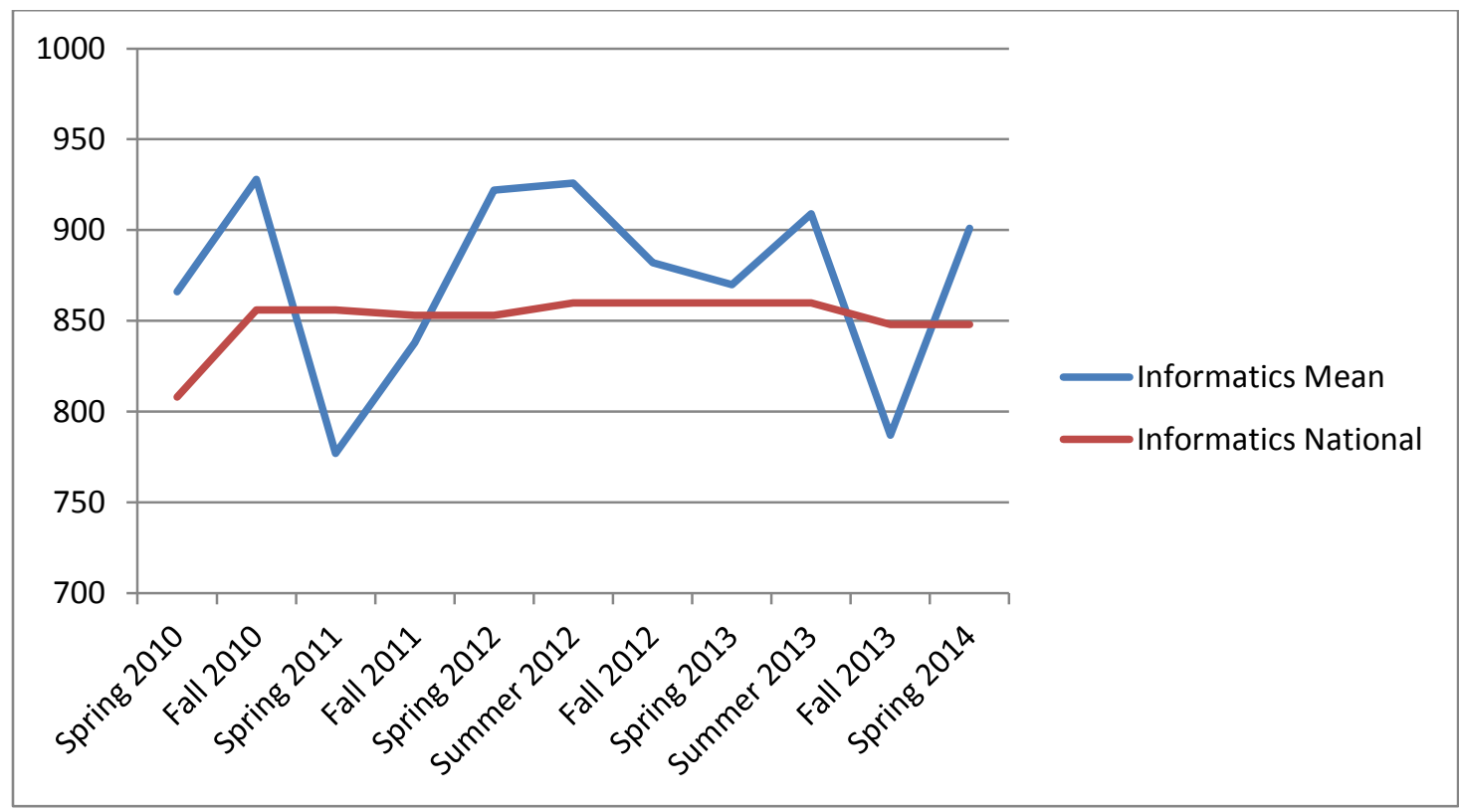

Figure 7. HESI RN-EXIT exam (E2) scores aggregated for semester student cohorts and specific AACN essential IV informatics based questions compared to national HESI scores. The students in these cohorts have completed semester four out of four in the LOC nursing program ad are preparing to graduate. 


\section{Interview Data and Analysis}

As previously mentioned in Chapter 3 , the focused interview sessions were conducted as follows. Ten participants from a mix of full time and part time adjunct faculty that responded to email invitation were selected to participate in one-on-one interviews according to the interview protocol presented in Appendix H. The interviews took place in the fall 2012 and spring 2013 terms at Liberal Oak College. Before the interview, the participant(s) reviewed and signed a consent form required for participation (Appendix I). All interviews were conducted face-to-face and recorded. The interview audiotape was transcribed verbatim within one week of the interview and clarified with the nurse educator participant for accuracy. All interviews took place in a private office. To insure confidentiality and provide a system for organizing interview data, the names of the nurse educator participants were changed to the following pseudonyms:

Table 16

Participants' Overview

\begin{tabular}{lclclll}
\hline Pseudonym & $\begin{array}{l}\text { Years } \\
\text { as RN }\end{array}$ & Specialty Area & $\begin{array}{l}\text { Years as } \\
\text { Educator }\end{array}$ & Teaching area & $\begin{array}{l}\text { Highest } \\
\text { Degree }\end{array}$ & $\begin{array}{l}\text { Appointment/ } \\
\text { Position }\end{array}$ \\
\hline Alice & 20 & Long term care & 5 & Fundamentals & Masters & Other \\
\hline Brenda & 40 & $\begin{array}{l}\text { Acute care } \\
\text { pediatrics }\end{array}$ & 24 & Fundamentals & Doctorate & Full-time/classroom \\
\hline Claire & 12 & $\begin{array}{l}\text { Acute care } \\
\text { pediatrics }\end{array}$ & 5 & Acute Care & Baccalaureate & Adjunct/clinical \\
\hline Doris & 10 & $\begin{array}{l}\text { Long term care } \\
\text { (LTC) }\end{array}$ & 3 & Long-Term Care & Doctorate & $\begin{array}{l}\text { Full-time/classroom } \\
\text { \& clinical }\end{array}$ \\
\hline Elaine & 33 & Acute care & 7 & Acute Care & Baccalaureate & Full-time/clinical \\
\hline Francine & 17 & ICU & 8 & Fundamentals & Doctorate & $\begin{array}{l}\text { Full-time/classroom } \\
\& \text { clinical }\end{array}$ \\
\hline Gloria & 41 & $\begin{array}{l}\text { Clinical } \\
\text { Specialist }\end{array}$ & 8 & Specialty & Masters & $\begin{array}{l}\text { Full-time } \\
\text { other/classroom }\end{array}$ \\
\hline Heidi & 29 & Clinical Specialist & 10 & Fundamentals & Masters & Adjunct/clinical \\
\hline Irene & 26 & $\begin{array}{l}\text { Nurse } \\
\text { Practitioner }\end{array}$ & 2 & Long-Term Care & Doctorate & Full-time/classroom \\
\hline Jennifer & 45 & ICU, ED, LTC & 26 & Specialty & Doctorate & Full-time/classroom \\
\hline
\end{tabular}


In the final interview analysis, five major findings emerged from the interview

portion of the study:

1. Nurses have a major role in information management and workflow design in the healthcare setting. The overwhelming majority of the interview participants indicated that EHR's provide tremendous benefits to the quality and safety of patients in the healthcare setting and that nurses play a significant role in the management of these systems.

2. Students need adequate knowledge and support to develop both nursing and information management skills. All faculty participants recognized that students need support to transition the performance of nursing skills, and be proficient with documentation expectations of nurses in the clinical practice environment.

3. Nursing faculty members are poised to play a significant role in educating nursing students regarding healthcare informatics regardless of the faculty member's previous EHR experiences. As experienced RNs, as well as educators, nursing faculty members hold a wealth of knowledge and information regarding nursing skills and nursing documentation. Additionally, faculty participants contributed great ideas about the integration process.

4. Significant barriers and resistance to the academic EHR negatively affects the AEHR implementation process.

5. Strategies that promote faculty support with the academic EHR have a positive influence in the AEHR implementation process.

The qualitative constant comparative method (CCM), used to analyze the interview data, provided opportunities to identify significant patterns among the participants. According to Glaser (1965), constant comparisons, based on as many of the similarities and differences as possible, tends to result in the analyst creating a developmental theory. Therefore, this method fit with the overall purpose of understanding the faculty experience during a developmental process such as integration of a program into the curriculum. Table 17 illustrates the correlations between themes, clusters, categories, and coded fragments found in the analysis of the interview data. 
Table 17

Summary of Major Themes Based on Coded Fragments, Similar Category Characteristics, and Descriptive Clusters.

\begin{tabular}{|c|c|c|c|}
\hline Major Theme & Cluster & Categories & Coded Fragments \\
\hline $\begin{array}{l}\text { Nurses have a major role } \\
\text { in information } \\
\text { management and } \\
\text { workflow design in the } \\
\text { healthcare setting }\end{array}$ & $\begin{array}{l}\text { Appreciation } \\
\text { Benefits of } \\
\text { system } \\
\text { Collaboration }\end{array}$ & $\begin{array}{l}\text { Real-time access to data } \\
\text { Multiuser availability } \\
\text { Data integrity } \\
\text { Communication clarity } \\
\text { Data organization } \\
\text { Safety and quality } \\
\text { Input into EHR design }\end{array}$ & $\begin{array}{l}\text { Faculty acknowledgment of } \\
\text { change toward EHR in } \\
\text { practice environment } \\
\text { Healthcare EHR designs } \\
\text { Course specific designs }\end{array}$ \\
\hline $\begin{array}{l}\text { Students need adequate } \\
\text { knowledge, support, and } \\
\text { opportunities for practice } \\
\text { to facilitate their } \\
\text { combined development } \\
\text { of nursing and } \\
\text { information management } \\
\text { skills }\end{array}$ & $\begin{array}{l}\text { Knowledge } \\
\text { Skills } \\
\text { Attitudes } \\
\text { Support }\end{array}$ & $\begin{array}{l}\text { Anxiety reduction } \\
\text { Confidentiality } \\
\text { Documentation concepts } \\
\text { Workflow efficiency } \\
\text { Feedback } \\
\text { Role modeling }\end{array}$ & $\begin{array}{l}\text { Feedback } \\
\text { Positive about system } \\
\text { Confidentiality } \\
\text { Role modeling }\end{array}$ \\
\hline $\begin{array}{l}\text { Nurse educators play a } \\
\text { significant role in the } \\
\text { healthcare informatics } \\
\text { education for nursing } \\
\text { students regardless of } \\
\text { prior level of EHR } \\
\text { experiences }\end{array}$ & $\begin{array}{l}\text { Knowledge } \\
\text { Skills } \\
\text { Creativity }\end{array}$ & $\begin{array}{l}\text { How to teach } \\
\text { What to teach } \\
\text { When to teach }\end{array}$ & $\begin{array}{l}\text { New ways of thinking } \\
\text { Document what you do } \\
\text { Fragmentation versus } \\
\text { holistic view }\end{array}$ \\
\hline $\begin{array}{l}\text { Significant barriers and } \\
\text { resistance to the AEHR } \\
\text { negatively affects the } \\
\text { AEHR implementation } \\
\text { process }\end{array}$ & $\begin{array}{l}\text { Attitude } \\
\text { Resistance }\end{array}$ & $\begin{array}{l}\text { Don't like it } \\
\text { Not my job } \\
\text { It's not useful in SON } \\
\text { I don't have time for this }\end{array}$ & $\begin{array}{l}\text { Preference for paper } \\
\text { Steep learning curve }\end{array}$ \\
\hline $\begin{array}{l}\text { Strategies that promote } \\
\text { faculty use of the AEHR } \\
\text { have a positive influence } \\
\text { in the AEHR } \\
\text { implementation process }\end{array}$ & $\begin{array}{l}\text { Attitude } \\
\text { Acceptance } \\
\text { Support }\end{array}$ & $\begin{array}{l}\text { Support /w technology } \\
\text { Work-a-rounds } \\
\text { Meet them where they are } \\
\text { Vendor support } \\
\text { Super-user model }\end{array}$ & $\begin{array}{l}\text { Transfer of skills } \\
\text { "Superuser" available } \\
\text { One-on-one support }\end{array}$ \\
\hline
\end{tabular}

The next part of this section will take each of these findings and describe them

further through the eyes of nurse educators. The variety of descriptions that follows is representative of the multiple and varied experiences of these nurse educators. The discussion is organized according to the five major thematic findings, significant codes 
ELECTRONIC HEALTH RECORDS IN NURSING EDUCATION

discovered during the interview process that fall under these themes, and exemplar quotes from nurse educator participants.

\section{Finding \#1}

Nurses have a major role regarding information management and workflow design in the healthcare setting. All of the interview participants $(100 \%)$ indicated that EHR's provide tremendous benefits to the quality and safety of patients in the healthcare setting and that nurses play a significant role in the management of these systems. Nurses have traditionally been the organizers of patient care in clinical settings, providing for the physical, emotional, social, and informational needs of people during their stay in the healthcare setting in a holistic manner. The quality of this experience for patients is dependent upon the quality of care provided by the collaborative efforts of the multidisciplinary healthcare team. Several key elements of EHR systems that interview participants mentioned as significant for providing increasing patient quality and safety were a) real-time access to data, b) multiuser availability, c) improved data integrity, d) improved clarity in communication, e) improved organization of data, f) mitigation management of errors, and g) nurse input into EHR design.

Real-time access to data. Real-time information means that information becomes available to others as it is gathered. An example of this concept is that when the nurse at the bedside inputs the most up-to-date information about their patient, the physician or healthcare provider (HCP) can be in another location accessing that same data. Multiple accesses to the same chart means that multiple members of the healthcare team access information and respond to patients concerns in a timely manner. This improved 
management of knowledge and data through technology, allows the HCP to review data and input "orders" from another location. Such timely responses from members of the healthcare team in data management and processes lead to better quality of care for the patient because their concerns are addressed promptly. One interview participant, Brenda, expressed gratitude when she talked about her experience during a time when she recently found herself as the receiver of healthcare services following an emergency in her family:

"My son got better care because of electronic records. We had to transfer from one hospital to another and when we got to the other hospital, and the continuity of care was significant. All the previous work done at the first hospital was available instantly to the physicians. They just pulled up his electronic records and the CAT scan was there, all the previous treatments and results were accessible, and the nurses could see which medications were already given; which orders were already carried out. " [Brenda]

In contrast, Alice had some concerns but felt that the benefits of accessibility of EHR records did outweigh the risks:

"I suppose there's also the question of personal privacy following you everywhere you go, umm, a 1984 scenario type thing, big brother, or whatever. But, I think the overall outcome, is that you do want people to know what your medical condition as in an emergency, you know. Whether you're wearing a bracelet, or necklace or something. But having your medical records available wherever you are certainly is to your advantage. In an emergency, particularly." [Alice]

Multiuser availability. The perspective from nursing educators experienced with EHR systems the clinical setting provided a wealth of information regarding the benefits of having multiple access points for data. Since the EHR exists in cyberspace and not in a physical space, the patient's information is housed in a virtual rather than a physical format. This allows accessibility to all the patient record elements such as notes, lab tests, medication records, or any other data to all members of the healthcare team 
simultaneously. Information can be easily shared providing interoperability, from department to department, or from healthcare facility to healthcare facility. If you want to know something, you can just go look it up. Because all faculty participants are experienced nurses, and electronic health records is a recent change in healthcare documentation, all of the interview participants recalled the time when paper charting was the prevalent method for information management. This was a time when all healthcare information was kept in a binder "the chart" on a specialized shelf usually housed at the nurse's station. Only one copy of information was available. Multiple users trying access the chart was always an issue. Physicians or healthcare providers (HCP) would always get priority for chart access. At times, the charts would be taken away from the nurses' station and be placed in another area making it difficult for others to get access to the information. Nurses developed the habit of keeping their own personal handwritten paper copy of notes, on the patients under their care, in their possession on priority care issues, medications, significant assessment data, etc. This habit carries forward to this day. Unfortunately, Data in the pocket is not accessible to others and many nurses did not record information until they were not "busy," or at the end of their shift.

Since the implementation of EHR systems, nurses have been able to access hospital records or patient data information whenever they need it from computer terminals in their work area. This has led to more efficient management of information and improved patient care quality and safety. Francine recalls the frustration she felt of working with paper charting after being exposed to EHR systems for so long: 
"When our facility changed over to another EHR system, we had to use a hard copy of each chart. I felt very frustrated. Kinda like, oh my gosh, where can I locate the answers? How can I find what I need? I do like the electronic health record so much better!" [Francine]

Improved data integrity. Data integrity occurs when information is recorded as it is collected. As a result of having computer charts at the bedside with the patient, nurses that open the EHR in the room and input data while they are in the room working with their patient, have more "correct" information documented on that particular patient. This process, contrasted to previous nursing behaviors before EHR systems, whereby nurses would do something for patient and leave the room without documenting. They would input the data in the charting system at a time in the future from when the data was gathered. In the recent past, and for some of today's nurses, a common practice would be to wait until the end of the day to write up all their documentation. Patient care comes first and documentation considered as secondary to the needs of the patients. Unfortunately, the longer the lapse of time, the less likely information details are remembered about what occurred in the patient's room with the patient. Nurses that input their documentation as they go along in their day not only have better integrity of their data, but also experience greater efficiency in their workflow; at the end of their shift their documentation is in order.

Improved clarity in communication. Since all documentation recorded in electronic health record systems is typewritten, illegibility is not an issue. Decrypting handwriting was once a very coveted skill that experienced nurses were known for; the art of being able to figure out what physician's handwriting really meant in a patient's 
chart. In EHR systems, the healthcare provider (HCP) typewrites all patient care orders directly into the system. The issue of errors related to improper processing of orders related to an inability to decrypt the healthcare provider's handwriting no longer exists.

"I love the EHR! It improves outcomes for the patient because of clear communication, error prevention, and better overall care." [Alice]

Improved organization. Nurse educators that have worked with EHRs and students in clinical practice expressed a positive change in their workflows related to better organization. Many of the participants interviewed describe the benefits of working in the EHR, as providing a way of "pulling everything together," and "faster, and more efficient." For Elaine, this meant she could focus more on her patient care.

"Rather than sitting at the nurse's station doing a bunch of documentation, in the EHR, the charting is all right there. I always document at the bedside as I am providing care. The EHR organizes assessment data and is a tool for helping me organize what I need to be doing. I can open the chart and document assessments and other stuff in the template at the bedside while I am doing care. I use the shift assessment template that puts you through the process and it is quicker, less time consuming. I believe the EHR is worthwhile to have around because I can do more patient care. It is so much better than paper, it makes the nurse's job efficient; they can spend more time with the patient." [Elaine]

Mitigation of errors. Nurse educators discussed the appreciation of safer medication management practices reinforced with the EHR system. Some of the former safety issues related to medication errors are prevented because computer alerts and clinical reminders pop up on the screen at key times during medication administration to either alert the nurse about an assessment that needs to be paired with medication or alert the nurse that something is not right. This could be anything from an allergy issue to a timing conflict. The scanning system matches barcodes with patients name bands 
ensuring an extra safety check. The Typewritten display format gives lots of information about the medication including reminders to the nurse about assessments or extra checks they need to make before giving medication to a patient. Multidisciplinary care providers such as pharmacists, physicians, and nurses must stop and think again before continuing with the process, which in turn aids in preventing errors and promoting improved clinical decisions. When the system is followed, medication administration to patients is safer because the EHR system prompts improved clinical decisions.

"In my opinion, I think that after a period of time, the nurses don't pay too much attention to what they're doing with medication administration when they're doing all the checks at the bedside. That's why the barcode scanning helps because if the nurse is too busy and not paying close attention to what they're doing with the patient identifiers, the system will red flag and not allow the nurse or student to go further until they have resolved the issue. So it will tell you 'hey, wait a minute, something is not right here.' You are gonna have to go through the process and see what's going on. It could be the wrong patient that you scanned, or maybe a wrong med that you brought into the room. So the error is really, you know, very, very, very slim if nurses are just paying attention to the electronic health record.” [Elaine]

Nurse input into EHR design. Practicing nurses and nursing faculty need to be a part of the design process in EHR systems. Half of the interview participants Doris, Gloria, Brenda, Jennifer, and Claire, brought up the topic of nurses being integral to the design of EHR systems. They commented that in their experience, when nurses are part of the design of the EHR systems, the systems were more "user-friendly." When nurses' workflow is not considered during the design of EHR processes, tasks may get accomplished in a way that winds up being counterproductive as far as efficiency is concerned. Nurses have specific ways of organizing their work. This organization has developed over a period of years carefully balancing the elements of nursing practice, 
patient priority, nursing skills, and nursing ethics. Nurses design things from a user perspective. In addition, the system will get better use if people that are using it feel like they have an investment into it. Since nurses are the primary managers of information in healthcare settings, it makes sense that a usability model is followed during the design process. The following quotes exemplify this idea:

"Ya know, sometimes I think the VA system, which is one of the oldest, is a good example where there is design by nurses. I know that nurses, (a nurse), originally designed their medication system. I think that we design things, from a user perspective, umm, because of that, it's gonna work better." [Doris]

"Where I was before [previous employer], we implemented Epic ${ }^{\circledR}$ right before I came and umm, we were part of it, of the development, of the programs and what kind of information was there and in what format, so that it was as usable as possible for the nurses." [Gloria]

"I would like to have input. I think it ought to be fairly intuitive. Some of them [EHR systems] are, and some of them are not, this LOCAEHR is not. I wish we could be more involved in the development and design of it." [Jennifer]

\section{Finding \#2}

\section{Students need adequate knowledge, support, and opportunities for practice}

\section{to facilitate their combined development of nursing and information management}

skills. The first exposure that students have to electronic documentation occurs in their third semester of nursing school during their acute-care clinical rotation in hospitals. In addition to providing clear documentation in the clinical EHR, students are expected to perform total patient care, which includes physical assessments, personal care, medication administration, procedure skills, and care planning, as well as respond to any priority situations that arise. Although many students have had some online training regarding use of the hospital EHR system, they still require extensive review and 
mentorship by clinical instructors and RN preceptors when it comes to using the EHR "live" in the clinical setting. Faculty members and nurse educators acknowledge this as a significant issue in nursing education and voiced concerns that students will need to understand informatics together with the basic skills of nursing practice if they are to be successful as practicing nurses. Students need to pull the two skills together in practice. Several faculty interview participants mentioned important elements for facilitating student learning in this complex clinical practice paradigm. These key elements include a) anxiety reduction, b) understanding confidentiality, c) knowledge of documentation concept, d) incorporation of the EHR into nursing workflow, e) providing meaningful feedback, and f) role modeling of EHR skills.

Anxiety reduction. There are many reasons students have anexity when they first come to the clinical setting. The idea that they will be expected to interact and perform nursing care with "live" patients is only compounded by the expectation that they will be expected to perform accurate documentation in the electronic healthcare record. Anything we can do as nurse educators to lessen their anxiety before they get to this stage would be very beneficial to them, as well as increase their ability to pay attention and synthesize more learning experiences. Elaine, Claire, and Doris elaborated on their experience and strategies with the most recent clinical group they supervised:

“...it's all positive having the electronic health record in the school. What I did is I made them [the students] understand that this kind of technology is here to stay and that the advantage to the students, like my group, is that when they are exposed to electronic health record in the school, transition to the clinical area is much better. Rather than when nothing is done at school and then expose the student into the clinical area with electronic health record, it's overwhelming to them. It is one of the barriers; it delays their learning. You know, the process of 
learning how to apply the skills, you know what they need to do in the clinical area. So one thing you should know is that if we can educate them about the EHR at the school, so much the better. And I can see it! Because I know in 2004, 2005, when I was bringing students into the clinical area, it is a shock to them to do the electronic health record. Now they are more prepared even though they complain a little bit about it, but you know, they still accept it. Because they know, and I know for a fact that it's helping them in the transition process." [Elaine]

"Students need to be able need to document in a computer, to retrieve notes, retrieve data, and interpret the data, and then take action on that data and enter notes that are going to be accessible by other people in the healthcare team. I was able to get a hold of the super user support person at our facility during clinical. This is very helpful because students need to ask questions as they are using the system. In other words, they really don't have a question until they encounter an issue, then they need to have the help at that moment. So, the hospital has super users, people that know the system that are available by phone 24/7. Also being able to take students to a computer room and let them work in the sandbox or the practice area of the EHR at the clinical site really helps decrease student anxiety with clinical practice EHRs." [Claire]

"I have had at least one student give me the feedback that having had that experience [with the AEHR] made them much more comfortable when they actually had to use it [EHR] in an acute setting. Even though they didn't use it much... they got that exposure before they had to use it clinically, and that exposure helped them feel more comfortable even though the platform was not the same, because the theoretical piece was there." [Doris]

Understanding confidentiality. Nurses are responsible for role modeling confidentiality with medical records. Although all nurse educator and faculty participants understood the concept of medical record confidentiality and thought this was very important for students to understand, a few were unaware of the logistics of how that played out in the EHR. What students need to understand is that their identity is tracked by their password in the EHR, and any actions they take or records they access in the EHR is tracked and accounted for. When somebody logs into the system, wherever they go into the system, tracking codes are created and associated with those actions, and this creates a log that can be accessed by those with authority. If the students' enter into 
records that they are not authorized to enter into, they are violating the confidentiality agreement that they signed with the hospital. In addition to accessing information, several faculty members talked about how they would review and stress with students in the clinical setting the inappropriateness of using their cell phone to take pictures of data or printing medical record data from the EHR itself.

"Confidentiality needs to be explained clearly with students. An electronic health record gives you [anyone] access to the entire hospital or group of hospitals that it serves. So then, it is easier to be nosy about things you are not supposed to get into in the EHR, such as looking into charts of individuals because you are interested in that particular disease problem or possibly looking into the chart of somebody you might know. Another thing that I tell my students is that if you find a computer chart open and no one is next to it, you need to log that person out so that no unauthorized access can occur with the medical records. I'm very upfront and I tell them on the first day of clinical that these things are not okay. They cannot take pictures with their phones and they cannot print out information from the EHR. I think because they grew up with social media, we have to pay extra attention to teach them to respect the EHR data." [Irene]

The concept of documentation. Interview participants made several key points in regards to teaching nursing documentation. First, that documentation is crucial, and that nurses must be skilled at complete and accurate documentation in the EHR in order to practice safely in the clinical setting. Second, that documentation education skills need to be tied to a patient case rather than teaching students to use the check boxes out of context. The idea of having students document in the AEHR in case study charts brings together the big picture or concept about their learning. For example, students can do the process of assessment, then document the assessment, do the intervention or procedure and document that intervention or procedure, then evaluate the patient outcome after the intervention or procedure and document the outcome. They indicated that it would be 
clearer for the students if they were documenting in a case study chart, otherwise the act of using check boxes or data entry grids without a context to the data they are entering makes the skill seem fragmented. Third, that we need to be educating students to document in the EHR but also to be able to understand some of the documentation in writing [narrative form].

"Students should learn documentation expectations beginning the first day of nursing school; if they do something they need to document it. And to get into the habit of always, if they do something they document. Because you know, the way I was taught is that if it is not documented, it was not done." [Elaine]

"I think we need to teach students both documents on electronic health records but also to understand some of the documentation in writing. I believe writing and critical thinking go together. I don't believe electronic health records are geared to force critical thinking yet. Students need to do more than just check boxes, they need to be able to write out what they're doing. What would happen if the entire the time charting system went down? We would have to resort to writing on paper again so it's important that students understand how to write out documentation and understand the principles behind charting. I think the EHR is less thinking and more doing. The SOAP note for example had subjective, objective, assessment, and plan. This way of documenting forces critical thinking because you have all the data together and can do something with the information such as formulate a plan for action." [Brenda]

Incorporation of the EHR into nursing workflow. Interview participants

mentioned that they are still trying to figure out the best way to incorporate documentation into the nursing lab assignments. For example, nurses in practice settings have computer access at the bedside with their patients. They comment about the improvements to workflow efficiency in terms of documentation, location of information, and that they have more time to spend with their patients, "once you know how to use the system." Having computer terminals at the bedside in the school of nursing skills lab with the manikins is very helpful for students in learning about real-time documentation, but 
there are times when there is too many students and not enough space. In this instance, students feel rushed just to get the skills done in time. They do not get to the charting these because they have to make a compromise. Two nurse educators discussed specifically how they use the EHR as a tool for students:

"What they're gonna do is just go through that template and umm, that's a tool for them to make their assessment." [Elaine]

"...the electronic health record is the tool for documentation, so that is their way... their method for them [the students and nurses] for record-keeping. So, in that sense it's their ummm, telling what happened to the patient during the day, throughout the day and also as a record of for the next shift to know what is going on with the patient and with the changes are and where to make... ah, if medication changes have been made, or it's where you go to find out what labs are, it's where you go to find out what the current medications are, what current orders are, ummm, its... the electronic health record is the electronic version of the chart." [Irene]

Feedback and role modeling of EHR skills. Interview participants felt that quality feedback and role modeling of EHR skills is very important for student development. In particular, they felt that students need to receive quality and timely feedback on the assignments they submit in the AEHR system, and that when clinical faculty are inconsistent on the type and amount of feedback they give to students, the students lose interest in completing assignments. EHR systems are constantly being updated in the clinical setting so students and nurses need to have an attitude of continuous learning within any EHR system. Role modeling an interest in learning the AEHR along with the students was considered a positive behavior that facilitates student learning.

"When I give students feedback on their notes in the AEHR, they are very excited about that. The problem is they write so many notes and the way the system is 
formatted, it's very difficult to have the time to get feedback on each individual note. That is so much grading. When faculty don't cosign the notes, the students have frustration with the AEHR system. They have an expectation that if they do something that they will get feedback on it. Not all faculty members are doing that, so students are talking about that and feel that they shouldn't have to do the assignment if nobody is going to look at it." [Francine]

"Students will show interest if we show interest, therefore we must give feedback. Unfortunately, not all nursing faculty have time to give students proper feedback so students don't get the feedback they need in the AEHR system. We need to figure out a way to build in time for feedback." [Alice]

"Well, I think by showing the students that we actively use the EHR they are going to be more willing to participate in the assignments that were going to give them. I think that giving them feedback as soon as they submit it and it triggers us; I think giving them feedback on their charting is really important. So that they know that we are keeping an eye on what they're doing and so, I think us faculty need to be really aware of when they are charting so we can give them positive feedback." [Hedi]

\section{Finding \#3}

\section{Nurse educators play a significant role in the healthcare informatics}

\section{education for nursing students regardless of prior level of EHR experiences.}

Interview participants mentioned the use of case studies, clinical organizers, and narrative summaries as important to student learning. They also discussed how these educational methods transition into the EHR platform. Concerns were voiced about effective use of the EHR for teaching at a conceptual level, as well as creative strategies for use of the AEHR as an educational tool.

Teaching conceptually versus simple data entry. Data entry exercises (the use of check boxes in the AEHR) is considered "busy work" by many faculty members and therefore not regarded as a useful exercise for conceptual learning. Simple data entry exercises appear fragmented or out of context and this makes it difficult for faculty to 
give meaningful feedback to students because they have no frame of reference for the

data. When students are working through a case study using the AEHR, they can

document the assessment, intervention, and evaluation steps in the nursing process, which

is a more cohesive, meaningful exercise.

"...where I feel part of the learning curve for us [faculty] is that how do we do that balance? It's the same in all of our teaching, how do we do that balance between guiding, so that we are teaching. So that if we have a bunch of checkboxes that helps reinforce the behavior, they have to get that. But at what point does it become a blank text box so that we know that they have incorporated the information conceptually? That if you're doing an assessment and you think that somebody is, is, having umm, a cardiac event. What are the assessments that you are gonna do? What is the information you're going to gather? And not be guiding them through it, but making them think a little bit harder. And that's a hard one. That's a little tricky thing to figure out." [Doris]

The AEHR as an educational tool. Nursing educators and faculty members also

came up with creative ways for students to learn nursing concepts and information

management skills together with the AEHR platform. The ideas and activities were based on course syllabus and clinical expectations.

"They [the students] need to learn how to link the information together from the beginning. If they learn conceptually, they can adjust themselves to any system in any hospital. The most important thing is they have to learn how you can use the data that's in the system, how to locate the data that they want to look for, how to connect the data together, and how to include important information."[Francine]

"One of the things I like about using the AEHR is that I can have my students use a template to put in their prep on their patient that they will be caring for. Students are expected to go to the clinical site to do a workup on patient and spend the night before clinical understanding the information. I can then review their data and get an idea about how prepared they are for the clinical experiences.'[Elaine]

"The nice thing about the AEHR is that there is the language for all the different systems and it organized and it can be a very good resource for students. I think what needs to happen is we need to look at developing formats for 
ELECTRONIC HEALTH RECORDS IN NURSING EDUCATION

communication reports that students can use in the AEHR. Something like handoff reports, or SOAP notes. [Hedi]

\section{Finding \#4}

\section{Significant barriers and resistance to the academic EHR negatively affects}

the AEHR implementation process. Although nursing faculty members recognize that it is imperative for students to be prepared for using the electronic health record in workplace, and that EHR skills have become a necessary component of some chroniccare and all acute-care nursing skills set for students in the clinical setting, resistance to the AEHR integration exists. Even when EHR systems were first introduced in the clinical practice settings, personnel at the hospitals and other healthcare organizations had pushback from their employees until the employees got used to learning that the EHR as a part of their work, and that they need to use the new program.

People do not necessarily like change. It is a learning curve, and it is frustrating and very stressful when you have so many other things to do as a faculty around organization of courses. To add another element such as proficiency in using a new documentation system is a lot to ask on top of that, especially when this is not something that was taught to faculty when they became RNs. One nurse educator commented that when faculty members' are not excited about learning in the EHR it is like "walking through molasses in the winter." Barriers and resistance factors to AEHR implementation that were identified during the interviews included, a) limited knowledge skills and motivation of nurse educators, b) technical difficulties and perceived poor user-ability 
with the system, c) unclear expectations, d) difficulty with change, and e) distaste for EHR technology.

Limited knowledge skills and motivation of nurse educators. If faculty do not see the value in a particular education tool, they are unlikely to adapt to it. An issue brought up by interview participants was that adding the complexity of technology on top of the complexity of nursing concepts would be too complicated for students to grasp in a classroom setting:

"I teach in a classroom primarily. I don't think using the EHR in the classroom is the best way to teach because you spent too much time working in a technology when what you want to do is focus on the concept. If I want to show a document or a graph I can use a PowerPoint slide to do that, I don't need to learn how to learn a new computer program to get a concept across to the students....that is like too much work. And I don't see the value of it. I don't see how it applies to practice. I can get all kinds of critical thinking things on my own without having to do that, and bog everybody down." [Brenda]

Factors that impeded the motivation for faculty to learn how to use the system were the perceived steep learning curve, and lack of time and energy to learn the technology,

Poor user-ability with the system. Faculty may value the EHR at their own clinical site when they are working as a practicing nurse, but they do not see the value of the educational platform in class. Although the LOCAEHR system is easier to learn to use when compared to the Epic ${ }^{\circledR}$ system predominately used at the clinical sites, many faculty commented on the poor user interface and lack of intuitiveness of the program. In particular, interview participants mentioned several other issues with the LOCAEHR interface such as a) poor connectability (users would get booted out of the system without 
warning), b) delayed uploading time, c) inability to use in the clinical setting, d) lack of differentiation styling between student work and faculty feedback comments,

e) difficultly when using on smaller devices such as tablet or phone, f) lack of similarity to most clinical site EHRs, and g) overall "clunkiness" with the system.

Distaste for the technology. A few faculty members commented that they do not like EHR systems, and that they do not want to teach students in the AEHR. Reasons for this varied from lack of interest in leaning the technology to preference in teaching with paper-based medium.

"If the learning curve is too high, then I am not going to do it. I will find an easier way." [anonymous]

"If I don't see the value of a learning program or how to applies to practice, I won't use it." [anonymous]

"This is not the best use of my time and knowledge." [anonymous]

"I don't like it... But we have to have it." [anonymous]

"Students already have to learn a clinical platform: this is just another system on top of that." [anonymous]

\section{Finding \#5}

\section{Strategies that promote faculty use of the academic EHR have a positive}

influence in the AEHR implementation process. When faced with the prospect of change, the initial response may be resistance or regression into a more familiar circumstance. To combat this phenomenon and promote the necessary changes that move innovations forward, strategies need to be identified which reward the efforts required to change. These efforts have a positive influence on the integration process as more adopters join in to support and promote the implementation. Factors that promoted facilitation of the AEHR integration include a) positive attitude, b) individualized 
support, c) learning as we go along, d) collaborative design environment, and e) onsite integration support team.

A positive attitude improves acceptance. When faculty members have positive things to say about the AEHR system and share what they have done and what they can do with others during collaborative workshops or classroom sessions, the whole room becomes energized. Positive energy really does enhance the learning experience for everyone.

"When faculty are excited it's a very satisfying energizing feeling and the positive feelings are contagious to others. I am not experiencing as much resistance from faculty as I anticipated. Faculty just need to get used to it; accept that technology is here." [Alice]

Individualized and technical support increases acceptance. Faculty expressed that they had a strong need for technical support with the AEHR integration in terms of assignment development and use of the system. Learning to use the AEHR takes more than one workshop; it involves practice and experimentation with the program from a user standpoint as well as designing and organizing step-by-step instructions that match up with meaningful assignments to exemplify nursing concepts. Support is crucial because if the process was just dependent on faculty learning the system on their own and bringing it up and putting it in place, it wouldn't happen.

"I won't get involved in the EHR unless someone else writes the instructions into the computer. It is important that faculty do not have to do the 'grunt work.' I believe it's better to have the support. ...to have someone else do the button pushing, someone to integrate your ideas into the platform and you, the faculty person come up with the conceptual ideas." [Brenda]

"The lab coordinator teaches students about the EHR, all I have to do is log and cosign." [Gloria] 
"I just think that it's a great tool. It's a really great tool. Umm, 24/7 tech technical help is really valuable. I had, ah, one adjunct tell me that she couldn't sleep at night so she got up at two in the morning and started working on it and it wasn't, wasn't working right, so she called in their technical desk, and umm, and somebody answered, and sounded a little bit sleepy, but they answered, and were very, very pleasant. The adjunct asked what time it was at that person's location? And they said it was 4 o'clock in the morning. She said well, don't feel bad. It's 2 o'clock here. (laughs). But uh, she said that they were just really, really helpful and uh, patient. Everything you would want in a help desk. So that's really valuable." [Alice]

Learning as we go along. "Just in time" and "work-a-round" strategies for faculty mean that support needs to be available when the faculty member needs it. When nursing faculty switch from course to course within the academic year, they may only teach a course once or twice which means they may not have familiarity with the material. With the support of an integration specialist, assignment templates can be created from the course syllabus materials. Modifications during the learning process include support strategies such as short cut notes or cut and paste processes to save time. Many nurse educators keep short cut directions easily accessible, or have students email assignments and use the track changes feature for grading and feedback when the system goes down.

"The hardest thing is trying to figure out how to get enough expertise to exploit all the things the technology can do in the time that we have as faculty to do our jobs. Having premade templates is helpful then, you still have to test drive the assignment with students." [Gloria]

"I think it does not matter what system it is that we use. I think it needs to be a relatively simple system early on, so that the students become more competent and more savvy with it." [Brenda] 
Collaboration and support. These are key elements to AEHR integration. It is very important to have somebody who is dedicated to the integration project, run it. In addition, having collaboration between a faculty and staff running the simulation is very beneficial to the success, blending the expertise of theory and logistics of operations to ensure meaningful and practical application of assignments. Knowing that faculty members are available for collaboration increases the buy-in and the comfort with the system. If there is no buy-in from people that are working with the project then it is going to fail. In addition, if faculty feel like the expectations of them are too demanding and that they are going to be unsupported, then there will be resistance. There is going to be some form of resistance until somebody sees how it is useful for them [the user] personally.

"Figuring out how to infiltrate the consciousness of the faculty is the tricky part. People want just in time learning; they want information when they are ready to utilize it so scheduled workshops are not the way to go." [Francine]

Need to have an onsite integration team available. Concerns raised by one interview participant pointed to the lack of a full time informatics nurse on staff at the school of nursing. Another suggested incorporating on-site "super users," such as how the hospital systems integrated their clinical EHR systems, to support faculty and students as they are learning. This would involve having extra people that are very knowledgeable in the system to be available in courses where the AEHR is used. Many participants mentioned that it helps to have a support person in the lab while students are working independently in the AEHR to troubleshoot any issues [because the faculty, are still learning too]. 
"Seems like this project needs more people to make the plan, like you should have a group to do this. There should be a team in place and they should present the plan to you and you could say, 'you want this, or you want that.' They can then make that happen." [Gloria]

\section{Summary of Interview Discussion}

Information gathered and analyzed from the surveys and focused interview sessions provides rich descriptive data from which to develop an understanding of the challenges, concerns, and successes of nursing educators and faculty members experiencing the collaborative learning by developing process of integration of an academic electronic health records integration in their nursing school curriculum. As a result, five major themes emerged from the analysis of the interview data based on direct quotes, codes, categories, and clusters. These themes represent qualitative discovery of faculty knowledge, skills, and attitudes during their experience with the integration of an academic electronic health records integration project framed in the Learning by Developing (LbD) model at a small liberal arts college school of nursing.

The interview time spent with nurse educators and faculty members was also a significant time for collaboration and building rapport for the project through mutual exchanges of information. Faculty members responses elicited were very candid and open. Comments and questions that may not have been raised during workshops or faculty meetings were brought up and disclosed in a very professional manner. The interview atmosphere was one of collaboration, honor, and respect. In the next section of this document, the nursing educators' and faculty members' experiences are described as viewed through the lens of the Learning by Developing action research conceptual 
framework model. Research data discussed in the surveys, artifacts, and interviews from this section are folded back into the AEHR integration to inform and evolve the project. 
Part II Findings and Analysis Framed by the LbD

The method for examining this research question was a case study of a small liberal arts college involved in the action research process of integrating an AEHR platform into the nursing curriculum. This section describes the process of the AEHR integration process as framed by the 10 steps in the action research LbD framework. Information gathered and described in chapter 4 through surveys, interviews, and artifacts were folded back into the integration process and the AEHR project and faculty developed evolved as a result. Suggestions and adjustments integrate into the evolution of the AEHR into the curriculum. This section is a discussion of this action research process framed by the LbD steps. The first part discusses the theory behind the Learning by Developing model as a framework for faculty development during the integration of the AEHR platform into the curriculum. The second part tells the story of the integration as it is framed in the LbD and the corresponding assessments, activities, and development that occurred along the way.

\section{The LbD Model as a Framework}

As mentioned in Chapter 2, the Laurea University of Applied Sciences in Finland used the LbD model as a method for creation and development of informatics skills and competencies in nursing education (Ora-Hyytainen et al., 2010). The model serves as a framework by providing a collaborative community approach for educators and staff at the Liberal Oak College for the integration process. Thus, the direction and process for the AEHR integration evolves as nurse educators' and faculty members' knowledge, skills, and attitudes develop during their participation in the integration process. These 
development paradigms fold back into the integration process as the evolutionary process of curriculum development.

The 10 stages in the model labeled (a) through (j) revolve like a wheel around three central products of the implementation project, Individual Learning, Community Learning, and Producing New Knowledge. Individual learning is the knowledge, skills, and attitudes of individual faculty members, nurse educators, and students as they participate. Community learning is the knowledge skills and attitudes of the college faculty as a whole regarding informatics curricula. Producing new knowledge is the activities, artifacts, and behaviors in the form of new habits and action models.

The LbD is a pragmatic research model based on Dewey's (1963) assumption that the sources of theory lie in the practical world: a connection/close link between school and life. Dewey (1931) defines pragmatism as "the doctrine that reality possesses practical character" (p.31). From this perspective, the world is seen as a set of practical actions that are born from thinking. Learning and doing are two sides of the same coin. Practical experimentation and intervention, a foundational pedagogy in nursing education, are seen as an essential part of studying human practices (Raij, 2013).

The stages that steer implementation have overarching themes of creativity, authenticity, partnership, experiencing, and research orientation. Learning consists of restructuring and building experiences, handling new situations, and acting in a purposeful way (K. Raij, 2007). Integration of the AEHR into the Liberal Oak nursing school curriculum is based on emergent design, allowing for flexibility, collaboration, 
and growth within the project (Christie, Montrosse, \& Klein, 2005). The LbD model with the above mentioned descriptions and characteristics is shown in Figure 8.

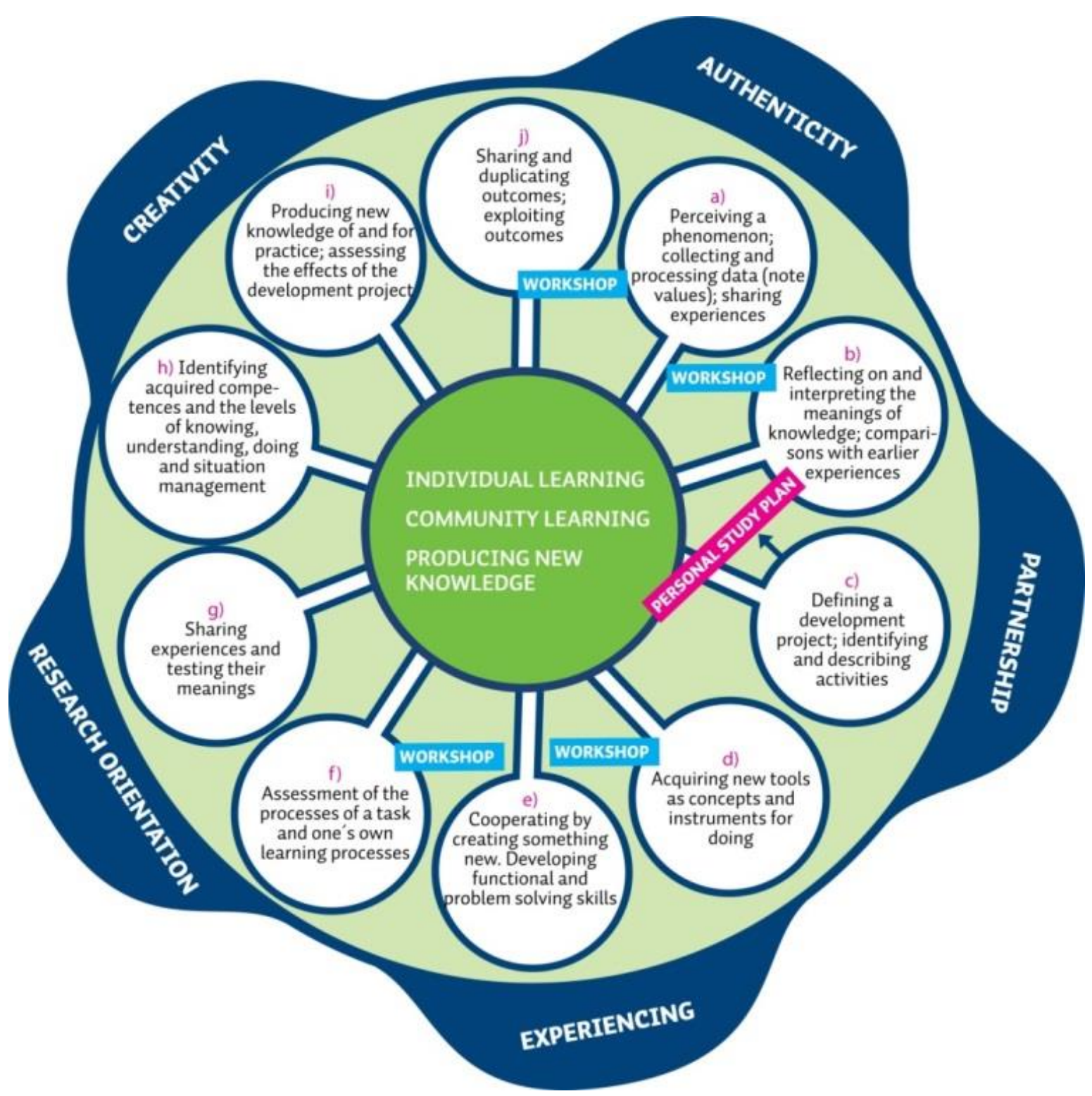

Figure 8. The $\mathrm{LbD}$ model chosen as an action research conceptual framework for faculty development and integration of the AEHR. Adapted from "Learning by developing: LbD guide," by Raij et al., 2011. 
As faculty knowledge, skills, and attitudes regarding the AEHR platforms evolves the AEHR purpose and design develops, and they [the faculty] become more familiar with the technology and build adaptive expertise by participating in the creative process of AEHR integration. In other words, the needs of the learners (faculty) change accordingly to their individual competency level change(s) and the AEHR integration develops as a result as the project evolves.

Riel (2010) describes the action research process as essential to lifelong learning and development of adaptive practice expertise. For example, we can begin by thinking of the EHR as a tool in the healthcare setting that practicing nurses use for communication, documentation, and data management. Current concepts of communication, documentation, and data analysis that nursing students learned through paper-based patient charts in years past can be now taught using this electronic platform. The concepts have not changed but the paradigm has. As collaborative partners in the process, the nursing educators and faculty apply their nursing and educational experience to learn and adapt nursing processes in this new technological paradigm. Benefits to nursing students learning in this environment are that they can desensitize and familiarize themselves to the technology of EHR systems while learning and applying nursing language and processes. Because this is a continual process of learning and curricular adjustment, both the learners and the field of nursing education are viewed as evolving, thus balance and continual adjustments are required. 
The next section is the story of integration framed the by LbD steps. In review, this model focuses on acting together and discovering new ways of thinking and doing in order to be able to manage changing situations, such as the integration of the AEHR curriculum. Faculty development (learning) is regarded as a tool that facilitates the achievement of competencies. Roles of the nurse educators and faculty are a) as preparers and organizers of the AEHR integration, b) as implementers, and c) as evaluators. Since the AEHR project has connections with authentic working life, the learning outcomes may be something unexpected. Therefore, because of the complex, evolving nature in nursing informatics, learning outcome evaluations are described as competencies. The information gathered regarding informatics competencies through surveys, interviews, and artifacts folds back into the project to inform evolution of the AEHR integration (Raij, 2013).

The written story follows a chronological order of events and activities. Each step will begin with a general definition followed by the description of the step as it pertains to the AEHR process, then by the associated events and activities, and finally with discovery and outcomes. Key findings from survey, interview, and artifacts research data are discussed in regards to how this information informs the faculty development as well as the evolution of the AEHR integration. 


\section{Story of Integration through the Lens of the LbD Model}

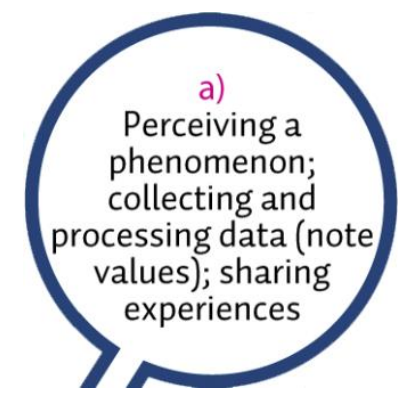

The first stage of the LbD model is a) Perceiving a

phenomenon; collecting and processing data (note values);

sharing experiences. According to Raij (2007) the LbD starting

point is praxis-based as it is related to a development project. It

is a time of inquiry sharing and discussion for innovative ideas.

For example, the Liberal Oak College (LOC) school of nursing educators identified the

phenomenon that electronic health records will be the future for documentation and

healthcare data management for their graduating nurses and that the school of nursing

needed to be active in facilitating this process. For the LOC school of nursing

community, the goal is to create new learning products, operating models, and working

cultures with informatics. The identified objectives of this development project are

change, the development of new documentation and information management

procedures, and the reorganization of student nursing workflow.

Events and activities: The phenomenon was explored further as the curriculum

committee chose to explore options for AEHR use at Liberal Oak College in the spring of 2009. A task force was formed consisting of transdisciplinary members, which included nursing faculty and staff, simulations department, health sciences faculty and staff, and the college grant writer. Members met bimonthly. Initial exploration included literature research, onsite visits for community partnership options, and AEHR vendor demonstrations. The task force team worked towards researching and collecting data about academic electronic health records platforms as they fit with the needs of the 
nursing school and shared their findings and experiences formally with the nursing faculty at department meetings, and the faculty development retreat the following summer in 2010.

Discovery and outcomes. A major consideration in AEHR program fit for the nursing department is faculty development. Since the majority of faculty members became nursing educators before EHR information management and documentation became so prevalent in healthcare, the nursing faculty knowledge, skills, and attitudes regarding informatics must evolve with the integration. How can they [the faculty] be comfortable in this type of environment, whereby they do not know all the "ins" and "outs" of the technology but are expected to teach others to work in it?

An additional major concern was funding. Cost factors to consider includes a) vendor costs, b) faculty time for training, c) associated equipment and ancillary staff time, d) student expense, and e) faculty development and training expenses. The following is a list of the major outcomes from the work of this committee:

- A list of evaluation criteria for vendor exploration based on literature review and faculty development needs.

- AEHR vendor narrowed to 2 choices based on the needs of the SON.

- LbD collaborative framework chosen as the process for integration.

- Avenues for funding through development and submission of grant applications. The case study research portion of this project began as the task force began preparing for implementing the academic electronic health records (AEHR) platform into the curriculum on December 2011, when a three-year contract was signed with the chosen AEHR vendor. A pilot implementation into the first nursing course was planned for the following spring in 2012. 
Workshop related events and activities. As part of the first two stages in the LbD, workshops are included according to Raij (2007). The criteria for workshops can range from formal interactive gatherings in the classroom setting, to small group interactions with online web based instruction. These workshops afforded opportunities for observational data regarding the AEHR integration. From December 2011 to March 2012, I attended and observed in the five following small faculty workshop situations.

- Exploratory workshop with LOCAEHR online orientation videos and 2 faculty members

- Orientation to LOCAEHR self-directed activity workshop with 4 faculty members in computer lab

- Interactive computer instructional technology (IT) staff lead workshop on computer technology

- Webinar workshop with LOCAEHR vendor integration specialist and 2 faculty

- Webinar workshop with LOCAEHR vendor integration specialist on AEHR faculty development ideas and creating the first assignments in the LOCAEHR

Workshop related discovery and outcomes: Stemming from my observations at the workshops, a formally structured 2-hour interactive computer-classroom faculty development workshop was scheduled in March 2012. Collecting and processing data about this new technological paradigm in preparation for the workshop was carried out by way of a faculty AEHR integration needs assessment survey (Appendix D) developed, distributed, and analyzed by the project faculty lead in early March 2012. The results from this survey were used to design and develop the faculty development workshop held late March 2012. Details of this workshop are discussed in the next LbD stage. 
b)

Reflecting on and interpreting the meanings of knowledge; comparisons with earlier experiences
The second stage in this model is b) Reflecting on and interpreting the meanings of knowledge; comparisons with earlier experiences. In this stage, the meanings of previous research findings and solutions explored, inform the structure

and process of the project (Raij, 2013). The analysis from literature research in chapter 2 on the integration of AEHR into schools of nursing, and faculty development strategies was combined with the results of the faculty needs assessment and competency assessment results to inform the integration process and customize the faculty development in this particular project.

Events and activities. Reflection and interpretation of significant findings from the faculty needs survey during this stage of the integration included the realization that although faculty voted to approve of the AEHR platform integration into the curriculum, increased support is needed to generate active involvement in the AEHR integration process. The following information helped to inform the structure and process of a 2-hour formal faculty development workshop. For example, only 6 out of 13 faculty members surveyed logged into the LOCAEHR system, only 4 out of 13 reported doing the scavenger hunt self- directed orientation activity, and only 2 have viewed the short 4-5 minute tutorial videos made available from the LOCAEHR website. Many faculty members were unsure of how to use the AEHR in the curriculum and all commented on their concerns about using an AEHR. Based on these results and the literature on faculty development by Curran (2008), six principles of significant learning were highlighted in 
the faculty development workshop a) foundational knowledge, b) application of the new knowledge and skills, c) integration with existing knowledge, d) a human dimension, e) caring, and f) learning how to learn.

The first faculty development workshop was located in a computer lab with ten faculty attendees. A work-study student oriented to the LOCAEHR platform was available during the workshop to guide faculty with IT computer logistics such as login, and navigation in the system. In addition, all attendees received a binder with printed materials describing key components of the LOCAEHR system at the beginning of the workshop. Discussion included topics such as electronic record chart navigation, order entry, creation of notes for nursing assessment data, students' portfolio versus case study charts, and high fidelity and low fidelity simulation charts. The workshop began with a live webinar with the integration specialist and two workshop leaders to do a walkthrough orientation of the system while faculty worked at their computers.

Since the workshop was located in a computer-equipped classroom, the faculty attendees participated in an integrated activity whereby each faculty member created notes in their own portfolio and preformed the LOCAEHR scavenger hunt activity. Email follow-up from attendees at the workshop was very positive regarding the comprehension of information presented, reference materials, and interactive activities. Concerns voiced by several nurse educators were about taking time away from in their busy schedules to create assignments or activities for students in the LOCAEHR platform. One of the biggest "ah-ha" moments was the realization that nursing faculty are at such varied levels with their informatics knowledge, skills, and attitudes. 
Discovery and outcomes. In order to provide an organized structure and individualize the faulty development support for the AEHR integration, a second survey was designed and distributed to all nursing faculty, the Nurse Educator Informatics Competencies Assessment Survey, (details of this survey are in chapter 4) which provided insight regarding informatics knowledge and skill set of faculty, as well as how often and in what manner they used informatics competencies.

Key finding results from this second survey confirmed and informed the varied faculty skill set suspected from earlier workshop observations, and guided further integration planning activities. For example, knowledge, skill, and access competencies rated very high $(100 \%)$ for respondents reporting themselves as competent, independent, or master users of computer communication applications such as email, and also high (95\%) for competence with basic desktop software such as word processing, printing, and power point presentation skills. Given that these computer skills are commonly used in the academic setting on a daily basis, it is not surprising that the rating is so high. On the other hand, $40 \%$ of faculty reported a lack of knowledge and skills related to computer documentation of patient data, assessments, interventions, and plan of care. This correlates with the report from respondents in the sample that slightly more than half (52\%) never or rarely have access to an EHR system for this purpose. This survey finding is significant because knowledge and skills for electronic documentation of these basic nursing concepts is an expectation for currently practicing nurses as well as clinically placed nursing students. 
Opportunity for faculty members to improve their knowledge and skill competencies in electronic nursing documentation needs to be available, especially for those working with the AEHR. As mentioned in the previous section on survey analysis in chapter 4 in Tables 11-14, faculty reported competency of informatics knowledge regarding ways nursing data can improve practice, limitations of computer use in health care, and patients' rights related to computerized information with an average of $86 \%$ competency in these areas and the remaining $14 \%$ that would need help at times. Very few faculty $4 \%(n=2)$ reported a lack of informatics knowledge for recognizing the value of clinician involvement in design, selection, implementation, and evaluation of computer applications while over $87 \%$ felt confident in this knowledge.

This understanding about the value of nurse input into an EHR system is a key point for faculty collaboration on curriculum development of future student assignments in an academic EHR. Additional information from workshop observations includes a) faculty are at different levels of computer competence, if they get sidetracked or cannot follow with the instructor on their computer at the same pace, they get distracted and lose interest, and b) faculty are more positively engaged when they have successes from the written or verbal instructions. The next stage in the LbD further discusses action taken as a result of these survey results and the discovery in the literature to promote engagement and faculty development of informatics knowledge skills and attitudes. 


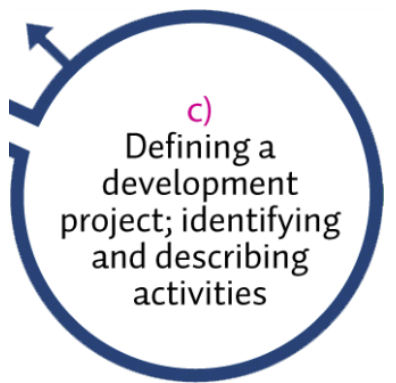

The third stage in this model is c) Defining a development project; identifying and describing activities. This is the stage of predictive recognition and description of processes related to the project, which makes it possible to develop a plan of action based on hypothesis (an initial presumption based on prior clarifications, facts and discoveries) (Raij, 2013). This stage also includes a personal study plan whereby students become collaborative partners in the progression of the integration project.

Previous analysis of literature, survey research, and initial workshop observations together are integrated to inform an action plan for progress in the integration.

Events and activities. The task force meetings to design and plan out of the implementation phase of the AEHR project took place monthly, and by email. A decision was made to meet on a weekly basis during the actual "go-live" implementation of student activities in the AEHR platform and sooner if needed as a strategy to provide extra support to the faculty for one-on-one mentoring as well as provide transparency to the project logistics. All faculty members received an open invitation to the open lab meeting. Topics in these discussions included:

a) An overview of the AEHR spring pilot

b) Development of competency outcomes

c) Planning of faculty development workshops and support structures

d) Faculty engagement strategies

e) Placement of senior RN-BSN student(s) in ELC for capstone project(s)

f) Development and evaluation strategies for course outcomes

g) Brainstorming and sharing of individual learning from AEHR project

The curriculum Integration Support Specialist from the vendor company assigned to Liberal Oak College provided orientation and integration information on the 
LOCAEHR platform usage via one-on-one webinar meetings, large group webinar meetings, email contact, and small group webinar support with faculty and staff. The suggested integration process form the vendor was to follow a novice to expert model and begin slowly in the first semester to integrate with simple activities such as data entry documentation of vital sign values. The Experiential Learning Center (ELC) director managed the spring pilot project with the AEHR project faculty lead as support and guide. In addition, faculty were provided access to an online faculty collaboration network for 24/7 online information, video demonstrations, example assignment templates, and LOCAEHR access. The Liberal Oak College Information Technology (IT) department assigned a person to the AEHR task force to assist and participate in the integration process. Student personal study plans were designed with RN to BSN leadership students. A field trip and meeting with a local healthcare facility informatics team discussed new graduate informatics knowledge, skill, and attitude expectations.

Discovery and outcomes. The RN-BSN online program faculty collaborated with the AEHR leaders to create the new clinical leadership placement criteria in the school of nursing experiential learning lab. RN students joined the integration project process as part of their leadership course and became collaborative members on the integration team. Study plan projects were designed using a combination of their leadership course objectives, their personal experiences as currently practicing RNs and the current needs of the AEHR integration. Products as a result of this win-win collaboration are leadership skills for the student in curriculum design in an AEHR, faculty development processes in the form of products and presentations created by the student, and evolution of the $A E H R$ 
integration as a whole as the faculty develop their informatics knowledge, skills, and attitudes.

Support strategy activities created and implemented to engage the faculty members included small 3-4 person group meetings in the computer lab or one-on-one support with the ELC director, curriculum integration specialist via webinar and/or lead faculty support person. As a result, scheduled meetings with individual faculty for LOCAEHR assistance proved to be more fruitful in gaining acceptance of the AEHR platform for courses. The LOCAEHR project leaders continued their scheduled weekly Friday meetings for the purpose of project collaboration and ongoing faculty development. These meetings were open to all faculty members and nurse educators on a drop-by basis in the nursing schools computer lab.

Nationally accepted and recognized QSEN and AACN curricular guidelines for informatics, discussed in chapter 1 , acted as the scaffolding guidelines for assignment and activity development in the LOCAEHR. Administrative support for the integration was recognized and supported. Since the nursing school was undergoing a major overall curricular revision "change over" or "phase in" period, planning of student learning activities in the new academic electronic health record platform became a part of the overall curricular change process; a tool to be used as part of the revised curriculum. The college president participated by inviting an informatics specialist guest speaker for a group of over 35 faculty participants at a special lunch lecture to discuss the future of healthcare information management and technology. The next stage will focus on the project evolution by discussing and highlighting new ways of doing. 


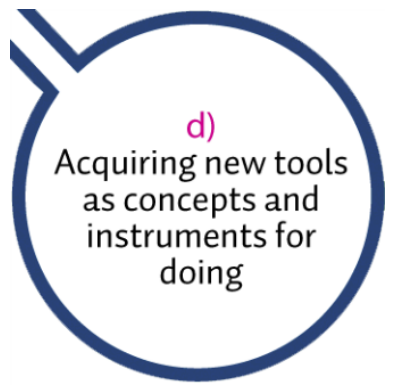

The fourth stage in this model is d) Acquiring new tools as concepts and instruments for doing. The focus on this stage is the use of existing theories and models, and subject related concepts, to create instruments for doing. The model includes a workshop activity as part of this stage (Raij, 2013).

Events and activities. Nursing students brought in to work on personal study plans created products in the LOCAEHR platform in the form of instructional documents, evidenced based practice informed assignment templates, and case study critiques. These products became part of the faculty development and integration of the LOCAEHR platform into the nursing curriculum. For example, the first student project consisted of research and development of an evidenced based nursing assessment note to be used by students at the Liberal Oaks College both in the lab environment as well as with select patients in the community.

The RN to BSN student, which developed this documentation template, presented her process and finalized product at a faculty development workshop. She emphasized her position as a novice AEHR learner, the support structures available for using the platform for assignment development, and the total investment time it took to get from concept to finished product. Her position as a student learning and doing in this new paradigm then sharing her experience was purposely intended to promote the learning and doing process to encourage and motivate faculty engagement. The result of her work in this project was a new product; a template tool for students to use for focused head to toe nursing assessment documentation. 
Collaboration with the instructional technology (IT) department resulted in a creative idea, which included recycling of equipment within the school of nursing. The idea was to create an environment in which students can practice integrating documentation with nursing skill practice in a safe low-stakes learning environment. Since the IT department was upgrading their computer lab with new equipment, and the current AEHR platform was web-based, which meant it could function on all computers, they "recycled" 8 computers from the computer lab and installed them in the nursing lab. As a result, a newly designed eight-bed patient-ward simulation room was finished in June 2012. The nursing lab gained bedside charting stations for AEHR use. Students can now learn and practice point-of-care documentation, the most effective way of using an EHR information management and documentation system in practice.

Discovery and outcomes. Summary of the learning concepts and new tools integrated into the spring pilot project includes:

- A newly designed ward with bedside computers (Figure 9)

- Creation and implementation of four AEHR documentation assignments

- Experiential Learning Center director in new role as "super user" for LOCAEHR

- Creation of theory-based customized functional health pattern AEHR template for student documentation in clinical community sites

- Assignment integration plan template for next two years (Appendix E)

- Strong professional relationship between lead faculty and curricular integration specialist

- Development of patient charts from faculty case studies

Ideas and suggestions from faculty during semi-structured interviews were used to inform, adjust, and support the integration. The next stage discusses problem solving processes and project logistics implemented and adjusted to promote the integration process. 


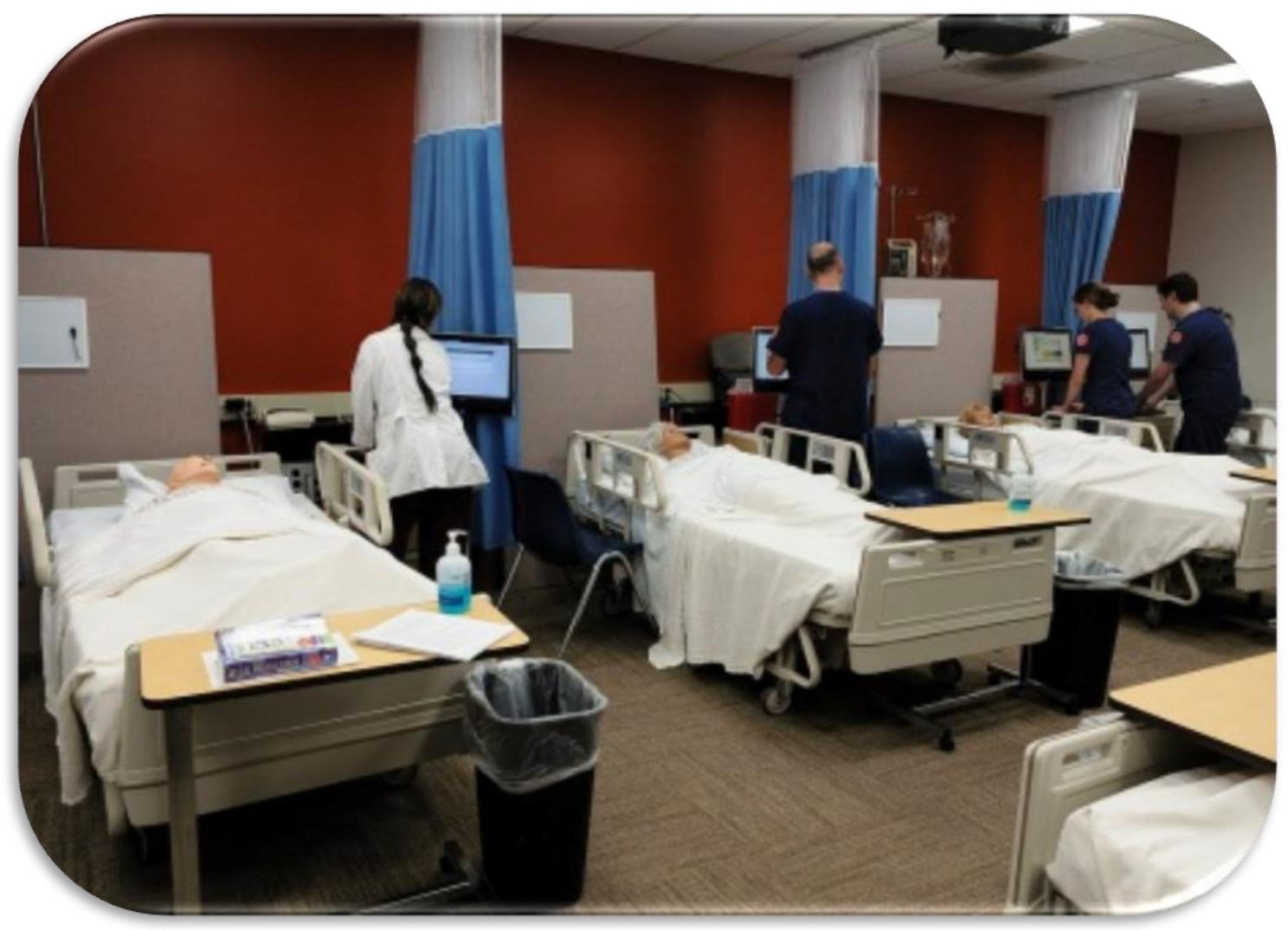

Figure 9. A newly designed eight-bed patient-ward simulation room was finished in June 2012. Since the IT department was part of the transdisciplinary team and were up-to-date on the AEHR integration process, they "recycled" 8 computers from another scheduled IT project upgrade occurring elsewhere at the college, and the learning resource center gained bedside charting stations for AEHR use. Students can now learn and practice point-of-care documentation, the most effective way of using an EHR in practice. Practicing documentation and data mining at the bedside adds to the quality and safety for patients because data immediately enters into the system as it is gathered making it readily accessible to all members of the healthcare team. Students also learn to incorporate technology into their nursing practice as they practice nursing and AEHR documentation skills together. 
e)

Cooperating by

creating something new. Developing functional and problem solving skills
The fifth stage in this model is e) Cooperating by creating something new. Developing functional and problem solving skills. In this stage continuous evaluation of the implementation project and personal learning process continue as new habits of action and problem solving skills are tested (Raij, 2013). The leaders of the integration project met frequently with faculty leads during staff meetings and curriculum meetings to discuss and troubleshoot logistics of integration. Semi-structured interviews were scheduled and arranged with a diverse mix of full time and part time faculty for evaluation purposes, as well as build rapport, provide support, and an inform faculty informatics knowledge skills and attitudes.

Events and activities. Key elements uncovered during faculty interviews as barriers to the integration process and strategies that facilitated the integration process were folded back into the integration project by way of new approaches. One-on-one meetings continued between faculty leads in specific courses and the project leaders to promote and support the integration activities with students. Ongoing strategies for integration included a) verbal feedback sought from students in praxis meetings, b) onsite visits from project leaders to orient and support clinical instructors and students, c) increased feedback evaluation time for faculty to do assignment critiquing, d) superuser model of faculty and student support implemented in the skills lab, and e) instructions and assignments adjusted for appropriateness and clarity. 
Discovery and outcome. Several faculty members created new ways to use the

LOCAEHR effectively as nurse educators.

- Modification of the LOCAEHR assessment note to fit the particular theory ideas that are being taught in the didactic course.

- Creation of a bank of common feedback notes which could be copy/pasted it into student assignments.

- Comparative analysis of student assignments across clinical sites for quality assurance of clinical instructor feedback across different clinical sites.

Learning paradigm concepts highlighted as the AEHR integration project evolved to became part of the curricular threads are a) use of students as collaborators in curriculum design, b) point-of-care electronic documentation and information management, and c) importance of consistent student feedback mechanisms. In addition, the lab was undergoing a major remodeling project. As part of the new ELC standards and learning paradigm, computers were installed at all simulated nursing workstations, and bedside stations. Real-time documentation and information management using computer technology was included as an expectation in the learning labs. The next stage continues with evaluation processes. 


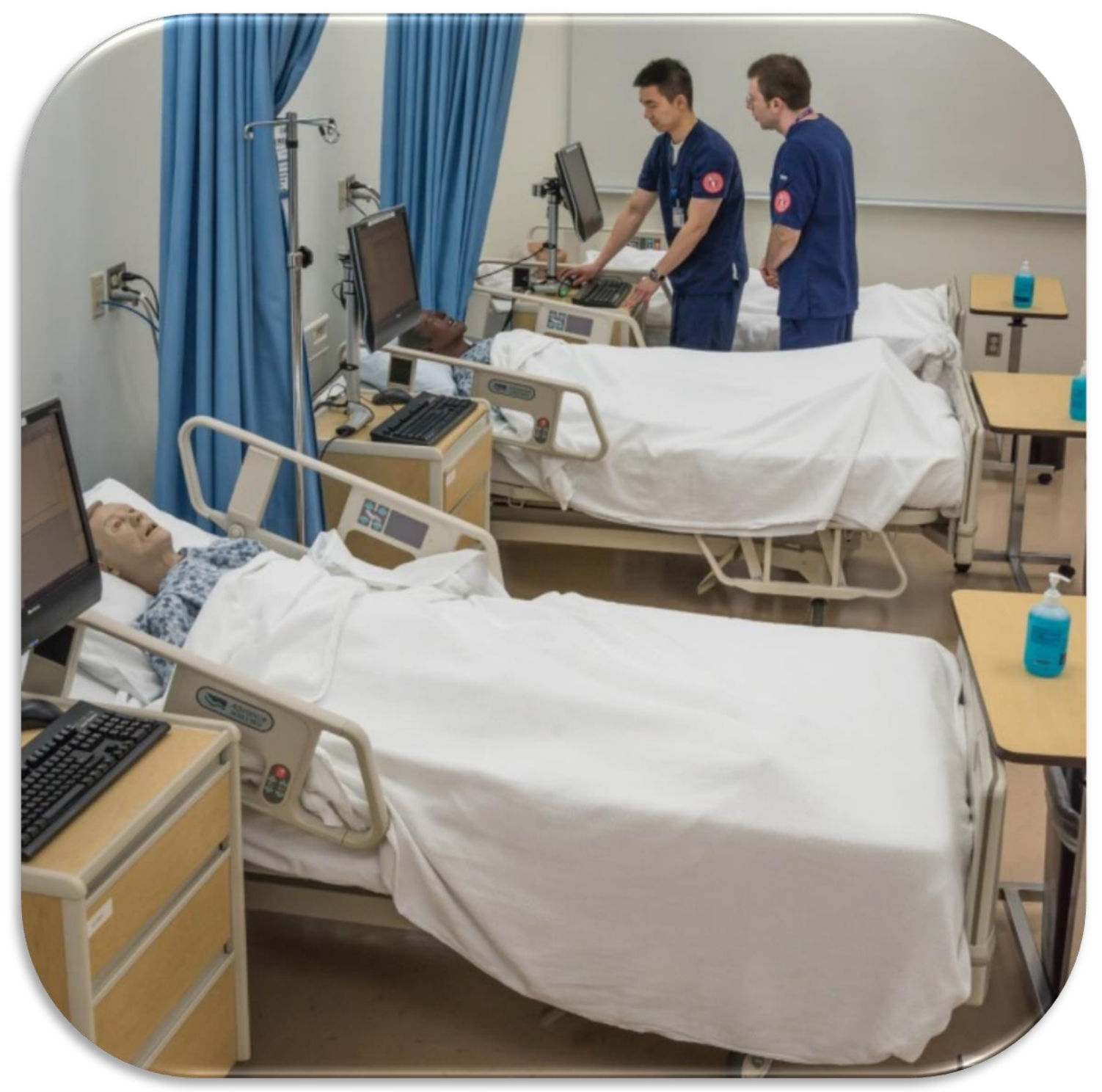

Figure 10. Additional lab space developed and finished in August 2013. This new area also included beside computers. Students can now practice their nursing lab skills for integrating human interaction with technology point-of-care documentation. This is now a permeant change in the nursing skill lab expectation at LOC: if you do a skill, documentation is expected. 


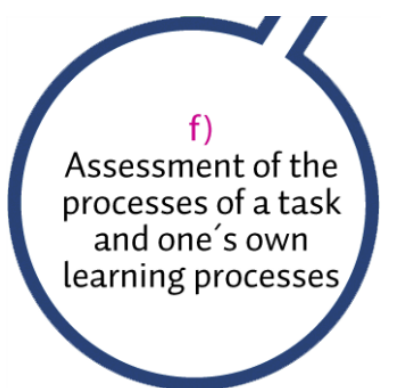

The sixth stage in this model is f) Assessment of the processes of a task and one's own learning processes. This stage is the ongoing evaluation throughout the project as the AEHR spreads across the courses and classes. Personal learning regarding the project leadership and faculty development occurs as adaptive expertise builds (Raij, 2013; Reil, 2010). This stage includes ongoing report updates of the project at faculty meetings as well as observations and analysis of student behaviors and assignment artifacts. Faculty development was continued through scheduled mentoring sessions, open workshops, and the use of resource persons available for each class. For example, the lab director became a significant resource person for "just-in-time" learners.

Events and activities. Data from surveys and interviews informed faculty development support approaches and methods. Nursing faculty members were reminded that their expertise regarding the nursing basics, which includes knowledge about documentation and concepts of patient data, assessments, interventions, and plans of care, is an important part of student learning. EHR technology is new, and all but a very limited few nurse educators and nursing faculty members are familiar with the technology. By redesigning assignment templates, and incorporating faculty expertise through cases into the electronic format, basic theoretical nursing concepts learned and practiced by seasoned faculty members were transferable into the AEHR platform.

Discovery and outcomes. During weekly meetings, the two lead members of the integration project analyzed and discussed the project process, their own personal learning process, barriers, strategies, and insights. In addition, the human dimension of 
caring and support was a significant factor in keeping a positive outlook on this change process. The project leaders worked to keep a collaborative perspective with the faculty despite tensions with the adaptive change process. Compromise and communication became key components for adaptation to avoid the temptation of "work-a-rounds" strategies to find an easier way. Meetings and discussions about "what works" and "what can be adjusted" between resistant educators resulted in further support and assignment adjustments. For example, students were allowed a 2-24 hour time period window to complete AEHR documentation after their high fidelity simulation scenario sessions. In another instance, clinical students were given the option of using a WORD document to compile their clinical prep work ahead of time. Then copy and paste it into the AEHR the evening prior to a scheduled clinical day.

The importance of consistency and faculty collaboration role modeled for students was emphasized with the faculty during this development stage. The student competency survey results were shared at faculty meetings. Faculty members were encouraged to seek out assistance with grading and providing student feedback. Prime examples of student feedback in the AEHR were data mined from aggregate student assignments and compiled to serve as examples for faculty. Rubrics compiled for specific assignments improved consistency rates among the faculty.

The next stage discusses evaluation artifacts and their role in the project integration adjustments and evolution. 


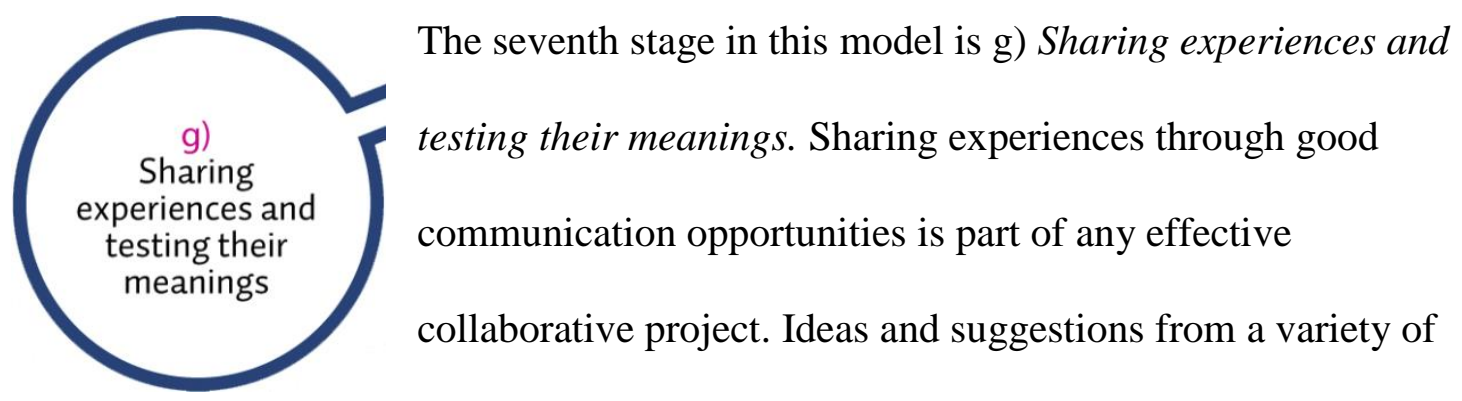

nursing experiences enrich the opportunities for creating new ways of doing. (Raij, 2013).

Events and activities. Sharing of experiences was elicited through the faculty interview process, mentoring meetings, and feedback during class work activities. Information obtained from the nurse educators during semistructured interviews folded back into the integration process in the form of quality improvements. In addition, the interview time provided an opportunity to assess knowledge, and provide support and mentorship for the process.

Discovery and outcomes. Some of the key points mentioned during the interview became ideas for adaptation of the system. The following is an example of how interview data applied.

Theme 1. Nurses have a major role in information management and workflow design in the healthcare setting. The overwhelming majority of the interview participants indicated that EHR's provide tremendous benefits to the quality and safety of patients in the healthcare setting and that nurses play a significant role in the management of these systems.

Having an appreciation for the EHR is a very powerful finding. According to a quantitative study on the relationship between nursing documentation and patient morality by Rothman, Solinger, Rothman, and Finlay (2012), findings were consistent in that nursing assessments are strongly correlated with in-hospital and post-discharge 
mortality, suggesting that nursing assessments are sensitive indicators of a patient's condition. Stressing and role modeling the importance of strong documentation skills improves the quality and safety of patient care. Providing avenues to share documentation feedback for students among faculty and providing rubrics and examples helped promote faculty informatics knowledge and teaching skills. Acknowledging the end user in design of informatics is the key to adoption and effective use for the quality and safety with patients (Koppel, 2012). Developing procedures and strategies to address faculty concerns with user design must be considered moving forward.

Theme 2. Students need adequate knowledge and support to develop both nursing and information management skills. All faculty participants recognized that students need support to transition the performance of nursing skills, and be proficient with documentation expectations of nurses in the clinical practice environment.

Providing student with the knowledge, support and opportunities to practice information management and documentation skills in the AEHR is invaluable for increasing confidence and decreasing anxiety and stress in the clinical settings. Students with proper support and effective feedback build skills, which transfer to concepts in similar clinical situations. Faculty mentoring and support via email and one-on-one appointments by project leaders and course coordinators facilitates the educators' ability to provide support to students.

Theme 3. Nursing faculty members are poised to play a significant role in educating nursing students regarding healthcare informatics regardless of the faculty member's previous EHR experiences. As experienced RNs, as well as educators, nursing faculty members hold a wealth of knowledge and information regarding nursing skills and nursing documentation. Additionally, faculty participants contributed great ideas about the integration process. 
The majority of clinical adjuncts that work with students in the clinical settings are also employed by healthcare sites with and without EHR systems. Their expertise in organization and prioritization of nursing work in clinical situations is invaluable to students whether they use the EHR system or not. They keep the students focused situation management; the priority of "what is going on?" to help them develop and exercise critical thinking skills.

Theme 4 and 5. Significant barriers and resistance to the academic EHR negatively affects the AEHR implementation process. Strategies that promote faculty support with the academic EHR have a positive influence in the AEHR implementation process.

It makes sense that keeping a positive attitude about the AEHR integration and focusing on the many benefits for the students will promote a smoother integration process for all. Students are very observant and notice negativity, which may impede progress with technology innovation. As mentioned by interview participants, userability issues should be noted and addressed promptly and user support needs to available and reliable. Strategies implemented for faculty support included increasing time for grading and feedback, adjusting templates and directions for clarity, and development of "model cases" for comparison.

The next stage discusses competency and growth as a result of the AEHR integration. 


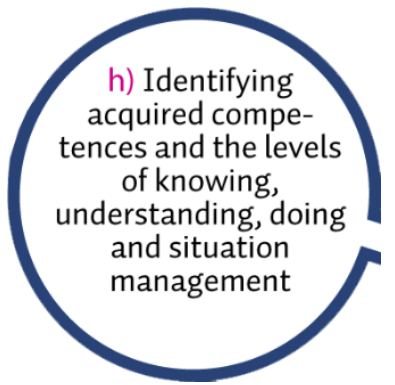

The eighth stage in this model is h) Identifying acquired

competencies and the levels of knowing, understanding, doing,

and situation management. This is the reflection phase of the

project. This stage is a time to see if the goals set out in earlier in

the planning stage have been met, are in the process, or need revision.

Events and activities. Reviewing the artifacts in the form of students'

assignments in the AEHR provided a rich demonstration of feedback by faculty for student documentation. Exemplar assignments were printed out from the AEHR and used as samples for accreditation purposes and faculty development examples. The Student Confidence Assessment with LOCAEHR Survey, mentioned in part 1 of this chapter, was designed specifically to gather information about the assignments created and performed by students in the AEHR during nursing courses. Seventeen questions regarding confidence level from 0 to 5 were rated $(0=$ not applicable to $5=$ know enough to teach others). The cut-off level for a rating of confidence with the LOCAEHR system is 3 , know enough to use competently. Each question refers to a particular assignment that students completed in the LOAHER.

Discovery and outcomes. Although the response rate is lower than desired, information collected provided some insights as to student confidence in using the AEHR for specific nursing related assignments in the fundamental skills lab on campus. The percent values compare students that self-identify as confident using the AEHR versus those that would like more help with the technology. A summary was compiled from the results in Appendix K into two sections; confident and needs help. Further division of 
information is from simple to complex. For example knowledge and understanding of concepts such as confidentiality or patient chart components, then data entry skills which requires understanding and application and third documentation skills which requires understanding, interpretation, and application. Students practiced their skills by working with and computers, manikins, and lab partners in the lo-fidelity labs. The act of "doing the skill" rated higher if students practiced it more frequently in the lab settings. Identification of chart components, measuring and documenting the vital signs of their lab, were rated higher than skills requiring more critical thinking such as physical exam documentation. Stemming from the analysis, more practice and student feedback in needed to increase the student confidence with information management and documentation skills. Another point could be that the assignments should be test driven for clarity and userability with "test students." These more complex assignments might need revamping or to be moved the next level in the nursing program. The summary in Table 18 provides student confidence rating snapshot with current assignments.

Table 18

Summary of Student Confidence Ratings with LOCAEHR

\begin{tabular}{lrrc}
\hline Concept/task preformed in LOCAEHR & Need help & Confident & USE IN LAB \\
\hline Understanding confidentiality & $9.3 \%$ & $90.7 \%$ & Yes \\
\hline Identification of patient chart components & $37.0 \%$ & $63.0 \%$ & Yes \\
\hline Data entry: intake and output & $47.3 \%$ & $53.7 \%$ & Yes \\
Data entry: vital signs & $14.5 \%$ & $85.5 \%$ & Yes \\
Data entry: risk assessment grids & $49.1 \%$ & $50.9 \%$ & Yes \\
Data entry: pain assessment grid & $31.5 \%$ & $68.5 \%$ & Yes \\
\hline Documenting: focused physical assessments WNL & $42.9 \%$ & $57.1 \%$ & Yes \\
\hline Documenting: focused physical assessments not WNL & $52.7 \%$ & $47.3 \%$ & Yes \\
\hline Documenting: wound assessment information & $78.6 \%$ & $21.4 \%$ & Yes \\
\hline Documenting: mental health assessment information & $85.5 \%$ & $14.5 \%$ & No \\
\hline Documenting: information in open text boxes & $51.8 \%$ & $48.2 \%$ & Yes \\
\hline Documenting: clinical functional health pattern information & $57.4 \%$ & $42.6 \%$ & No \\
\hline Documenting: nursing procedures \& interventions & $66.7 \%$ & $33.3 \%$ & Yes \\
\hline Documenting: nursing care & $54.7 \%$ & $45.3 \%$ & Yes \\
\hline Medication administration using LOCAEHR & $61.8 \%$ & $38.2 \%$ & Yes \\
\hline Documentation: of a handoff report in LOCAEHR & $78.9 \%$ & $21.1 \%$ & Yes \\
\hline
\end{tabular}




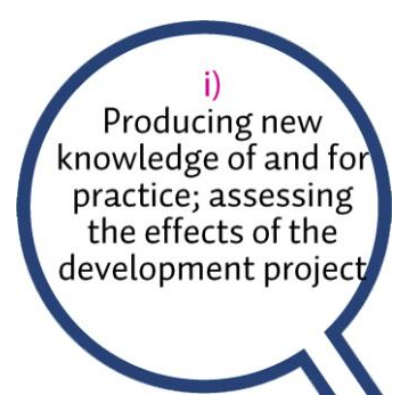

The ninth stage in this model is i) producing new knowledge of and for practice; assessing the effects of the development project.

Events and activities. The new knowledge gained from assignment artifacts in the form of faculty feedback comments provided rich data. The course coordinators were able to get a more comprehensive picture of the type and quality of feedback students were receiving from faculty members. These artifact documents provided an avenue for assessing quality and consistency in student feedback among various clinical sites and situations. Information elicited from faculty interviews and student assessment and evaluation tests and surveys provided good assessment data for the progress and applicability of the AEHR activities created. For example, Semester 3 clinical instructors used a template designed from the syllabus for student prep prior to clinical. This document provided an avenue for the nurse educator to evaluate the student's level of preparedness prior to a scheduled clinical day. The nurse educator had the ability to email the student or make comments in the template in the AEHR to provide immediate feedback. Students' make better use of their clinical day by making adjustments in their prep information ahead of time, prior to doing direct patient care. In addition, the clinical nurse educator could better prioritize the needs of their multiple students by knowing the patient situations and data ahead of time for each student.

Discovery and outcomes. Several significant teaching and learning key points as a result of this project are, first, that some students and faculty noticed a smoother 
transition from school lab experiences to healthcare clinical site EHR systems such as Epic $^{\circledR}$ or VistA ${ }^{\circledR}$ with student that were exposed to the AEHR in their semester 1 and 2 school lab courses. Second, students are expected to document as they learn new skills in the lab setting. Third, faculty feedback on student skills and documentation is very important for increasing the students' desire to use the AEHR system, as well as the success of the student in this new innovative leaning environment.

Faculty attitudes, whether positive or negative in regards to the AEHR system, may impact the students progression and competency with the system. The following quote from a student exemplifies this point:

“...feedback is so limited through LOCAEHR, it makes the whole exercise seem fruitless. What I really want to know is how well I am capturing the pertinent information, how accurate I am, and how well I am using appropriate terminology and abbreviations." 
ELECTRONIC HEALTH RECORDS IN NURSING EDUCATION

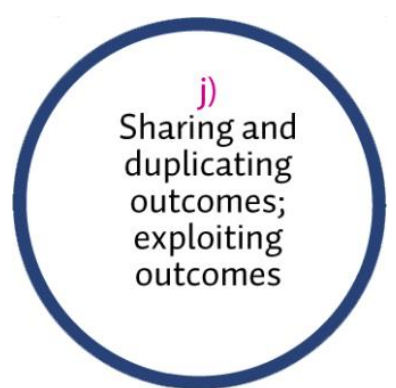

Events and activities. Graded AEHR assignments were presented during the

AEHR project update during a March 2013 nursing faculty assembly meeting. Multiple examples of the student work that resulted from the project were showcased as outcome evidence in meeting curriculum requirements for the AACN essential IV on information technology for view and evaluation during the school of nursing accreditation visit. The analyzed and compiled feedback examples for student assignments were crowd sourced for quality information to provide a feedback data bank for development of a grading rubric tool that nurse educators now use while grading student AEHR assignments. An abstract of the AEHR project process and outcomes was presented as part of a larger 30minute podium presentation on conceptual curriculum integration at a national nursing research conference, which was well received by over 120 session attendees.

Discovery and outcomes. As a result of user ability issues that came up during evaluation of the academic EHR project, an AEHR platform which addresses usability and increased academic support was sought and the process of concept transfer with current AEHR-based assignments is in progress. In addition, the LbD action research model has been incorporated into an upcoming grant funded Community Engaged Research to the Classroom summer collaborative research project. The details of which will be discussed in the next chapter on research recommendations. 
ELECTRONIC HEALTH RECORDS IN NURSING EDUCATION

\section{Summary of Key Evaluation Elements for LbD and Study Limitations}

Creswell (2008) provides a list of eight criteria to consider for assessment of quality in practical and applicable action research. In the following narrative summary, these eight quality criteria questions are discussed with answers that address the research components of the AEHR project.

\section{Does the project clearly address a problem or issue in practice that needs}

to be the solved? The answer for this would be yes. The issue is one of providing the students of a small school of nursing in a liberal arts college, the opportunity for development and practice of informatics knowledge, skills, and attitudes in a low stakes environment. Stemming from previous findings in the literature, faculty development plays a major role in the success of any healthcare informatics curricular evolution. The project provided the school of nursing with an avenue for faculty development of knowledge, skills, and attitudes by providing access to and support in an evolving academic informatics environment. Faculty development opportunities were available by way of online resources, group interactive workshops, one-on-one mentorship appointments, weekly drop-in sessions, and super-user in-class assistance. The collaborative nature of the LbD project framework honored faculty expertise while engaging the faculty in the AEHR curricular learning process and evolution.

\section{Did the action researcher collect sufficient data to help address the}

problem? Yes, there was sufficient data to help address the problem. The research data collected from the Nurse Educator Competencies Assessment Survey confirmed previous literature findings from chapter 2 . The majority of nurse educators do not use informatics 
technologies for documentation of patient data, assessments, interventions, plans and care and discharge planning unless they are working in a healthcare facility, which requires this skill from them on a routine basis (Curran, 2008). The results for this case study group revealed computer applications for documentation for example: hospital system for documenting patient data, assessments, interventions, plan of care, and discharge planning rated the lowest for faculty knowledge (60\%), skill (56\%), and access (48\%). This research finding specifically correlates with the assumption by Curran (2008) mentioned in chapter one, "One does not learn technology unless there is a compelling reason to do it" (p. 524). In addition, findings also indicated that many of the nursing faculty had varied baseline understandings of the use of EHR in the healthcare setting. This was significant in designing the faculty development program in that, KSA AEHR activities as a "one-size-fits-all" approach would be inappropriate for this group whereas a catered development program may work.

The survey data collected for specific faculty development needs, $A E H R$ Integration Project Faculty Needs Assessment Survey, provided information for design of faculty development workshops, mentorship appointments, and instructional materials to address the comprehension level, competency level, and opportunity for interactive usability of this specific group of faculty learners.

The rich responses elicited from interview data provided a clear picture of the faculty experiences while learning and working with students in the AEHR platform. Many of the design ideas, technical issues, barriers, strategies, support mechanisms, and concerns folded back into the project as adjustments in the project activities, 
communication, support structures, or assignment logistics in the AEHR platform. In addition, these interviews provided time to acknowledge the faculty efforts and struggles learning and working in a new paradigm, and elicit support for the project moving forward. The ten nurse educator/faculty members were very candid in their responses: they were respectful of the professional atmosphere yet did not "pull any punches" in the interview process. Follow-up focus group interviews for the next phase of the project may provide more opportunities for logistics problem solving, and discussions regarding appropriate assignment development and activities for students.

\section{Did the action researcher collaborate with others during this study? Was}

there respect for all collaborators? Collaboration is a significant structure for the study and the success of the project. Without collaborating with all lead faculty members in courses, the project would never move forward. As the researcher, I promoted the atmosphere of collaboration by taking care to incorporate it through the various key project relationships. These key relationships included a) community interviews with informatics team at a local healthcare site, b) personal study plans with RN-BSN students working in their leadership courses, c) work study students hired to work in the simulation lab areas to critic instructions, act as super-users, and reverse engineer learning assignments, d) faculty members as co-designers and implementers of the project, and e) instructional technology (IT) department for high and low fidelity simulation workspace redesign. Respect for all collaborators was a part of the project ethics. 
4. Did the plan of action advanced by the researcher build logically from the

data? Yes. The survey and interview data folded back to create workshops and provide support for faculty to help them with creating assignments that highlight of nursing concepts. Throughout this study, a dynamic process unfolded which included trying out ideas, making adjustments, and exploring other ideas.

\section{Is there evidence that the plan of action contributed to the researcher's} reflection as a professional? Yes. The researcher is a faculty member of the college and currently studying for an educational doctorate. This research is about curriculum development and the researcher's experience and development as an educational leader of faculty members and students. The researcher learned a lot about faculty development, collaborative design, learning methods, knowledge skills and attitudes regarding change, as well as about the ins and outs of designing conceptual nursing assignments with an electronic healthcare platform. There is room for much dissemination from this project because electronic healthcare records are here to stay, thus finding ways to facilitate nursing education with the use of an electronic healthcare records platform is a vital current and future need for the profession of nursing education.

\section{Has the research enhanced the lives of the participants by empowering} them, changing them, providing them with two new understandings? The answer here is yes. Students that received feedback from their assignments in the new academic EHR from semester 1and 2 noticed that the transition they had into the more complicated Epic $^{\circledR}$ system at their clinical site in semester 3 was smoother and with less anxiety. Students that went to the clinical site where VistA ${ }^{\circledR}$ was used as the primary EHR 
reported being very empowered because the platform at the sites were very similar to the academic EHR. The impact on the lives of faculty may require further investigation, possibly through focus group discussions.

\section{Did the action research actually lead to a change or did a solution to a} problem make a difference? The research project led to a change in how the faculty view and implement documentation in the nursing labs at the school of nursing in several ways. Other new understandings that were significant because of the project were the need for students to learn how to document as they go along learning their skills. For example, having computers located at the bedside with the manikins in the nursing school skills lab provides students the opportunity to practice assessment data entry while interacting with the "patient". Students entering the 3rd semester come to the clinical site with an understanding that they will be expected to do extensive documentation during their clinical time in the hospital EHR. Having a background in electronic documentation reduces some of the anxiety of performing documentation in the clinical setting.

Faculty are becoming more aware of how important feedback is to students with documentation skills in addition, faculty are becoming more aware of design elements necessary for crafting concept based meaningful assignments with an AEHR platform. Documentation and information management expectations have been incorporated into the first and second semesters of the nursing program.

\section{Did the author report the action research to audiences who might use the}

information? The author reported routinely to nursing faculty meetings the progress of EHR integration in the curriculum. Additional reporting occurred through email notices 
ELECTRONIC HEALTH RECORDS IN NURSING EDUCATION

sent periodically to faculty regarding EHR workshops, EHR open lab time, and EHR one-on-one support meetings. A report of the AEHR project was published in the main college periodical. The two lead faculty members of the AEHR project process presented at a nursing research conference in the spring of 2014 as part of a podium presentation for conceptual curriculum integration.

\section{Study limitations}

To address issues of bias, and in light of critical subjectivity, I asked three educational doctoral student cohort colleagues (outsiders) to serve as critical friends during this process. In addition, I consulted with two (insiders) colleagues at the school of nursing. They helped me reflect on my role as educator and reflect on my practice (Herr \& Anderson, 2005).

The results may not be generalizable except where other readers or researchers see the application. According to Lincioln \& Guba (1985), the burden of truth lies with the original investigator, it would be wise to accumulate empirical evidence about contextual similarity, my responsibility therefore, ends in providing sufficient descriptive data to make the similarity possible.

The final chapter highlights the case study main points and offers recommendations, discusses the implications of the work for continued faculty development, ties the significance to national recommendations for higher education, and presents a plan for dissemination. 


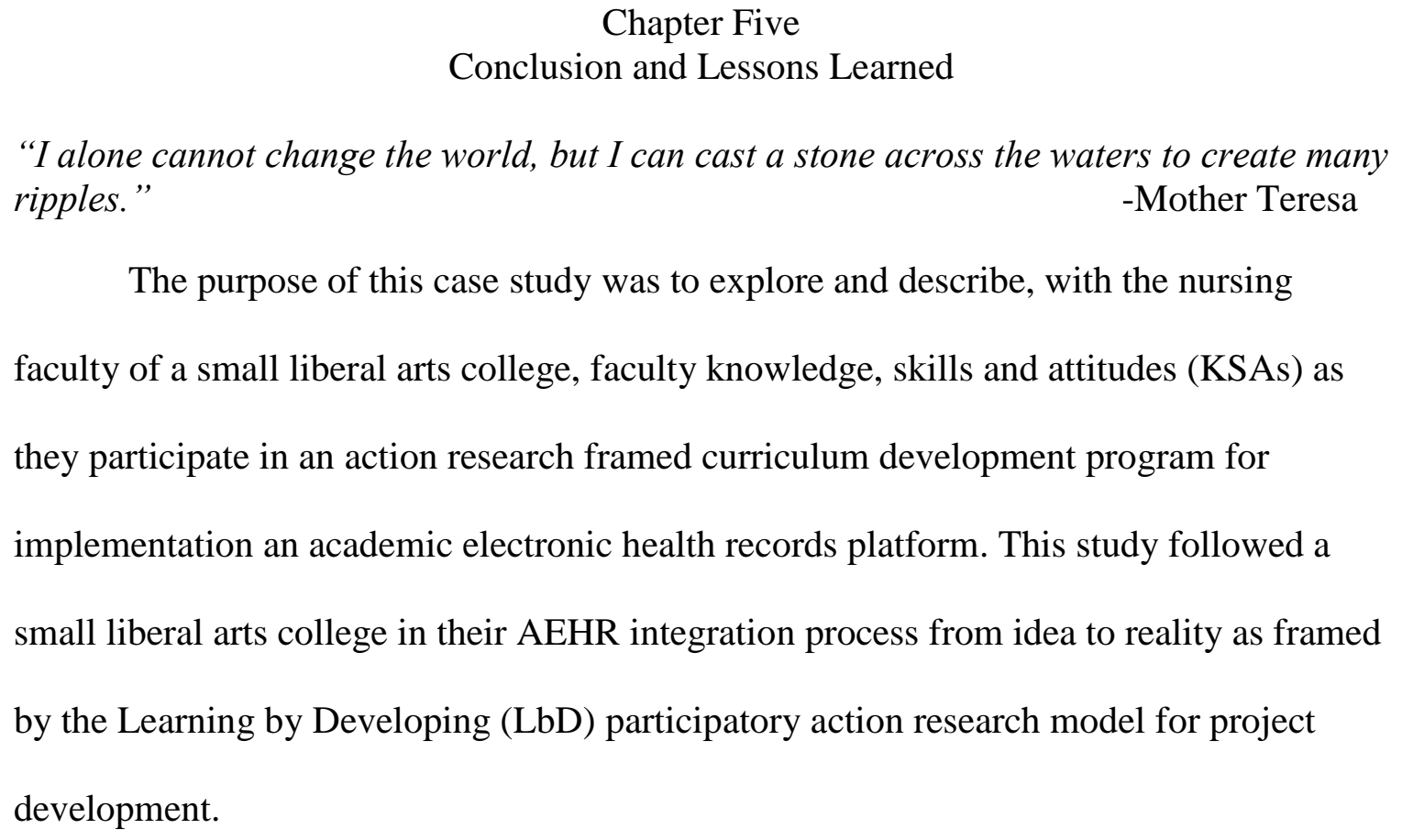

The purpose of this case study was to explore and describe, with the nursing faculty of a small liberal arts college, faculty knowledge, skills and attitudes (KSAs) as they participate in an action research framed curriculum development program for implementation an academic electronic health records platform. This study followed a small liberal arts college in their AEHR integration process from idea to reality as framed by the Learning by Developing (LbD) participatory action research model for project development.

Nursing faculty members need support to not only learn the AEHR technology for their own knowledge and skill enhancement but also to be comfortable using the technology in the provision of essential direction and feedback in the education of nursing students. The Learning by Developing (LbD) model for AEHR integration is a collaborative approach between faculty, students, and practicing nurses that takes into account the learning needs for all that will use this technology. The LbD is an action research model of learning in a professional context which involves a) knowledge in theories and models, b) knowledge embedded in skills and abilities, c) moral knowledge, and d) experiential knowledge corresponding to the components of professional competence; i) knowing, ii) understanding, iii) doing, and iv) situational management (Taatila \& Raij, 2011). As part of the LbD model, select students on the collaboration team have a "personal study plan." The products from this personal study plan fold into 
the integration of the AEHR as new knowledge in the form of informatics activities, workshop elements, and/or instructional materials.

This section discusses conclusions from the study that address the research question: What is the experience of nursing educators and nursing faculty members involved in the integration of an AEHR project framed in the Learning by Developing model at a small liberal arts college school of nursing? Triangulated data including surveys, interviews, and artifacts analyzed as part of the project for AEHR integration, illustrated and described nursing faculty experiences regarding aspects of informatics knowledge, skills, and attitudes, which folded back into the integration as the project evolved and became part of the curriculum. The findings were grouped into four themes; a) nurses have a major role in workflow design of information management systems; b) students need adequate knowledge, support, and opportunities for confidence development of nursing and informatics skills; c) nurse educators' expertise plays a significant role in healthcare informatics education for student nurses; and d) barriers and strategies negatively or positively sway the AEHR integration process.

The following parts of this chapter discusses faculty development in a collaborative process, summarizes significant findings related to Curran's (2008) literature on faculty development assumptions, outlines a follow up research-based integration project plan, and presents recommendations for nursing faculty development programs considering AEHR curriculum integration. Finally, I give my reflections and thoughts on this dynamic personal journey in educational leadership growth. 
Faculty Development: A Collaborative Process

Used as the basis to inform an integrated faculty development program in undergraduate nursing education, the list of assumptions discussed from the literature in chapter one, regarding faculty development by Curran (2008), create a baseline of considerations when designing a program for innovative curricular changes. These eight assumptions are used to frame a comparison analysis of this study's findings.

The first assumption. One does not learn technology unless there is a compelling reason to do it. Based on survey data and interview analysis in this study, this assumption held true. Faculty in academia were mostly educated prior to the integration of EHR systems in healthcare, therefore, those that are not currently practicing, as nurses in clinical settings, have no compelling reason to learn EHR systems. Survey data reveled that furthermore, if the learning curve is too steep, they [the faculty] will avoid using the system altogether and find ways to work around or avoid actively using the technology in class time by incorporating strategies such as the use of screenshots in PowerPoint slides, cut-and-paste, or resorting to paper-based methods of data collection with their students.

The first recommendation to address this would be to create situations in which technology match with pedagogy for educating students in nursing practice. Use of an academic EHR provides more opportunities for defining and exploring concepts, analyzing ideas, and creating new approaches. If nursing faculty members see the value of an academic EHR for teaching nursing concepts as well as providing comfort or students with the technology, they might be more compelled to learn about. Providing positive examples and experiences whereby the technology works for the faculty instead 
of adding to their courses, for example, replacing current student assignments with those that can be completed in the AEHR such as health assessments and care planning.

The second recommendation is to recognize nurse educators and faculty for their work in clinical practice. In order to work as a nurse educator, one must be licensed as a registered nurse (RN). The demands of service, teaching, and scholarly activity in the world of academia take away from the time that nursing faculty have left to practice in the clinical setting. As a result, nursing faculty may decide to stop clinical practice due to the demands to keep current in their practice environment; including competence in EHR systems. Unfortunately, this negatively affects nursing education. Faculty who do not have access to the various clinical EHR information systems, that nurses will use as integral components of practice, will have difficulty understanding how the nursing curriculum needs to change (Skiba, 2006). Nurse educators should instead be motivated to practice in the current paradigm of nursing and get credit for the work they do as RNs, mainly because this work informs evidenced based teaching practices.

Nurse educators pull from their RN experiences in the form of narrative pedagogy, providing evidence and information regarding current trends in nursing practice. Educators that practice in the clinical setting, bring these trends into the classroom. Currently, the world of academia views the work of RNs as "extra" and unnecessary for nurse educators. If the mission of the nursing profession is truly that of creating life-long learners, the academic environment should honor this mission by recognizing those that partake in this life-long learning process as practicing RNs and credit them with the hours to academic scholarship or service. Faculty would then be 
more inclined to gain informatics in the practice setting such as data mining skills, decision-support management skills, clear concise documentation and organization of data, real-time documentation skills, SBAR communication, multidisciplinary collaboration through patient case management, priority and organization within and across multiple patient situations, and priority action-management strategies to address urgent patient situations. All of which could be incorporated in classroom settings.

The second assumption. Technology is a tool used to improve nursing practice rather than an end in itself. This assumption proved to be a common belief held by many nurse educators and faculty. Findings from interview data revealed that nurse educators agreed about the benefits of electronic healthcare systems such as a) real-time access to data, b) multiuser availability, c) improved data integrity, d) improved clarity in communication, e) improved organization and, f) mitigation of errors.

One recommendation to address this would be to highlight the rationale and present the big picture for students regarding informatics technology by incorporating the benefits of data mining, and the connection between real-time documentation and patient safety. The Quality and Safety Education for Nurses (QSEN) informatics competencies (as illustrated in Table 2) incorporated into all nursing programs could inform the structure of informatics curriculum outcomes for students.

The third assumption. Technology needs to be introduced to nurses first as students, and not just when they enter the practice field. This assumption was sustained by the interview data but not necessarily through the actions or behaviors of the nursing faculty in the early AEHR integration period. Faculty agreed that students need 
knowledge and support when learning in EHR systems in order to reduce their anxiety and to facilitate their transition to the clinical setting. Other concepts faculty considered important were for students to have an understanding of patient confidentiality, as well as the concept of documentation and how to incorporate this EHR task into nursing workflow. Many faculty commented that students gain a lot of their EHR skills through feedback on EHR assignments and role modeling by practicing RNs in the clinical setting. Even though faculty understood this assumption, they had a hard time operationalizing it for the students without lots of mentoring and support from the integration team.

Several recommendations to address this issue, which proved fruitful for this case study integration, would be to engage faculty in the integration by honoring their opinions, ideas, suggestions regarding assignment composition, time to grade, and ways to incorporate AEHR into nursing skills practice. In addition, provide ongoing support and mentoring through interactive workshops, private meetings, and onsite "Superusers".

The fourth assumption. Technology can be a vehicle to transform how we teach nursing concepts to students; it requires an interactive engaged learner. This assumption is confirmed through observations at workshops, during class observation periods in the low fidelity simulation lab, and through artifact analysis of feedback and student assignments. When the AEHR was actively used as a prep document for students in the clinical setting on a weekly basis, clinical faculty members were able to give asynchronous feedback through the system. Students that did not receive feedback on their assignments, or were under the direction of faculty that chose not to use the system, 
had a negative opinion regarding the AEHR; some considered it "busy work." Faculty mentoring strategies employed to address some of these instances had good results. Recommended action would be further evaluation with faculty to elicit effective mentoring or support in this area. Additionally to consider usability issues with the current AEHR platform and investigate ways to address this as the project moves forward.

The fifth assumption. Creating the most realistic environment for students will ease their transition into actual practice setting. The information obtained from the participant interview data, and results from the student survey on self-reported confidence in the AEHR, shows data that matches with this assumption. Faculty commented about future pedagogic strategies, such as creating assignments that closely match with what they [the students] should be doing in clinical settings, is an important element in transitioning students to the practice environment. Additional data from the HESI high stakes testing scores revealed upward trajectory rates in comparison to previous Liberal Oak College scores and national informatics scores for the fundamental semester cohorts (had AEHR exposure), and the third semester cohort students (transitioned to clinical practice EHRs after using the AEHR platform). A recommendation would be to create evidenced based teaching assignments based on student focus groups.

The sixth assumption. Faculty development activities must be sensitive to the faculty's historic expert role. Information in support of this assumption was elicited through many workshop observations, mentoring observations, and interview opportunities with nurse educators and faculty. Nurse educators appreciated that their 
opinions and voices for collaborative creation and design counted as part of the project. Although the learning curve was difficult at times, and technical difficulties did arise, the interview data overwhelmingly indicated they felt supported throughout the process. Nurse educator pedagogic expertise was sought and their ideas and syllabus content was incorporated into custom assignment templates for students' activities. The recommendation would be to continue the support and engage key faculty members to become "Superusers."

The seventh assumption. Experiential learning of technology and informatics concepts by faculty will improve the ability to teach them. This was true over time. According interview data, workshop observations, and assignment analysis, nurse educators that spend time in the system learned more and thus created short-cuts for themselves, navigation groups, and feedback banks. The recommendation would be to provide ample time for faculty to learn the system, provide online materials for review, and include them in classroom semester-start orientation sessions.

The eighth assumption. Informatics competencies are the foundation for learning to use technology effectively to deliver high quality patient care. Faculty mentioned through interviews the importance of confidence and competence for students in the EHR.

\section{Summary of Themes}

Four major themes evolved as significant faculty experiences during the AEHR integration. The first theme is nurses have a major role in information management and workflow design in the healthcare setting. Faculty members realize that nurses are 
imperative to the information management in healthcare facilities and that their use or misuse of EHR systems is depended on the quality of informatics knowledge, skills, and attitudes competency. Competency with informatics processes involving data integrity, clear communication, and mitigation of errors improve the safety and quality of healthcare for all.

The second theme is nursing students need adequate knowledge, support, and opportunities for practice to facilitate their combined development of nursing and information management skills. Faculty members also realize that students need informatics education. Educating nursing students to be active competent participants in this nursing technology paradigm ensures patient care advocacy as healthcare complexity evolves into the future. Providing students support through feedback and role modeling, learning how to incorporate the EHR into the nursing workflow, and developing a clear concept regarding documentation reduces student anxiety and builds confidence to face the complexities of situation management in nursing.

The third theme is nurse educators play a significant role in the healthcare informatics education for nursing students regardless of prior level of EHR experiences. Honoring the faculty expertise and providing support through collaborative teamwork is imperative to the success of AEHR integration. In this light, the AEHR incorporates as a tool for aiding the conceptual nursing education of information/data management, nursing assessments, communication, documentation, medication management and safety, etc. 
The fourth theme is that significant barriers and resistance to the AEHR negatively affects the AEHR implementation process. Conversely, strategies that promote faculty use of the AEHR have a positive influence in the AEHR implementation process. Although powerful forces have created the market drive to improve clinical information education for healthcare students at the academic level, change cannot occur without nursing faculty involvement to structure and implement informatics experiences for students (De Gagne, Bisanar, Makowski, \& Neumann, 2011). Faculty development is the key to successful integration of informatics in undergraduate nursing education. Building a strong program based on a collaborative Learning by Developing framework facilitates buy-in from faculty, adaption to technology, and leads to innovative practice changes geared towards improved patient safety and quality.

\section{Recommendations for Continued Collaborative Integration}

Based on previous literature findings and outcomes from this case study, a proposal for continuation to the next phase of the integration project at this nursing school approved. The triangulated data findings from surveys, interviews and artifacts, provided evidence for status assessment to guide the next phase of the project. The forcefield analysis in Figure 11 provides a summary of this information, which serves to focus and guide AEHR resources and energy for the overall goal of supporting faculty with the integration of informatics competencies into student nurses' learning experiences. 


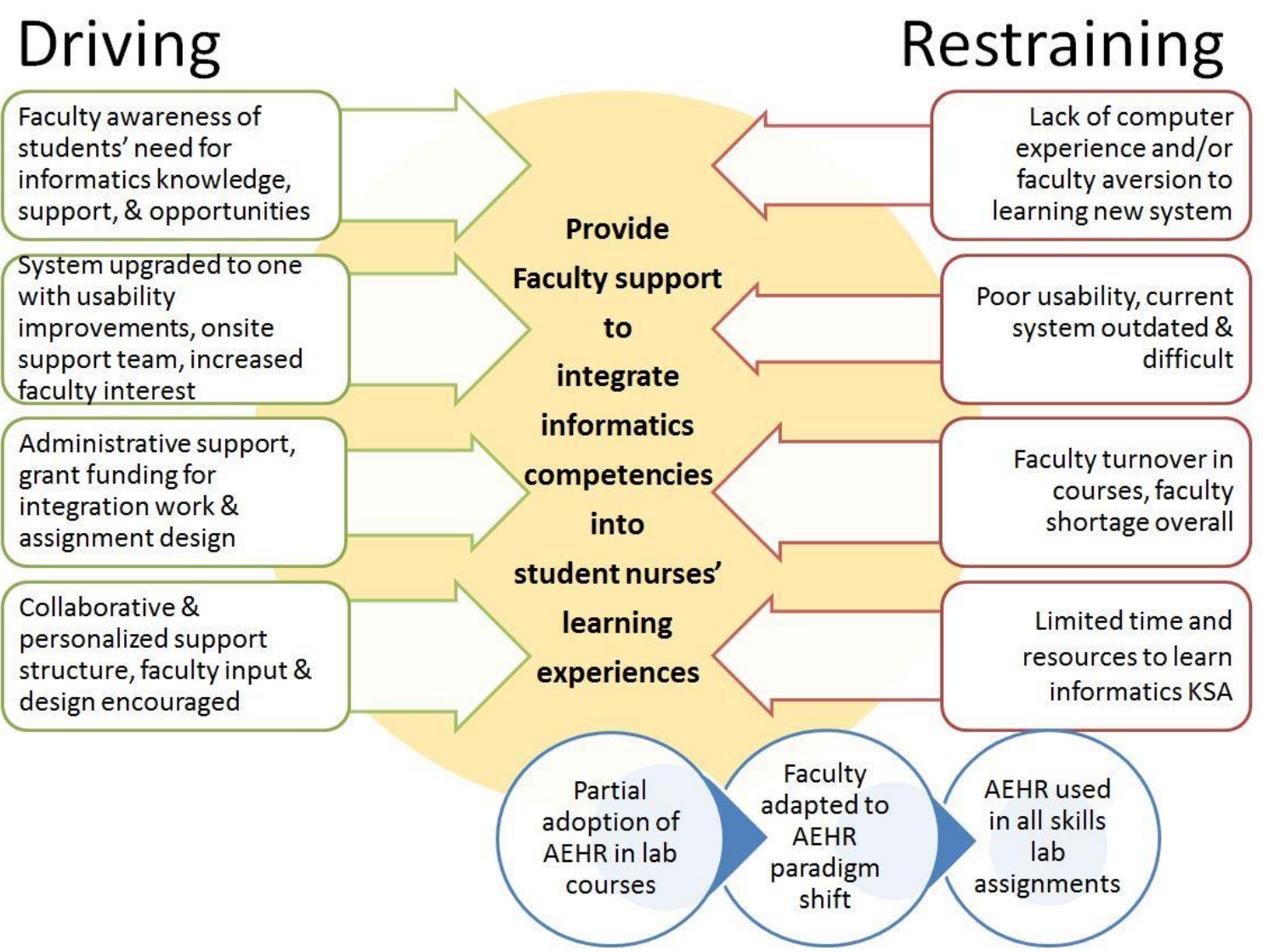

Figure 11. Illustration of force-field analysis summary of the driving and restraining forces discovered from surveys, interviews and artifacts in the PAR case study data. Green arrows on the left represent driving forces and red arrows on the right represent restraining forces. The size of the arrows represents the strength of the force as evidenced from the research data in this case study. The center of the field is the overall goal or focus of the project. The small circles illustrate the present state moving towards the desired state or change. This assessment represents the first phase of the next AEHR integration PAR cycle. Adapted from ideas based on Kurt Lewin's "Field theory in social sciences:

Selected theoretical papers", 1975.

In addition to identification of successful strategies both in the literature and through research findings, several new practice outcomes and faculty needs were identified as necessary components for continued integration. Moving forward, several recommended expectations are suggested to promote success during the next AEHR integration cycle. The first expectation is that students must include documentation for nursing skills lab practice. The faculty included this expectation to teach students the importance and significance of information management. If a student preforms a skill in 
the lab, they must also provide AEHR assessment and documentation associated with the skill. The second expectation is that faculty members will provide feedback for students on key AEHR assignments. Students rely on faculty feedback to verify or correct nursing skill and documentation behaviors. Without feedback, students could be at risk of repeating unsafe behaviors which may lead to unsafe or poor quality care. In order to accommodate this requirement, faculty should be granted adequate time and support to adjust to AEHR grading/feedback requirements. Other faculty development strategies geared toward successful integration involve

- Development of clear online or PowerPoint presentation resources for using the AEHR assignments for both students and faculty

- Create AEHR faculty orientation support prior to start of a new course, beginning of the semester, or any course time where AEHR assignments are expected

- Consider usability function with the AEHR platform. Streamline and field test assignments and directions for clarity and ease of use

- Create a student team to critic assignments, create case studies, and provide feedback on learning

- Provide sample charting experiences for faculty and students to practice their skills

\section{The Learning by Developing Model Situated in Larger Context, Moving Forward}

Although the results of the research from this case study, limit the generalizability to a specific population, the $\mathrm{LbD}$ framework for collaborative innovative project development may be appropriate in other research situations whereby application to practice is a goal. These situations may include a) a university or college where competence is the expectation, b) with genuine working life-oriented research and development projects and, c) when the objective is learning the process of discovery and self-sufficiency. For example, the LbD model is continuing as the framework for further 
study and process with the AEHR integration at the Liberal Oak College. A grant proposal was submitted and approved for a student collaborative summer research project. This grant funded a Community Engaged Research to the Classroom (CERC) collaborative project, which partially supports the next steps in the AEHR integration process. Lessons learned and research data from this case study fold into the framework and organization of the next steps in the CERC AEHR integration project. The positive response and artifacts that resulted from student involvement as collaborators in this case study prompted the idea to progress with a larger student team as a method to develop evidenced based teaching practice guidelines for the AEHR.

The project timeline is June 2014 to August 2015 and includes student competence opportunities for research and leadership. This project is significant because it is a part of the continuing collaborative informatics integration at Liberal Oak College. Two students funded from the proposal will join with three other students at the school of nursing to conduct evidenced based teaching practice (EBTP) research, and develop appropriate student nursing informatics assignments and support materials based on this evidence informed by nursing American Association of Colleges of Nursing (AACN) curriculum essential IV guidelines, and faculty guidance. In addition, the students will provide "user-friendly" materials and present these during faculty development workshops scheduled in the fall. The students will gain experience and develop EBTP research and leadership skills by collaboratively developing curricular and faculty development materials; actively apply research; and build strong healthcare informatics skills. 
The focus of the project is a collaborative team, which includes five nursing students, two nurse educators, two community based informatics specialists, and the informatics platform vendor. The following is a description of the student collaborative team partners, and their characteristics. One nursing student with skills in the current AEHR and no skills in clinical practice EHRs, two nursing students with skills in the AEHR and novice skills in a clinical based EHR systems, and two nursing students who are practicing RNs in the community with expertise in clinical based EHRs and no experience in any academic based EHR systems.

The learning goals for these students are to develop skills needed to advance nursing's contribution to the profession, develop project collaboration skills, and learn project design and development using evidenced-based practice. In addition, these students will have opportunities to highlight their work by participating in scholarly opportunities such as professional nursing conference presentations and/or shared publication status with the project manager and faculty lead. The proposed summer collaborative process is one that requires students to develop research skills, and create effective orientation and training media for faculty and student users of the new AEHR. They [the students] will also design, facilitate, and participate in an AEHR orientation workshop for faculty and critique and design informatics activities based on previous syllabi activities and AACN essential curricular guidelines. These five students also benefit from the faculty members' nursing knowledge and doctoral work in informatics and educational learning theories, which will provide them with leadership skills in informatics project design and development. The LbD pedagogic approach enables 
student nurses to develop innovative and creative life-long learning skills to participate, adapt, and collaborate in nursing practice for today and in the future. The aims and purposes of this specific research and creative work are

1. To create EBTP activities that will build on informatics curricula to better prepare LOC nursing students for real-life work in healthcare documentation and data management in EHR platforms as mandated by the government.

2. To develop an evidenced-based academic electronic health records orientation and support program on all AEHR assignments for both students and faculty in the first and second semesters of the LOC curriculum courses from the learner's (student's) perspective.

3. To provide students with an opportunity to be active participants in curriculum research and development, practice leadership skills by developing workshops and materials, and gain informatics and instructional technology design and development skills.

Further suggested research includes the use of the LbD model for collaborative development in design projects in related healthcare fields, or other applied degree areas.

\section{National Recommendations for Nursing Faculty Development}

The recent updated TIGER Initiative Foundation report: The Leadership Imperative: TIGER's Recommendations for Integrating Technology to Transform Practice and Education (2014) provides recommendations focused on providing guidance or incorporating technology into transformational practice changes to enhance patient, family, and economic outcomes. Practice begins with education. In order to promote this type of transformation, faculty and schools of nursing need support beginning with current faculty members and incorporating recommendations into nursing leadership programs. Therefore, I agree with the following recommendations: 
- Develop programs for nurse executives and faculty that stress the value of information technology and empower them to knowledgably use health IT. Innovation will be advanced by the programs including the following elements:

a) Foster collaboration to move ideas into practice by leveraging the experience of all professionals and disciplines.

b) Accelerate the development and adoption of evidence and innovation into practice.

c) Transform the provider-vendor relationship to fund new initiatives.

d) Develop knowledge, competence and skills to engage with public policy initiatives.

- Expand and integrate informatics competencies into nursing leadership development programs. These expanded informatics competencies include an emphasis on evidence-based practice, inquiry and innovation, standardized terminologies, and the use of data analytics.

- Promote the sharing of best practices using health IT effectively to improve the delivery of patient care through leveraging and replicating the best practices of the industry. The emphasis on nursing's role with patient outcomes and quality metrics provides a unique partnership to further health IT as a tool for efficiency and efficacy.

- Promote alignment with the ANCC Magnet Recognition Program ${ }^{\circledR}$ as a mechanism to demonstrate excellence in patient care outcomes through the use of technology as a tool to improve nursing practice. 
ELECTRONIC HEALTH RECORDS IN NURSING EDUCATION

\section{Recommendations for Schools of Nursing}

Information Management Systems Society (HIMSS) is a global, cause-based, notfor-profit organization focused on better health through information technology (IT). Schools of nursing need to address informatics curricula because nurses are an integral part of successfully achieving improved outcomes, optimal wellness and overall population health management. The Board of Directors (2011) Position Statement on Transforming Nursing Practice through Technology \& Informatics has set forth recommendations for academic organizations to integrate informatics content throughout the nursing undergraduate and graduate curriculum in the following manner:

- Include information literacy, nursing terminologies, electronic health records, usability, clinical decision support, personal health records, human factors design, evidence-based practice, telehealth, privacy and security of electronic records.

- Incorporate information literacy and informatics competencies into the performance expectations for all nursing students.

- Incorporate information literacy and informatics competencies into the job expectations for all nursing faculty.

- Promote and financially support faculty development in informatics and information technology.

- Supplement patient care experiences with human simulation laboratories that are integrated with electronic health records 
ELECTRONIC HEALTH RECORDS IN NURSING EDUCATION

\section{Recommendations for Policy Change in Colleges and Universities}

To promote life-long learning and inform evidenced based education for nursing students, it is imperative that nursing faculty are encouraged and honored for spending time working in their respective $\mathrm{RN}$ specialty. In fields other than nursing, the careers may reflect a migration from industry to education to public service and back. Nurse educators must focus on curriculum design, tests, and pedagogy. The criteria for promotion and advancement rely more heavily on scholarly accomplishments than on practice skills, and knowledge. The net effect is the evolution of nursing faculty with limited knowledge and experiences in current practice environments, and little or no incentives to engage in the practice environment. This current dilemma seems counterproductive to the understanding of how to prepare graduates for the realities of practice. Why would nursing faculty engage in informatics systems if they are not encouraged or honored for actively practicing in this paradigm? Nursing faculty need to be honored and supported in their efforts for life-long learning. Evidence of nursing's dilemma is well stated by the following from the IOM (2010) report on the Future of Nursing: Advancing Health:

The body of knowledge required for safe practice has grown geometrically, as have the tools for accessing information, and the skills required for the safe delivery of care. Educational reforms must address how we improve access to needed and relevant information for students within nursing, how we develop the nurse's ability to access and use information following program completion and how the educational pathway is ordered to assist in building a career pathway in clinical nursing. (IOM, 2010) 
Additionally, I would like to include two recommendations stated in the report and strongly urge colleges and universities to implement these policy changes for faculty in schools of nursing:

- Require nurse faculty members to maintain professional certification and tie these qualifications to educational accreditation. Develop institutionally based incentives for faculty to maintain clinical competency, such as participation in a faculty practice plan.

- Expand criteria for faculty appointment and advancement to include recognition of practice-based accomplishments, including leadership, innovation and evaluation. Normalize the career movement between the practice and educational settings within nursing. (p.I-47, IOM, 2010)

\section{Ending thoughts}

Walking the middle road of adaptive expertise for faculty development with technology involves having an attitude of flexibility, allowing for collaborative ideas, honoring individual expertise, and considering end-user design. Input is of extreme importance from those that will be actually utilizing the product otherwise resistance will prevail. Additionally, a technology system should not be so complex as to force users to create unsafe work-a-round strategies to get the job done. Nurses and nursing faculty want and should be a part of EHR design processes whether in clinical practice sites or in schools of nursing. In addition, technology needs to be adaptable in providing end user ease of use and function. I believe that providing an avenue through a collaborative 
process model, allows for input from end-users, increases buy-in, and promotes the type of change needed to bridge theory and practice in the world of innovative technology.

Faculty development is crucial to the success of integrating informatics into nursing programs. The key is to provide the vital elements of support, development strategies, and technical expertise to help develop nursing faculty informatics knowledge, skills, and attitudes. The LbD model as a framework for AEHR integration had many benefits to the faculty development process. The collaborative nature of the model promoted engagement from the faculty. As with most innovative transformative processes, the late adopters are moving slowly towards the goals of AEHR integration. In the spirit of life-long learning, the LbD was a successful method to help develop faculty KSA and begin to promote practice change at this one small liberal arts school of nursing.

On a personal note, this collaborative participatory action research process allowed for me to develop knowledge and skills related to project management, faculty leadership, integrative pedagogic theories, innovative technology, usability design, and transformative strategies. I learned the power of persuasion, the importance of active listening, and how truly honorable and courageous my nurse colleagues are. I have grown tremendously during this process and believe this PAR project was an excellent means for preparing me as a doctoral nursing faculty. I look forward to future work in student [learner] centered research and pedagogic development. 


\section{REFERENCES}

Adamson, C., \& Britt, R. (2009). Repeat testing with the HESI exit exam-sixth validity study. Computers Informatics Nursing, 27(6), 393-397.

American Association Colleges Nursing. (2008). The essentials of baccalaureate education for professional nursing practice. Washington DC: American Association of Colleges of Nursing. Retrieved from http://www.aacn.nche.edu/education-resources/baccessentials08.pdf

American Library Association. (2001). Library advocacy now! Action pack 2001: A library advocate's guide to building information literate communities. Retrieved from http://www.ala.org/aboutala/sites/ala.org.aboutala/files/content/governance/officer s/kranich_1.pdf

American Nurses Association. (2008). Nursing informatics: Scope and standards of practice. Silver Spring, Maryland: nursesbooks.org.

American Nurses Association. (2012). What is nursing? Retrieved from http://www.nursingworld.org/EspeciallyForYou/What-is-Nursing

Bakken, S., Cook, S., Curtis, L., Desjardins, K., Hyun, S., Jenkins, M., . . Soupios, M. (2004). Promoting patient safety through informatics-based nursing education. International Journal of Medical Informatics, 73(7), 581-589. doi:10.1097/01.mlr.0000109125.00113.f4

Bell, K., \& Bradford, A. (2008). Defining key health information technology terms. Chiago, IL: Department of Health \& Human Services: Office of the National Coordinator for Health Information Technology. Retrieved from https://www.nachc.com/client/Key\%20HIT\%20Terms\%20Definitions\%20Final_ April_2008.pdf

Benner, P., Sutphen, M., Leonard, V., \& Day, L. (2010). Educating nurses: The call for radical transformation. San Francisco: Jossey-Bass.

Bostrom, A., Schafer, P., Dontje, K., Pohi, J., Nagelkerk, J., \& Cavanagh, S. (2006). Electronic health record: Implementation across the Michigan Academic Consortium. Computers Informatics Nursing, 24(1), 44-52.

Bozak, M.G., (2003). Using Lewin's Force Field Analysis in Implementing a Nursing Information System. Computers, Informatics, Nursing, 21(2), 80-85 
Bransford, J., Brown, A., \& Cocking, R. (2000). How people learn: Brain, mind, experience, and school (expanded ed.) Washington, DC: National Academies Press.

Card, A. J. (2013). A new tool for hazard analysis and force-filed analysis: The lovebug diagram. Clinical Risk 19(4-5)

Christie, C. A., Montrosse, B. E., \& Klein, B. M. (2005). Emergent design evaluation: A case study. Evaluation and Program Planning, 28(3), 271-277. doi:org/10.1016/j.evalprogplan.2005.04.002

Connors, H. R., Weaver, C., Warren, J., \& Miller, K. L. (2002). An academic-business partnership for advancing clinical informatics. Nursing Education Perspectives, 23(5), 228-233. doi:10.1043/1536-5026(2002)023<0228:aabpfa>2.0.co;2

Cornell, L.R. (2009). A study of transformational change at three schools of nursing implementing healthcare informatics. (Doctoral dissertation) Available from ProQuest Dissertation Publishing (UMI No. 3394140)

Creswell, J. (2008). Educational research: Planning, conducting, and evaluating quantitative and qualitative research (3rd ed.). Upper Saddle River, NJ: Pearson Hall.

Cronenwett, L., Sherwood, G., Barnsteiner, J., Disch, J., Johnson, J., Mitchell, P., ... \& Warren, J. (2007). Quality and safety education for nurses. Nursing outlook, 55(3), 122-131. doi:10.1016/j.outlook.2007.02.006

Curran, C. R. (2008). Faculty development initiatives for the integration of informatics competencies and point-of-care technologies in undergraduate nursing education. The Nursing clinics of North America, 43(4), 523-533. doi:10.1016/j.cnur.2008.06.001.

Curran, C. R., Elfrink, V., \& Mays, B. (2009). Building a Virtual Community for Nursing Education: The Town of Mirror Lake. Journal of Nursing Education, 48(1), 3035.

Curry, D. G. (2011). Selection and implementation of a simulated electronic medical record (EMR) in a nursing skills lab. Journal of Educational Technology Systems, 39(2), 213-218. doi:10.2190/ET.39.2.j

DeGagne, J. C., Bisanar, W. A., Makowski, J. T., \& Neumann, J. L. (2012). Integrating informatics into the BSN curriculum: A review of the literature. Nurse Education Today, 32(6), 675-682. doi:10.1016/j.nedt.2011.09.003 
ELECTRONIC HEALTH RECORDS IN NURSING EDUCATION

DesRoches, C., Donelan, K., Buerhaus, P., Potter, V., \& Zhonghe, L. (2008). Registered nurses' use of electronic health records: Findings from a national survey. Medscape Journal of Medicine, 10(7). Retrieved from http://www.ncbi.nlm.nih.gov.proxy.lib.pdx.edu/pmc/articles/PMC2525465/?repor $\mathrm{t}=$ classic

DesRoches, C. M., Campbell, E. G., Vogeli, C., Zheng, J., Rao, S. R., Shields, A. E., ... Jha, A. K. (2010). Electronic health records' limited successes suggest more targeted uses. Health affairs, 29(4), 639-646. doi:10.1377/hlthaff.2009.1086

DesRoches, C. M., Charles, D., Furukawa, M. F., Joshi, M. S., Kralovec, P., Mostashari, F., .. \& Jha, A. K. (2013). Adoption of electronic health records grows rapidly, but fewer than half of US hospitals had at least a basic system in 2012. Health Affairs 32(8):1478-1485. doi:10.1377/hlthaff.2013.0308

Dewey, J. (1931). Philosophy and civilization. New York: Moulton, Bach \& Company.

Dewey, J. (1963). Experience and education. New York: Collier Books.

Doordan, A. M. (1998). Lippincott's need to know research survival guide. Philadelphia, PA: Lippincott.

Carr, W. (2005). Philosophy and education. The RoutledgeFalmer reader in the philosophy of education, 1-14.

Doordan, A. (1998). Lippincott's need to know research survival guide. Philadelphia, PA.

Elsevier. (2014). HESI definition of terms: Reports. Retrieved from https://evolve.elsevier.com/

Fetter, M. S. (2009a). Curriculum strategies to improve baccalaureate nursing information technology outcomes. The Journal of nursing education, 48(2), 7885. doi:10.3928/01484834-20090201-06

Fetter, M. S. (2009b). The electronic health record. Issues in mental health nursing, 30(5), 345-347. doi:10.1080/01612840902754677

Fink, L.D. (2003). Creating significant learning experiences: An integrated approach to designing college courses. San Francisco: Jossey-Bass.

Forehand, M. (2010). Bloom's taxonomy. Emerging Perspectives on Learning, Teaching, and Technology, 41-47. 
Freire, P. (1970) Pedagogy of the Oppressed. Herder \& Herder, New York.

The Future of Nursing: Leading Change, Advancing Health. ( http://www.nap.edu/catalog/12956.html

Gloe, D. (2010). Selecting an academic electronic health record. Nurse Educator, 35(4), 156. doi:10.1097/NNE.0b013e3181e337d3

Greiner, A. C., \& Knebel, E. (2003). Health professionals education: A bridge to quality Quality Chasm Series. Washington DC: Institute of Medicine.

Griffin-Sobel, J. P., Acee, A., Sharoff, L., Cobus-Kuo, L., Woodstock-Wallace, A., \& Dornbaum, M. (2010). A transdisciplinary approach to faculty development in nursing education technology. Nursing Education Perspectives, 31(1), 41-43. doi:org/10.1043/1536-5026-31.1.41

Gugerty, B., \& Delaney, C. (2009). TIGER informatics competencies collaborative (TICC) final report: Technology informatics guiding educational reform (TIGER) initiative. Retrieved from www.tigersummit.com

Halstead, J. H., Bonnel, W., Chamberlain, B., Green, P. M., Hanna, K. R., Heinrich, C., ...Rizzolo, A. (2005). Core competencies of nurse educators with task statements. National League for Nursing. Retrieved from http://www.nln.org/profdev/corecompetencies.pdf

Healthcare Information and Management Systems Society, Board of Directors (2011). Position Statement on Transforming Nursing Practice through Technology \& Informatics. Retrieved from http://www.himss.org/files/HIMSSorg/handouts/HIMSSPositionStatementTransf ormingNursingPracticethroughTechnologyInformatics.pdf

Healthcare Information and Management Systems Society (2011). Promoting usability in health organizations: Initial steps and progress toward a healthcare usability maturity model. Chicago, IL: HIMSS.

Healthcare Information and Management Systems Society (2014). Resource Library: Electronic Health Records. HIMSS transforming health through IT. Retrieved from http://www.himss.org/library/ehr/

Hebda, T., \& Calderone, T. L. (2010). What nurse educators need to know about the TIGER initiative. Nurse Educator, 35(2), 56-60. doi:10.1097/NNE.0b013e3181ced83d 
Herr, K. \& Anderson, G. L. (Eds.) (2005). The action research dissertation: A guide for students and faculty. Thousand Oaks, CA: Sage.

Hillestad, R., Bigelow, J., Bower, A., Girosi, F., Meili, R., Scoville, R., \& Taylor, R. (2005). Can electronic medical record systems transform health care? Potential health benefits, savings, and costs. Health Affairs, 24(5), 1103-1117. doi:10.1377/hlthaff.24.5.1103

Hunt, E. C., Sproat, S. B., Kitzmiller, R. R., \& Kitzmiller, R. R. (2004). The nursing informatics implementation guide. New York: Springer-Verlag.

H.R. 1--111th Congress (2009). American Recovery and Reinvestment Act of 2009. Public Law 111-5. Retrieved from http://frwebgate.access.gpo.gov/cgibin/getdoc.cgi?dbname=111_cong_bills\&docid=f:hlenr.pdf

Institute of Medicine. (2010). The Future of Nursing: Leading Change, Advancing Health. Washington, DC: The National Academies Press. Retrieved from http://www.rwjf.org/content/dam/farm/reports/reports/2011/rwjf67190

Institute of Medicine (November 4, 2013). About the IOM. Retrieved from http://www.iom.edu/About-IOM.aspx

Jeffries, P. R., Hudson, K., Taylor, L. A., \& Klapper, S. A. (2011) Bridging technology: Academe and industry. In Ball, M.J., Hannah, K.J., DuLong, D., Newbold, S.K., Sensmeier, J.E., Skiba, D.J., ... Douglas, J.V. (Eds.), Nursing Informatics (pp. 167-188). London: Springer. doi:10.1007/978-1-84996278-0_11

Johnson, C. L., Carlson, R. A., Tucker, C. L., \& Willette, C. (2001). Using BCMA software to improve patient safety in Veterans Administration Medical Centers. Journal of healthcare information management: JHIM, 16(1), 46-51.

Johnson, D., \& Bushey, T. (2011). Integrating the academic electronic health record into nursing curriculum: Preparing student nurses for practice. Computers Informatics Nursing, 29(3), 133-137.

Kalb, K. A. (2008). Core competencies of nurse educators: Inspiring excellence in nurse educator practice. Nursing education perspectives, 29(4), 217-219. doi.org/10.1043/1536-5026(2008)029[0217:CCONEI]2.0.CO;2

Kutney-Lee, A., \& Kelly, D. (2011). The effect of hospital electronic health record adoption on nurse-assessed quality of care and patient safety. Journal of Nursing Administration, 41(11), 466-472. doi:10.1097/NNA.0b013e3182346e4b 
Langford, R., \& Young, A. (2013). Predicting NCLEX-RN success with the HESI exit exam: Eighth validity study. Journal of Professional Nursing, 29(2), S5-S9. doi:10.1016/j.profnurs.2012.06.007

Lewin, K. (1975). Field theory in social sciences: Selected theoretical papers. Westport, CT: Greenwood Press.

Lucas, L. (2010). Partnering to enhance the nursing curriculum: Electronic medical record accessibility. Clinical Simulation in Nursing, 6(3), e97-e102. doi:10.1016/j.ecns.2009.07.006

Mahon, P. Y., Nickitas, D. M., \& Nokes, K. M. (2010). Faculty perceptions of student documentation skills during the transition from paper-based to electronic health records systems. Journal of Nursing Education, 49(11), 615-621. doi:10.3928/01484834-20100524-06

Malloch, K. (2007). The electronic health record: An essential tool for advancing patient safety. Nursing outlook, 55(3), 159-161. doi:10.1016/j.outlook.2007.03.007

Manos, D. (2009, January 8, 2009). Obama: EHRs for Americans by 2014. Healthcare IT News. Retrieved from http://www.healthcareitnews.com/news/obama-ehrsamericans-2014

Maxwell, J. (1996). Qualitative research design: An interactive approach. Thousand Oaks, CA: Sage.

McCullough, J. S., Casey, M., Moscovice, I., \& Prasad, S. (2010). The effect of health information technology on quality in U.S. hospitals. Health affairs, 29(4), 647654. doi:10.1377/hlthaff.2010.0155

McGinn, C. A., Grenier, S., Duplantie, J., Shaw, N., Sicotte, C., Mathieu, L., . . Gagnon, M.-P. (2011). Comparison of user groups' perspectives of barriers and facilitators to implementing electronic health records: A systematic review. BMC medicine, 9(1), 46. doi:10.1186/1741-7015-9-46

McNeil, B. J., Elfrink, V., Beyea, S. C., Pierce, S. T., \& Bickford, C. J. (2006). Computer literacy study: Report of qualitative findings. Journal of Professional Nursing, 22(1), 52-59. doi:10.1016/j.profnurs.2005.12.006

McNeil, B. J., Elfrink, V. L., Bickford, C. J., Pierce, S. T., Beyea, S. C., Averill, C., \& Klappenbach, C. (2003). Nursing information technology knowledge, skills, and preparation of student nurses, nursing faculty, and clinicians: A U.S. survey. Journal of Nursing Education, 42(8), 341-349. 
McNeil, B. J., Elfrink, V. L., Pierce, S. T., Beyea, S. C., Bickford, C. J., \& Averill, C. (2005). Nursing informatics knowledge and competencies: A national survey of nursing education programs in the United States. International Journal of Medical Informatics, 74(11/12), 1021-1030. doi:10.1016/j.ijmedinf.2005.05.010

Melo, D., \& Carlton, K. H. (2008). A collaborative model to ensure graduating nurses are ready to use electronic health records. Computers Informatics Nursing, 26(1), 812.

Meyer, L., Sternberger, C. S., \& Toscos, T. (2011). How to implement the electronic health record in undergraduate nursing education. American Nurse Today, 6(5), 40-44. Retrieved from http://www.americannursetoday.com/assets/0/434/436/440/7770/7772/7792/7830/ 3e8777a7-fdd8-4a64-a764-c6f3a6bec3dd.pdf

Millard, M. (2010, December 10, 2010). Wolters Kluwer acquired iCare educational EMR software. Healthcare IT News. Retrieved from http://www.healthcareitnews.com/news/wolters-kluwer-acquires-icareeducational-emr-software

Munhall, P. (2001). Nursing research: A qualitative perspective (3rd Ed.). Sudbury, MA: Jones \& Bartlet.

Murphy, J. (2010). Nursing informatics: The journey to meaningful use of electronic health records. Nursing Economic\$, 28(4), 283-286.

National League for Nursing Board of Governors. (2008). Position statement: Preparing the next generation of nurses to practice in a technology-rich environment: An informatics agenda. Retrieved from http://www.nln.org/aboutnln/positionstatements/informatics_052808.pdf.

National Research Council (2003). Key capabilities of an electronic health record system: Letter report. Washington, DC: The National Academies Press. Retrieved from: http://www.nap.edu/catalog.php?record_id=10781

Nelson, R., \& Staggers, N. (2013). Health informatics: An interprofessional approach. St. Louis, MO: Elsevier Health Sciences.

Nibert, A. T., Young, A., \& Britt, R. (2008). The HESI Exit Exam: progression benchmark and remediation guide. Computers Informatics Nursing, 26(5), 70S$74 \mathrm{~S}$. 
Nickitas, D. M., Nokes, K. M., Caroselli, C., Mahon, P. Y., Colucci, D. E., \& Lester, R. D. (2010). Increasing nursing student communication skills through electronic health record system documentation. Computers Informatics Nursing, 28(1), 7-11.

Office of the Press Secretary. (2009). President Obama announces the creation of a joint virtual lifetime electronic record. Washington DC: The White House President Barack Obama. Retrieved from http://www.whitehouse.gov/the_press_office/President-Obama-Announces-theCreation-of-a-Joint-Virtual-Lifetime-Electronic-Reco/

Ora-Hyytiäinen, E., Ikonen, H., Ahonen, O., Rajalahti, E., \& Saranto, K. (2010). Case study 9B: Learning by developing. In C. A. Weaver, C. Delaney, P. Weber \& R. Carr (Eds.), Nursing and informatics for the 21st century: An international look at practice, education and EHR trends. Chicago, IL: HIMSS.

Page, A. (Ed.). (2004). Keeping patients safe: Transforming the work environment of nurses. Washington DC: National Academies Press. Retrieved from http://www.nap.edu/catalog.php?record_id=10851

Pravikoff, D. S., Tanner, A. B., \& Pierce, S. T. (2005). Readiness of U.S. nurses for evidence-based practice: Many don't understand or value research and have had little or no training to help them find evidence on which to base their practice. AJN The American Journal of Nursing, 105(9), 40-51.

Quality and Safety Education for Nurses (n.d.). QSEN Institute: Pre-licensure KSAs. QSEN Institute. Retrieved from http://qsen.org/competencies/prelicensure-ksas/\#informatics

Raij, K. (2007). Learning by developing. Helsinki, Finland: Laurea University of Applied Sciences.

Raij, K. (2013). Learning by developing in higher education. Journal of Education Sciences. Issue II, 6-21.

Raij, K., Niinistö-Sivuranta,S., Outi, A., Orpana, P., Pääskyvuori, M., Rantanen,T., Lassila, E. (2011). Learning by Developing: LbD Guide. Finland: Laurea University of Applied Sciences.

Raij, K., \& Niinistö, S. (2010). Learning by developing: LbD guide. Helsinki, Finland: Laurea University of Applied Sciences. 
Rantz, M. J., Alexander, G., Galambos, C., Flesner, M. K., Vogelsmeier, A., Hicks, L., ...Greenwald, L. (2011). The use of bedside electronic medical record to improve quality of care in nursing facilities: A qualitative analysis. Computers Informatics Nursing, 29(3), 149-156. doi:10.1097/NCN.0b013e3181f9db79

Rideout, E. (2001). Transforming nursing education through problem-based learning. Burlington, MA: Jones and Bartlett.

Riel, M. (2010). Understanding action research. Research Methods in the Social Sciences, 17(1), 89-96.Retrieved from http://cadres.pepperdine.edu/ccar/define.html

Rizzolo, M. A., Skiba, D. J., \& DuLong, D. (2009). Transforming education for an informatics agenda: TIGER education and faculty development collaborative. The TIGER Initiative. Retrieved from http://www.thetigerinitiative.org/docs/TigerReport_EducationFacultyDevelopmen t_000.pdf

Rogers, E. M. (2010). Diffusion of innovations. New York: Simon \& Schuster.

Rothman, M. J., Solinger, A. B., Rothman, S. I., \& Finlay, G. D. (2012). Clinical implications and validity of nursing assessments: A longitudinal measure of patient condition from analysis of the electronic medical record. BMJ open, 2(4). doi:10.1136/bmjopen-2012-000849

Sensmeier, J., \& Anderson, C. (2009). Technology informatics guiding education reform moves into phase III: Implementation. Computers Informatics Nursing, 27(4), 265-266. doi:10.1097/01.NCN.0000336485.81231.1e

Shulman, L. S. (2010). Forward. In Benner, P., Sutphen, M., Leonard, V., \& Day, L. (Eds.), Educating nurses: A call for radical transformation (pp. IX-XIII). San Francisco: Jossey-Bass.

Skiba, D. J. (2006). A call to action: Preparing the next generation of nurses. Nursing Education Perspectives, 27(6), 335-337. doi:org/10.1043/15365026(2006)027[0335:ACTAPT]2.0.CO;2

Skiba, D. J., \& Rizzolo, M. A. (2009). National league for nursing's informatics agenda. Computers Informatics Nursing, 27(1), 66-68. doi:10.1097/NCN.0b013e3181931eef 
Smith, E. L., Cronenwett, L., \& Sherwood, G. (2007). Current assessments of quality and safety education in nursing. Nursing Outlook, 55(3), 132-137. doi:10.1016/j.outlook.2007.02.005

Staggers, N., \& Thompson, C. B. (2002). The evolution of definitions for nursing informatics: A critical analysis and revised definition. Journal of the American Medical Informatics Association, 9(3), 255-261. doi:10.1197/jamia.M0946

Stake, R. (2005). Qualitative case studies. In Denzin, N. K., \& Lincoln, Y. S. (Eds.), The Sage handbook of qualitative research (pp. 443-466). Thousand Oaks, CA: Sage.

Suskie, L. (2010). Assessing student learning: A common sense guide. San Francisco: John Wiley \& Sons.

Taatila, V., \& Raij, K. (2011). Philosophical Review of Pragmatism as a Basis for Learning by Developing Pedagogy. Educational Philosophy and Theory, 44(8), 831-844. doi:10.1111/j.1469-5812.2011.00758.x

Taylor, L. A., Hudson, K., Vazzano, J., Naumann, P., \& Neal, M. (2010). The electronic health record meets baccalaureate nursing curriculum: Stories from the battlefield. Nurse Leader, 8(3), 40-44. doi:10.1016/j.mnl.2010.03.008

Technology Informatics Guiding Education Reform. (n.d.). Informatics competencies for every practicing nurse: Recommendations from the TIGER collaborative. The TIGER Initiative, Retrieved from http://www.thetigerinitiative.org/docs/TigerReport_InformaticsCompetencies_00 1.pdf

Thompson, B. W., \& Skiba, D. J. (2008). Informatics in the nursing curriculum: A national survey of nursing informatics requirements in nursing curricula. Nursing Education Perspectives, 29(5), 312-317.

Tomey, A. M. (2003). Learning with cases. Journal of Continuing Education in Nursing, 34(1), 34-38.

Weaver, C. A., Warren, J. J., \& Delaney, C. (2005). Bedside, classroom and bench: Collaborative strategies to generate evidence-based knowledge for nursing practice. International Journal of Medical Informatics, 74(11-12), 989-999. doi:10.1016/j.ijmedinf.2005.07.003

Yin, R. K. (2009). Case study research: Design and methods ( $4^{\text {th }}$ Ed.). Thousand Oaks: Sage. 
Young, A., \& Willson, P. (2012). Predicting NCLEX-RN success: The seventh validity study HESI exit exam. Computers Informatics Nursing, 30(1), 55-60. doi:10.1097/NCN.0b013e3182343edf

Zweighaft, E. L. (2013). Impact of HESI specialty exams: The ninth HESI exit exam validity study. Journal of Professional Nursing, 29(2), S10-S16. doi:10.1016/j.profnurs.2012.06.011. 
APPENDIX A

LIST OF TICC DIRECT CARE COMPONENTS FORMATTED AS CLINICAL INFORMATION MANAGEMENT COMPETENCIES FOR NURSES 
ELECTRONIC HEALTH RECORDS IN NURSING EDUCATION

\section{LIST OF TICC DIRECT CARE COMPONENTS FORMATTED AS CLINICAL INFORMATION MANAGEMENT COMPETENCIES FOR NURSES}

TICC has transformed the Direct Care components of the HL7 EHR System Functional Model into these recommended Clinical Information Management Competencies for nurses. TICC recommends that schools of nursing and healthcare delivery organizations will implement the information competencies listed below by January 2012.

\footnotetext{
1.0 Demographic/patient info

1.1 Identify and Maintain a Patient Record

1.2 Manage Patient Demographics

1.3 Capture Data and Documentation from External Clinical Sources

1.4 Capture Patient-Originated Data

1.5 Capture Patient Health Data Derived from Administrative and

1.6 Interact with Financial Data and Documentation

1.7 Produce a Summary Record of Care

1.8 Present Ad Hoc Views of the Health Record

1.9 Manage Patient History

2.0 Consents and Authorizations

2.1 Manage Patient and Family Preferences

2.2 Manage Patient Advance Directives

2.3 Manage Consents and Authorizations

3.0 Medication Management

3.1 Manage Allergy, Intolerance and Adverse Reaction Lists

3.2 Manage Medication Lists

3.3 Manage Problem Lists

3.4 Manage Immunization Lists

3.5 Manage Medication Administration

3.6 Manage Immunization Administration

3.7 Manage Medication Orders as appropriate for her scope of practice

4.0 Planning Care

4.1 Interact with Guidelines and Protocols for Planning Care

4.2 Manage Patient-Specific Care and Treatment Plans

4.3 Interact with Clinical Workflow Tasking

4.4 Interact with Clinical Task Assignment and Routing

4.5 Interact with Clinical Task Linking

4.6 Interact with Clinical Task Tracking

5.0 Order/Results Management

5.1 Manage Non-Medication Patient Care Orders

5.2 Manage Orders for Diagnostic Tests

5.3 Manage Orders for Blood Products and Other Biologics

5.4 Manage Referrals

5.5 Manage Order Sets

5.6 Manage Results

6.0 Care Documentation

6.1 Manage Patient Clinical Measurements

6.2 Manage Clinical Documents and Notes

6.3 Manage Documentation of Clinician Response to Decision Support Prompts

6.4 Generate and Record Patient-Specific Instructions

7.0 Decision Support

7.1 Manage Health Information to Provide Decision Support for Standard Assessments

7.2 Manage Health Information to Provide Decision Support for Patient Context- Driven assessments

7.3 Manage Health Information to Provide Decision Support for Identification of Potential Problems and Trends

7.4 Manage Health Information to Provide Decision Support for Patient and Family Preferences

7.5 Interact with decision Support for Standard Care Plans, Guidelines, and Protocols

7.6 Interact with decision Support for Context-Sensitive Care Plans, Guidelines, and Protocols

7.7 Manage Health Information to Provide Decision Support Consistent Healthcare
} 
7.8 Management of Patient Groups or Populations

7.9 Manage Health Information to Provide Decision Support for Research Protocols Relative to Individual Patient Care

7.10 Manage Health Information to Provide Decision Support for Self-Care

7.11 Interact with decision support for Medication and Immunization Ordering as appropriate for her scope of practice

7.12 Interact with decision Support for Drug Interaction Checking

7.13 Interact with decision Support for Patient Specific Dosing and Warnings

7.14 Interact with decision Support for Medication Recommendations

7.15 Interact with decision Support for Medication and Immunization Administration

7.16 Interact with decision Support for Non-Medication Ordering

7.17 Interact with decision Support for Result Interpretation

7.18 Interact with decision Support for Referral Process

7.19 Interact with decision Support for Referral Recommendations

7.20 Interact with decision Support for Safe Blood Administration

7.21 Interact with decision Support for Accurate Specimen Collection

8.0 Notifications

8.1 Interact with decision support that Presents Alerts for Preventive Services and Wellness

8.2 Interact with decision Support for Notifications and Reminders for Preventive Services and Wellness

8.3 Manage Health Information to Provide Decision Support for Epidemiological

8.4 Investigations of Clinical Health Within a Population.

8.5 Manage Health Information to Provide Decision Support for Notification and Response regarding population health issues

8.6 Manage Health Information to Provide Decision Support for Monitoring Response

8.7 Notifications Regarding a Specific Patient's Health

8.8 Access Healthcare Guidance

9.0 Facilitating Communications

9.1 Facilitate Inter-Provider Communication

9.2 Facilitate Provider -Pharmacy Communication

9.3 Facilitate Communications Between Provider and Patient and/or the Patient Representative

9.4 Facilitate Patient, Family and Care Giver Education

9.5 Facilitate Communication with Medical Devices

Adapted from TIGER from

http://www.thetigerinitiative.org/docs/TigerReport_InformaticsCompetencies_001.pdf 
APPENDIX B

AACN ESSENTIAL IV: INFORMATION MANAGEMENT AND APPLICATION OF PATIENT CARE TECHNOLOGY 


\title{
AACN ESSENTIAL IV: INFORMATION MANAGEMENT AND APPLICATION OF PATIENT CARE TECHNOLOGY
}

\author{
Essential IV: Information Management and Application of Patient Care Technology \\ Rationale
}

Knowledge and skills in information and patient care technology are critical in preparing baccalaureate nursing graduates to deliver quality patient care in a variety of healthcare settings (IOM, 2003a). Graduates must have basic competence in technical skills, which includes the use of computers, as well as the application of patient care technologies such as monitors, data gathering devices, and other technological supports for patient care interventions. In addition, baccalaureate graduates must have competence in the use of information technology systems, including decision-support systems, to gather evidence to guide practice. Specific introductory level nursing informatics competencies include the ability to use selected applications in a comfortable and knowledgeable way.

Computer and information literacy are crucial to the future of nursing. Improvement of cost effectiveness and safety depend on evidence-based practice, outcomes research, interprofessional care coordination, and electronic health records, all of which involve information management and technology (McNeil et al., 2006). Therefore, graduates of baccalaureate programs must have competence in using both patient care technologies and information management systems.

In addition, baccalaureate graduates ethically manage data, information, knowledge, and technology to communicate effectively; provide safe and effective patient care; and use research and clinical evidence to inform practice decisions. Graduates will be aware that new technology often requires new workflow patterns and changes in practice approaches to patient care prior to implementation.

The use and understanding of standardized terminologies are foundational to the development of effective clinical information systems (CIS). Integration of standardized terminologies into the CIS not only supports day to day nursing practice but also the capacity to enhance interprofessional communication and automatically generate standardized data to continuously evaluate and improve practice (American Nurses Association, 2008). Baccalaureate graduates are prepared to gather and document care data that serve as a foundation for decision making for the healthcare team.

Course work and clinical experiences will provide the baccalaureate graduate with knowledge and skills to use information management and patient care technologies to deliver safe and effective care. Graduates will have exposure to information systems that provide data about quality improvement and required regulatory reporting through information systems. Course work and clinical experiences will expose graduates to a range of technologies that facilitate clinical care, including patient monitoring systems, medication administration systems, and other technologies to support patient care.

Integral to these basic skills is an attitude of openness to innovation and continual learning, as information systems and patient care technologies are constantly changing.

The baccalaureate program prepares the graduate to:

1. Demonstrate skills in using patient care technologies, information systems, and communication devices that support safe nursing practice.

2. Use telecommunication technologies to assist in effective communication in a variety of healthcare settings.

3. Apply safeguards and decision-making support tools embedded in patient care technologies and information systems to support a safe practice environment for both patients and healthcare workers. 
4. Understand the use of CIS systems to document interventions related to achieving nurse sensitive outcomes.

5. Use standardized terminology in a care environment that reflects nursing's unique contribution to patient outcomes.

6. Evaluate data from all relevant sources, including technology, to inform the delivery of care.

7. Recognize the role of information technology in improving patient care outcomes and creating a safe care environment.

8. Uphold ethical standards related to data security, regulatory requirements, confidentiality, and clients' right to privacy.

9. Apply patient care technologies as appropriate to address the needs of a diverse patient population.

10. Advocate for the use of new patient care technologies for safe, quality care.

11. Recognize that redesign of workflow and care processes should precede implementation of care technology to facilitate nursing practice.

12. Participate in evaluation of information systems in practice settings through policy and procedure development.

Sample Content

- use of patient care technologies (e.g., monitors, pumps, computer assisted devices)

- use of technology and information systems for clinical decision making

- computer skills that may include basic software, spreadsheet, and healthcare databases

- information management for patient safety

- regulatory requirements through electronic data monitoring systems

- ethical and legal issues related to the use of information technology, including copyright, privacy, and confidentiality issues

- retrieval information systems, including access, evaluation of data, and application of relevant data to patient care

- online literature searches

- technological resources for evidence-based practice

- web-based learning and online literature searches for self and patient use

- technology and information systems safeguards (e.g., patient monitoring, equipment, patient identification systems, drug alerts and IV systems, and barcoding)

- interstate practice regulations (e.g., licensure, telehealth)

- technology for virtual care delivery and monitoring

- principles related to nursing workload measurement/resource and information systems

- information literacy

- electronic health record/physician order entry

- decision-support tools

- role of the nurse informaticist in the context of health informatics and information systems

Adapted from AACN (2008). The essentials of baccalaureate education for professional nursing practice. Washington DC: American Association of Colleges of Nursing. (pp. 18-21). Accessed from http://www.aacn.nche.edu/education-resources/BaccEssentials08.pdf 


\section{APPENDIX C}

AEHR COMPARTAIVE PRODUCT ANALYSIS RESULTS BETWEEN CONTENDER SYTEMS \#1 AND \#2 
ELECTRONIC HEALTH RECORDS IN NURSING EDUCATION

\section{AEHR COMPARTAIVE PRODUCT ANALYSIS RESULTS BETWEEN CONTENDER SYTEMS \#1 AND \#2}

\begin{tabular}{|c|c|c|}
\hline Product feature & $\# 1$ & \#2 \\
\hline Ready to use Pre-built forms & Y & Y \\
\hline System has embedded scenarios & Y & Y \\
\hline Faculty can create their own scenarios. & Y & Y \\
\hline Fully Functioning Order Entry and Order Review areas & Y & Y \\
\hline System can automatically "result" Lab and Radiology orders & Y & $\mathrm{N}$ \\
\hline System can automatically schedule Pharmacy items and place on fully functioning eMAR & $\mathrm{Y}$ & $\mathrm{N}$ \\
\hline System can utilize both "real/current time" as well as "scenario time" & Y & $\mathrm{N}$ \\
\hline Students can document in "scenario time" when working through a scenario & Y & $\mathrm{Y}$ \\
\hline Instructors can easily assign scenarios to individual students, groups or an entire class. & Y & Y \\
\hline Scenario can be assigned to a simulation mannequin. & Y & $\mathrm{N}$ \\
\hline System has NCLEX®-type questions embedded in the scenarios. & Y & $\mathrm{N}$ \\
\hline System has a Kardex® area. & Y & Y \\
\hline System has a Care Plan area. & Y & Y \\
\hline System aids the instructor in grading the student's charting & Y & Y \\
\hline System can have NCLEX $®$-type questions set up between each Phase of scenario & Y & $\mathrm{N}$ \\
\hline System shows the percentage of correct answers for the NCLEX®-type questions & Y & $\mathrm{N}$ \\
\hline System has a "lab and diagnostic test" research area with world class peer reviewed content & Y & $\mathrm{N}$ \\
\hline System automatically handles admitting "patients" for each student and setting up records & Y & $\mathrm{N}$ \\
\hline Can be used in Simulation Lab & Y & $\mathrm{N}$ \\
\hline Can be used in Classroom & $\mathrm{Y}$ & $\mathrm{N}$ \\
\hline Can be used from Home & Y & Y \\
\hline Can be used in Clinicals & Y & Y \\
\hline Students can create their own "patients" to use for their Clinicals & Y & $\mathrm{Y}$ \\
\hline No limitation on number of users at any given time & Y & Y \\
\hline System documentation areas teach documentation & Y & Y \\
\hline System shows appropriate choices based on student selections in charting & Y & $\mathrm{Y}$ \\
\hline System has Med/Surg, Peds, OB and Psych flow sheets & Y & Y \\
\hline System can be used for Case Studies ie Case Studies are embedded and can be changed & Y & $\mathrm{N}$ \\
\hline System is easy to ease with little or no learning curve & Y & Y \\
\hline System has Instructor area with class management, grading and scenario assignment & Y & Y \\
\hline System is not a simple Excel Sheet & Y & Y \\
\hline $24 / 7$ technical support & $\mathrm{N}$ & $\mathrm{Y}$ \\
\hline eMar with barcode scanner included & $\mathrm{N}$ & Y \\
\hline First Year Cost & LESS & MORE \\
\hline Annual cost (including first year) & LESS & MORE \\
\hline Annual student fee & SAME & SAME \\
\hline Supported / guided / designed implementation and integration & $\mathrm{N}$ & Y \\
\hline Web-based; no installed client required & $\mathrm{N}$ & Y \\
\hline Cross-platform compatibility & $\mathrm{N}$ & $\mathrm{Y}$ \\
\hline Real EHR, (based on open source EHR) & $\mathrm{N}$ & $\mathrm{Y}$ \\
\hline
\end{tabular}


ELECTRONIC HEALTH RECORDS IN NURSING EDUCATION

APPENDIX D

AEHR INTERGRATION PROJECT FACULTY NEEDS ASSESSMENT 


\section{AEHR INTERGRATION PROJECT FACULTY NEEDS ASSESSMENT}

Dear Colleagues;

I am planning some one-on-one integration assistance as well as small group workshops. To better meet your needs, I would like to gather some information from you. Please take a few minutes to answer these questions. Thanks.

1) Do you have experience using electronic health records in practice? If yes, which system?

YES NO

2) Have you logged into the (LOCAEHR) academic electronic health record ?

YES NO

3) Have you done the scavenger hunt?

YES NO

4) Have you viewed any of the tutorial videos in "the community" in LOCAEHR?

YES NO

5) What would you like to know about NP? (Please circle below)

AVAILABLE ASSIGNMENTS

ASSIGNMENT DEVELOPMENT

HOW TO MAKE A CHART WITH MY CASE STUDIES

HOW TO USE THE PORTFOLIO TO GRADE ASSIGNMENTS

6) Would you attend an overview workshop on LOCAEHR?

7) How do you see LOCAEHR working in your course?

8) What are your concerns regarding LOCAEHR?

9) Comments?

10) Your name

Please turn in this page to me

Thank you,

NP integration needs assessment

Karen Maxwell

$3 / 5 / 2012$ 
APPENDIX E

INFORMATICS INTERGATION WITH EHR COLLEGE CURRICULUM STATUS AND PLAN 


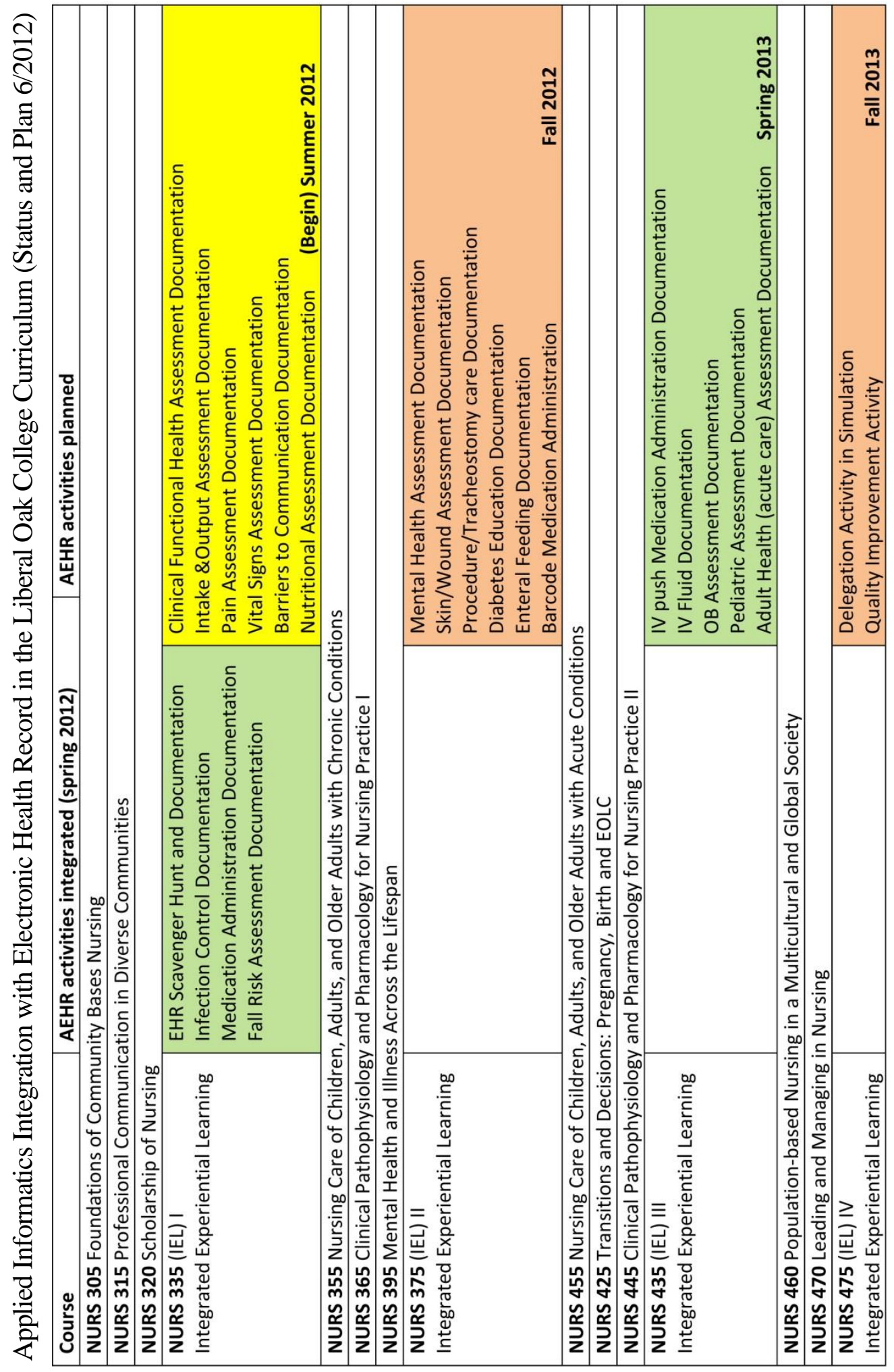


ELECTRONIC HEALTH RECORDS IN NURSING EDUCATION

APPENDIX F

INFORMATCS COMPETENCIES ASSESSMENT SURVEYS 


\section{INFORMATCS COMPETENCIES ASSESSMENT SURVEYS}

\section{Each set of questions describes ways that nurses relate to information technology in clinical practice. For each, please rate your KNOWLEDGE, SKILL and ACCESS to these competencies, at this point in your nursing practice.}

Questions 1-12: Please rate on a 1-5 scale your KNOWLEDGE (theory and concepts) of the following informatics competencies.

(1=know nothing about this)

(2=know some, need help at times)

(3=know enough to use competently)

(4=independent user, comfortable with technology)

(5=know enough to teach others)

1) Knowledge of computer applications for administration

$\begin{array}{lllll}1 & 2 & 3 & 4 & 5\end{array}$

Example: patient acuity classification (quadramed)

2) Knowledge of computer applications for communication

$\begin{array}{lllll}1 & 2 & 3 & 4 & 5\end{array}$

Examples: email, internet

3) Knowledge of computer applications for data access

$\begin{array}{lllll}1 & 2 & 3 & 4 & 5\end{array}$

Example: local clinical information systems (hospital intranet systems)

4) Knowledge of computer applications for documentation $\begin{array}{lllll}1 & 2 & 3 & 4 & 5\end{array}$ Example: hospital system for documenting patient data, assessments, interventions, plan of care and discharge planning (Epic $\AA$, VistA $®$ )

\begin{tabular}{lllllll}
\hline 5) Knowledge of computer applications for education & 1 & 2 & 3 & 4 & 5 \\
Examples: on-line literature searches; PDA resources; patient \\
education (Health Facts for You)
\end{tabular}

6) Knowledge of computer applications for patient monitoring $\quad \begin{array}{lllll}1 & 2 & 3 & 4 & 5\end{array}$ Examples: automated BP, pulse oximetry, telemetry

7) Knowledge of computer applications for basic desktop software $\quad \begin{array}{lllll}1 & 2 & 3 & 4 & 5\end{array}$ Examples: keyboarding, word processing, printing, Power point presentation skills

8) Knowledge of current peripheral devices used in patient care $12 \quad 3 \quad 4 \quad 4 \quad 5$ Examples: hand-helds (med administration; blood glucose meters); bedside computer terminals

9) Informatics knowledge: data $\begin{array}{lllll}1 & 2 & 3 & 4 & 5\end{array}$ Examples: recognizes ways that nursing data can be used to improve practice

10) Informatics knowledge: impact $\begin{array}{lllll}1 & 2 & 3 & 4 & 5\end{array}$ Example: recognizes benefits and limitations of computer use in health care 


\begin{tabular}{llllll}
\hline $\begin{array}{l}\text { 11) Informatics knowledge: privacy/security } \\
\text { Examples: recognizes patients' rights related to computerized health } \\
\text { info }\end{array}$ & 1 & 2 & 3 & 4 & 5 \\
\hline $\begin{array}{l}\text { 12) Informatics knowledge: systems } \\
\begin{array}{l}\text { Examples: recognizes value of clinician involvement in design, } \\
\text { selection, implementation and evaluation of computer applications }\end{array}\end{array}$ & 1 & 2 & 3 & 4 & 5 \\
\hline
\end{tabular}

Questions 13-20: Please rate on a 1-5 scale your SKILL (ability to perform) the following informatics competencies.

(1=no skill)

( $2=$ can perform some, need help at times)

( $3=$ can do skill competently)

(4=independent user, comfortable with technology)

(5=proficient in skill, can teach to others)

13) Computer skills for administrative functions

$\begin{array}{lllll}1 & 2 & 3 & 4 & 5\end{array}$

Example: patient acuity classification (quadramed)

14) Computer skills for communication

$\begin{array}{lllll}1 & 2 & 3 & 4 & 5\end{array}$

Examples: email, internet

15) Computer skills for data access

$\begin{array}{lllll}1 & 2 & 3 & 4 & 5\end{array}$

Example: local clinical information systems (hospital intranet systems)

16) Computer skills for documentation

$\begin{array}{lllll}1 & 2 & 3 & 4 & 5\end{array}$

Example: hospital system for documenting patient data, assessments, interventions, plan of care and discharge planning (Epic®, Health Link)

17) Computer skills for education

$\begin{array}{lllll}1 & 2 & 3 & 4 & 5\end{array}$

Examples: on-line literature searches; PDA resources; patient education (Health Facts for You)

18) Computer skills for patient monitoring $\begin{array}{lllll}1 & 2 & 3 & 4 & 5\end{array}$ Examples: automated BP, pulse oximetry, telemetry

19) Computer skills in basic desktop software $\begin{array}{lllll}1 & 2 & 3 & 4 & 5\end{array}$ Examples: keyboarding, word processing, printing, Power point presentation skills

20) Computer skills with peripheral devices used for patient care $\begin{array}{lllll}1 & 2 & 3 & 4 & 5\end{array}$ Examples: hand-helds (med administration; blood glucose meters); bedside computer terminals 
Questions 21-26 Please rate on a scale of 1-5 (1=never, 5=daily), your ACCESS to (how often you use) the following informatics competencies as a nurse in practice.

(1=never have access)

(2=access rarely)

( $3=$ access enough to do competently)

(4=weekly access, comfortable with technology)

(5=daily access)

21) Use of computer skills for administrative functions

$\begin{array}{lllll}1 & 2 & 3 & 4 & 5\end{array}$

Example: patient acuity classification (quadramed)

22) Use of computer skills for communication

1223345

Examples: email, internet

23) Use of computer skills for data access

$\begin{array}{lllll}1 & 2 & 3 & 4 & 5\end{array}$

Example: local clinical information systems (U-Connect; hospital intranet systems)

24) Use of computer skills for documentation

$\begin{array}{lllll}1 & 2 & 3 & 4 & 5\end{array}$

Example: hospital system for documenting patient data, assessments, interventions, plan of care and discharge planning (Epic ${ }^{\circ}$, Health Link)

25) Use of computer skills for education

$123 \quad 345$

Examples: on-line literature searches; PDA resources; patient education (Health Facts for You)

26) Use of computer skills for patient monitoring

$\begin{array}{lllll}1 & 2 & 3 & 4 & 5\end{array}$

Examples: automated BP, pulse oximetry, telemetry

Adapted with permission from Jarzemsky (2009). Assessment of informatics competencies of nursing students. QSEN: Quality and Safety Education for Nurses. Accessed from http://qsen.org/assessment-ofinformatics-competencies-nursing-students/ 
APPENDIX G

DEMOGRAPHIC DATA FORM 


\section{DEMOGRAPHIC DATA FORM}

Date of birth:

Gender: Male

Female

Type of faculty appointment

Full-time tenure track

Full-time non-tenure track

Adjunct (primarily classroom)

Adjunct (primarily clinical)

Other (please describe)

Number of years teaching nursing at college level:

Describe other teaching experiences:

Previous degrees (indicates all that apply)

Associate degree

Area of study:

Baccalaureate degree

Area of study:

Masters degree

Area of study:

Doctoral degree

Area of study:

Other (describe)

Number of years in nursing:

Primary Pre-teaching position (describe):

Do you currently hold a clinical nursing position? Yes No

How many hours per month do you spend working in this position?

Does this position require the use of EHR? Yes No Which brand or type of EHR? 
ELECTRONIC HEALTH RECORDS IN NURSING EDUCATION

APPENDIX H

INTERVIEW PROTOCOL 
Time of interview:

\section{INTERVIEW PROTOCOL}

Date:

Place:

Interviewer:

Interviewee:

Position of the Interviewee:

This purpose of this study is to explore and describe, with the nursing faculty of a small liberal arts college, the faculty knowledge, skills, and attitudes (KSAs) as they participate in an action research framed curriculum development program for implementation of applied informatics using an AEHR platform. I am collecting data from nursing educators and faculty working full and part time that are participating in the AEHR integration through interviews, surveys, observations at workshops, document examination, and student work in the AEHR. I am coding documents so that names are not connected to data collection instruments for issues of confidentially. This interview should take about 90 minutes.

(Have participant sign the consent from)

(Turn the tape recorder on and test it)

QSEN attitude competencies and related questions:

Appreciate the necessity for all health professionals to seek lifelong, continuous learning of information technology skills.

1. What is your perception about the nurse's role in the EHR?

Value technologies that support clinical decision-making, error prevention, and care coordination.

2. What are your thoughts about educating students about clinical decision-making tools in the EHR?

Error prevention?

Care coordination?

Protect confidentiality of protected health information in electronic health records.

3. What are your thoughts about teaching students confidentiality in the EHR?

Value nurses' involvement in design, selection, implementation, and evaluation of information technologies to support patient care.

4. Tell me about your experience in with educating students using the AEHR? Barriers? Strategies?

5. Do you have anything you would like to tell me regarding support, collaboration, or mentoring?

(Thank the individual for participating in this interview. Assure him/her of confidentiality of responses and potential future interviews) 
APPENDIX I

\section{INFORMED CONSENT FORM}




\section{INFORMED CONSENT FORM}

You have been invited to volunteer to participate in a research study conducted by Karen Maxwell with the Nursing Department at Liberal Oaks College.

This purpose of this study is to explore and describe, with the nursing educators and faculty of a small liberal arts college, the faculty knowledge, skills, and attitudes (KSAs) as they participate in an action research framed curriculum development program for implementation of applied informatics using an AEHR platform. I am collecting data from nursing educators and faculty working full and part time that are participating in the AEHR integration through interviews, surveys, observations at workshops, document examination, and student work in the AEHR. I am coding documents so that names are not connected to data collection instruments for issues of confidentially. This interview should take about 90 minutes.

This study could provide information for other nursing schools that need help integrating this technology.

I have read the contents of the consent form and have listened to the verbal explanation given by the investigator. My questions concerning this study have been answered to my satisfaction. I hereby give voluntary consent to participate in this study. Signing this consent document does not waive my rights nor does it release the investigators, institution or sponsors from their responsibilities. I have been given a copy of this form.

Participant Signature

Date

Date

Participant name

Date

Witness Signature 
ELECTRONIC HEALTH RECORDS IN NURSING EDUCATION

APPENDIX J

OBSERVATION PROTOCOL 
ELECTRONIC HEALTH RECORDS IN NURSING EDUCATION

OBSERVATION PROTOCOL

\begin{tabular}{|l|l|}
\hline \multicolumn{2}{|c|}{ Length of Activity: } \\
\hline Descriptive Notes (objective data) & Reflective Notes (subjective data) \\
\hline $\begin{array}{l}\text { General: What is the experience of nursing } \\
\text { faculty involved in the integration of an AEHR } \\
\text { integration project, framed in the Learning by } \\
\text { Developing model, at a small liberal arts college } \\
\text { school of nursing? }\end{array}$ & \\
\hline Describe Activity: & \\
\hline Include Sketch of environment: & \\
\hline Describe environment: & \\
\hline & \\
\hline & \\
\hline
\end{tabular}


APPENDIX K

STUDENT CONFIDENCE ASSESSMENT WITH LOCAEHR AEHR SURVEY 
ELECTRONIC HEALTH RECORDS IN NURSING EDUCATION

\section{STUDENT CONFIDENCE ASSESSMENT WITH LOCAEHR AEHR SURVEY}

\section{Each set of questions describes ways that nurses relate to information technology in clinical practice. For each, please rate your confidence at this point in your nursing practice.}

Questions: Please rate on a 1-5 scale your confidence with the following informatics knowledge and skills. Use the $\mathbf{0}$ if you had no experience or exposure to this part of the AEHR.

( $0=$ not applicable/did not use)

(1=know nothing about this)

(2=know some, need help at times)

(3=know enough to use confidently)

(4=independent user, very comfortable with technology)

(5=know enough to teach others)

\begin{tabular}{|c|c|c|c|c|c|c|c|}
\hline 1 & How confident do you feel identifying the components of a patient chart? & 0 & 1 & 2 & 3 & 4 & 5 \\
\hline 2 & $\begin{array}{l}\text { How confident do you feel about your understanding of confidentiality in } \\
\text { the EHR? }\end{array}$ & 0 & 1 & 2 & 3 & 4 & 5 \\
\hline 3 & $\begin{array}{l}\text { How confident do you feel in documenting intake and output measure in } \\
\text { LOCAEHR? }\end{array}$ & 0 & 1 & 2 & 3 & 4 & 5 \\
\hline 4 & How confident do you feel in documenting vital signs in LOCAEHR? & 0 & 1 & 2 & 3 & 4 & 5 \\
\hline 5 & How confident do you feel in documenting risk assessments in LOCAEHR? & 0 & 1 & 2 & 3 & 4 & 5 \\
\hline 6 & How confident do you feel in documenting pain assessments in LOCAEHR? & 0 & 1 & 2 & 3 & 4 & 5 \\
\hline 7 & $\begin{array}{l}\text { How confident do you feel using computer skills for patient monitoring? } \\
\text { Examples: pulse oximetry, blood glucose monitor, hand-held devices. }\end{array}$ & 0 & 1 & 2 & 3 & 4 & 5 \\
\hline 8 & $\begin{array}{l}\text { How confident do you feel in documenting focused nursing assessments } \\
\text { that are within normal limits in LOCAEHR? }\end{array}$ & 0 & 1 & 2 & 3 & 4 & 5 \\
\hline 9 & $\begin{array}{l}\text { How confident do you feel in documenting focused nursing assessments } \\
\text { that are not within normal limits in LOCAEHR? }\end{array}$ & 0 & 1 & 2 & 3 & 4 & 5 \\
\hline 10 & $\begin{array}{l}\text { How confident do you feel in documenting additional information in open } \\
\text { text boxes in LOCAEHR? }\end{array}$ & 0 & 1 & 2 & 3 & 4 & 5 \\
\hline 11 & $\begin{array}{l}\text { How confident do you feel in documenting a wound assessment in } \\
\text { LOCAEHR? }\end{array}$ & 0 & 1 & 2 & 3 & 4 & 5 \\
\hline 12 & $\begin{array}{l}\text { How confident do you feel in documenting mental health nursing } \\
\text { assessments in LOCAEHR? }\end{array}$ & 0 & 1 & 2 & 3 & 4 & 5 \\
\hline 13 & $\begin{array}{l}\text { How confident do you feel in documenting clinical functional health } \\
\text { pattern assessments in LOCAEHR? }\end{array}$ & 0 & 1 & 2 & 3 & 4 & 5 \\
\hline 14 & $\begin{array}{l}\text { How confident do you feel in documenting nursing procedures and } \\
\text { interventions in LOCAEHR? }\end{array}$ & 0 & 1 & 2 & 3 & 4 & 5 \\
\hline 15 & How confident do you feel in using LOCAEHR to document nursing care? & 0 & 1 & 2 & 3 & 4 & 5 \\
\hline 16 & How confident do you feel in documenting medications in LOCAEHR? & 0 & 1 & 2 & 3 & 4 & 5 \\
\hline 17 & How confident do you feel in documenting a handoff report in LOCAEHR? & 0 & 1 & 2 & 3 & 4 & 5 \\
\hline
\end{tabular}

